\title{
Uso da "Mini Avaliação Nutricional" para o \\ diagnóstico de desnutrição e risco de desnutrição de \\ idosos residentes em Instituições de Longa \\ Permanência
}

\section{LUCIANA SILVA FERREIRA}

Dissertação apresentada ao Programa de PósGraduação em Saúde Pública da Faculdade de Saúde Pública da Universidade de São Paulo para obtenção do título de Mestre em Saúde Pública.

Àrea de concentração: Nutrição

Orientadora: Prof ${ }^{\mathrm{a}}$. $\mathrm{Dr}^{\mathrm{a}}$. Maria de Fátima Nunes Marucci.

SÃO PAULO

2005 


\section{$46703 / 2005$ doc}

Autorizo exclusivamente para fins acadêmicos e científicos, a reprodução total ou parcial desta dissertação, por processos fotocopiadores. Ao usá-lo, cite a fonte.

Assinatura: Data: 
Aos meus pais Frederico e Cristina e ao Vagner pelo apoio e incentivo. 


\section{AGRADECIMENTOS}

Primeiramente, agradeço à Prof ${ }^{\mathrm{a}}$ Maria de Fátima Nunes Marucci pela orientação e oportunidade proporcionada de, a cada dia, aprender e aperfeiçoar meus conhecimentos.

Aos idosos residentes nas Instituições de Longa Permanência de Guaratinguetá que aceitaram, prontamente, participar desta pesquisa.

Às Instituições de Longa Permanência de Guaratinguetá por permitirem a realização desta pesquisa.

Ao amigo Prof $^{\circ} \mathrm{Dr}^{\circ}$ Luiz Fernando Costa Nascimento pela grande contribuição nas análises estatísticas.

À Thereza Clemente P. da Silva por permitir ser fotografada e autorizar o uso das fotos neste trabalho. 


\section{RESUMO}

Ferreira LS. Uso da "Mini Avaliação Nutricional” para o diagnóstico de desnutrição e risco de desnutrição de idosos residentes em Instituições de Longa Permanência. São Paulo; 2005 [Dissertação de Mestrado - Faculdade de Saúde Pública da USP].

Introdução: A Mini Avaliação Nutricional (MAN) é um método multidimensional de avaliação nutricional que permite o diagnóstico da desnutrição e do risco de desnutrição em idosos, porém, pouco estudada no Brasil. Objetivo: Avaliar o estado nutricional e analisar a utilização da MAN em idosos residentes de Instituições de Longa Permanência para Idosos (ILPI's). Métodos: Este é um estudo transversal, com coleta de dados primários e secundários, realizado em ILPI's filantrópicas de Guaratinguetá, SP. O estado nutricional foi avaliado segundo a MAN e a Área Muscular do Braço corrigida (AMBc) e a utilização da MAN foi avaliada através da descrição das limitações, facilidades e dificuldades de cada questão no momento de seu registro. As médias foram comparadas, utilizando-se o teste $t$ de Student e ANOVA; quando a MAN foi categorizada, esta foi avaliada pelo teste qui-quadrado. Calculou-se a sensibilidade, especificidade e valores preditivos e traçou-se a curva ROC. A área muscular do braço corrigida foi a variável utilizada como "padrão" para o diagnóstico nutricional dos idosos. Resultados: 89 idosos residentes em 4 instituições, sendo 57 $(64,0 \%)$ homens e $32(36,0 \%)$ mulheres, com idade média, para ambos os sexos, de 73,7 anos (DP $=9,1$ ) participaram da pesquisa. Considerações prévias relativas às questões e alternativas da MAN foram necessárias, sendo que a identificação da presença de distúrbio cognitivo foi fundamental para seu registro. Conforme pontuação final da MAN, 28,1\% estavam desnutridos, $50,6 \%$ em risco de desnutrição, e $21,3 \%$ não desnutridos. $A$ sensibilidade foi de $84,0 \%$, a especificidade de $36,0 \%$, o valor preditivo positivo de $77,0 \%$, e o valor preditivo negativo de $47,0 \%$; a área sob a curva ROC foi de 0,71 . Conclusão: A MAN é um método adequado para o 
diagnóstico de desnutrição e risco de desnutrição em idosos, possibilita a identificação dos fatores de risco para a desnutrição, no entanto, possui limitações. Critérios e adaptações devem ser adotados para a avaliação fidedigna da população estudada.

Descritores: Mini Avaliação Nutricional, idosos, desnutrição. 


\section{ABSTRACT}

Ferreira LS. Uso da "Mini Avaliação Nutricional” para o diagnóstico de desnutrição e risco de desnutrição de idosos residentes em Instituições de Longa Permanência. [Use of the "Mini Nutritional Assessment" tool for undernutrition and the risk of undernutrition diagnosis for elderly people in long-term institutions]. São Paulo (BR); 2005 [Dissertação de Mestrado - Faculdade de Saúde Pública da USP].

Introduction: The Mini Nutritional Assessment (MNA) is a multidimensional tool that allows the diagnosis of undemutrition and the risks of undernutrition regarding to elderly people. However being well applied in Brazil, there aren't many studies about the MNA. Main goal: To evaluate and analyze the nutrition status and the MNA application within an elderly group in long-term institutions. Methodology: It is a cross-study, using primary and secondary data gathering from long-term charity institutions located in GuaratinguetáSP. All the nutritional status were evaluated according to the MNA and the Arm Muscle Area correct (AMAC). The application of the MNA was evaluate according to the features of each question and its answer. The main results (average) were compared using the $t$ Student and ANOVA test. The MNA results were gathered altogether to be evaluated by the qui-square test. It was calculated the sensibility, specificity, predicted values and from that information it was established a ROC curve. The AMAc was the variable used as a standard during the nutritional diagnosis of the elderly group. Results: This study was composed of 89 elderly people from 4 institutions around 73.7 years old (DP $=9.1)$ : 57 men $(64.0 \%)$ and 32 women $(36.0 \%)$. During all the analyses of the MNA application the identification of the cognitive disturbances was very important along the whole process. According to the MNA scoring, $28.1 \%$ were undernutritioned, $50.6 \%$ were under the risk of undernutrition and $21.3 \%$ were non-undernutritioned people. The sensibility was $84.0 \%$, the specificity was $36.0 \%$, the positive predicted value was $77.0 \%$, and the negative predictive value was $47.0 \%$. The area 
regarding the ROC curve was 0.71 . Conclusion: The MNA is a reliable tool for the nutritional diagnosis of elderly people and it can help the identification of the risk factors related to undernutrition issues. However have limitation and some new criteria should be applied to achieve better results.

Descriptors: Mini Nutritional Assessment, elderly people, undernutrition. 


\section{LISTA DE TABELAS}

Tabela 1: Determinação do estado nutricional pela $A M B C$ segundo distribuição em percentis. BARBOSA AR. p. 35

Tabela 2. Distribuição de idosos residentes, segundo sexo e Instituição de Longa Permanência. Guaratinguetá - SP, 2004. p. 48

Tabela 3. Distribuição de idosos participantes, segundo sexo e Instituição de Longa Permanência. Guaratinguetá - SP, 2004. p.50

Tabela 4. Distribuição de idosos participantes, segundo sexo e grupo etário. Guaratinguetá - SP, 2004 p.51

Tabela 5. Valores médios e desvios-padrão da MAN de idosos residentes em ILPl's, segundo grupo etário e sexo e respectivos valores de $p$. Guaratinguetá - SP, 2004 p.53

Tabela 6. Distribuição de idosos, segundo sexo e diagnóstico nutricional pela MAN. Guaratinguetá - SP, 2004 p.55

Tabela 7. Distribuição de idosos, segundo grupo etário e diagnóstico nutricional pela MAN. Guaratinguetá - SP, 2004. p.56

Tabela 8. Distribuição de idosos, segundo a avaliação nutricional pela Triagem e MAN. Guaratinguetá - SP, 2004 .p.57

Tabela 9. Distribuição de idosos, segundo as questões respondidas e a pontuação de cada questão da MAN. Guaratinguetá - SP, 2004. p.58

Tabela 10. Distribuição de idosos de acordo com a presença de distúrbios cognitivos e a capacidade de responderem as questões da MAN, segundo o sexo. Guaratinguetá - SP, 2004. .p.62 
Tabela 11. Distribuição de idosos de acordo com a presença de distúrbios cognitivos e a capacidade de responderem as questões da MAN, segundo o estado nutricional pela MAN. Guaratinguetá - SP, 2004. p.63

Tabela 12. Distribuição de idosos, segundo o diagnóstico nutricional e métodos de avaliação. Guaratinguetá - SP, 2004

p.72

Tabela 13. Distribuição de idosos, segundo o diagnóstico nutricional, agrupado em 2 categorias, e métodos de avaliação. Guaratinguetá - SP, 2004 p.72

Tabela 14. Valores de sensibilidade e especificidade de cada pontuação da MAN. Guaratinguetá - SP, 2004 .p.74

Tabela 15. Distribuição de idosos, segundo o diagnóstico nutricional pela Triagem da MAN e pela Área Muscular do Braço corrigida (AMBc). Guaratinguetá - SP, 2004 p.75

Tabela 16. Valores de sensibilidade e especificidade de cada pontuação da Triagem da MAN. Guaratinguetá - SP, 2004 .p.77

Tabela 17. Distribuição de idosos com distúrbios cognitivos incapazes de responderem a MAN, segundo o diagnóstico nutricional e métodos de avaliação. Guaratinguetá - SP, 2004 p.78

Tabela 18. Distribuição de idosos com distúrbios cognitivos incapazes de responderem a MAN, segundo o diagnóstico nutricional, agrupado em 2 categorias, e métodos de avaliação. Guaratinguetá - SP, 2004. p.78 Tabela 19. Distribuição de idosos com ou sem distúrbios cognitivos capazes de responderem a MAN, segundo o diagnóstico nutricional e métodos de avaliação. Guaratinguetá - SP, 2004. .p.79 
Tabela 20. Distribuição de idosos com ou sem distúrbios cognitivos capazes de responderem a MAN, segundo o diagnóstico nutricional, agrupado em 2 categorias, e métodos de avaliação. Guaratinguetá - SP, 2004................p.80 Tabela 21. Valores em porcentagem de sensibilidade, especificidade, valor preditivo positivo e valor preditivo negativo da MAN em diferentes situações. Guaratinguetá - SP, 2004 p.81

Tabela 22. Valores de sensibilidade e especificidade, com os respectivos intervalos de confiança, e valores preditivos de cada questão da MAN.

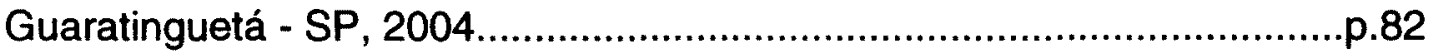




\section{LISTA DE FIGURAS}

Figura 1. Mini Avaliação Nutricional.............................................................31

Figura 2. Esquema de preenchimento da MAN...................................p. 37

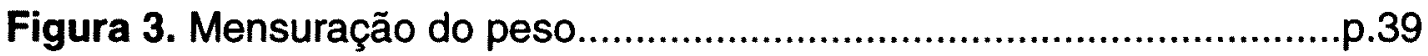

Figura 4. Mensuração da estatura..............................................................40

Figura 5. Mensuração da altura do joelho em decúbito dorsal...................p.41

Figura 6. Mensuração da altura do joelho na posição sentada..................p.42

Figura 7. Diagnóstico nutricional de idosos residentes em ILPI's, segundo a

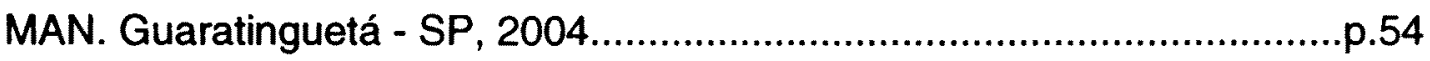

Figura 8. Graus de dificuldade de obtenção das respostas da MAN, segundo a ótica do pesquisador em relação a ele próprio, ao idoso e ao cuidador.

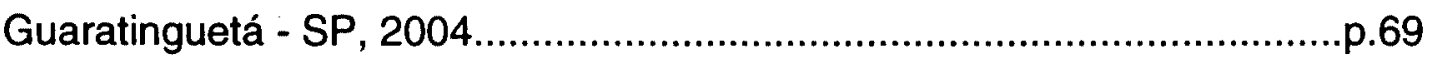

Figura 9. Diagnóstico nutricional segundo a $A M B c$ de idosos residentes em

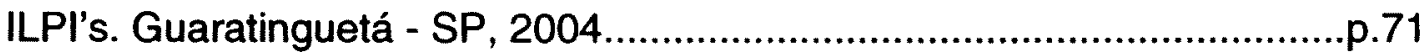

Figura 10. Curva ROC da MAN. Guaratinguetá - SP, 2004.....................p.73

Figura 11. Curva ROC da Triagem da MAN. Guaratinguetá - SP, 2004...p.76 


\section{ÍNDICE}

1 INTRODUÇÃO..........................................................................

1.1 Envelhecimento populacional e a institucionalização de

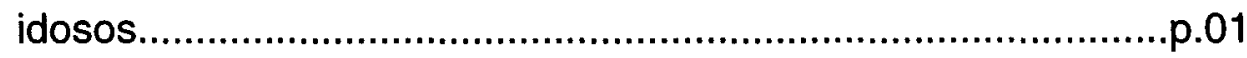

1.2 Fatores de risco nutricional e a desnutrição em idosos..............p.03

1.3 Diagnóstico de desnutrição em idosos.......................................p.10

1.4 Mini Avaliação Nutricional............................................................17

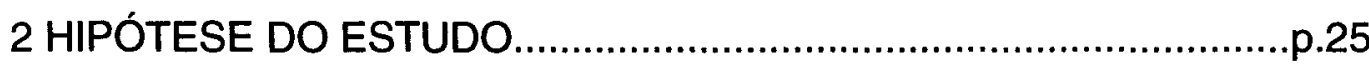

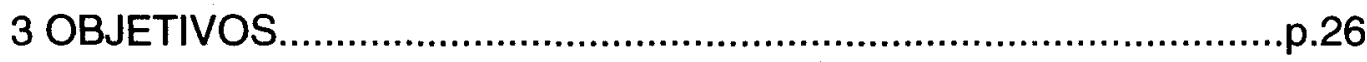

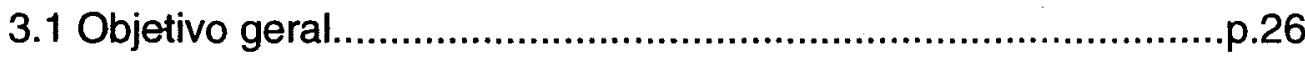

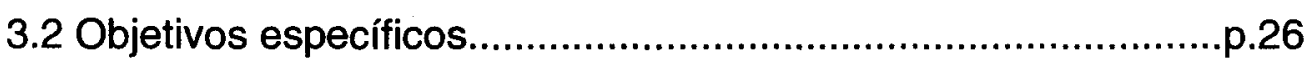

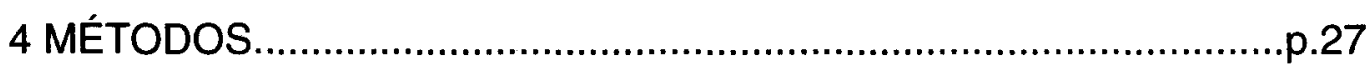

4.1 Delineamento e local do estudo..................................................27

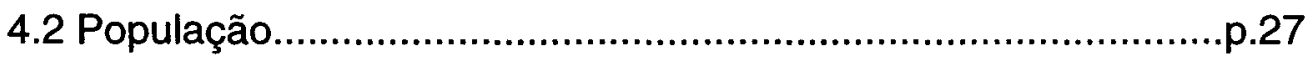

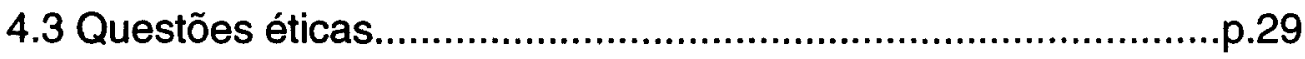

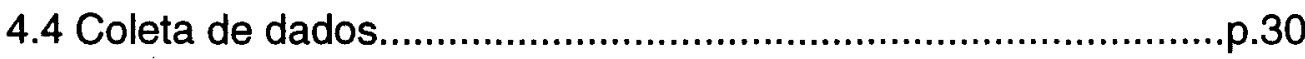

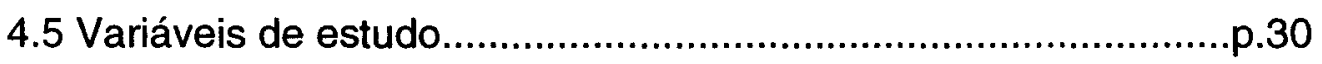

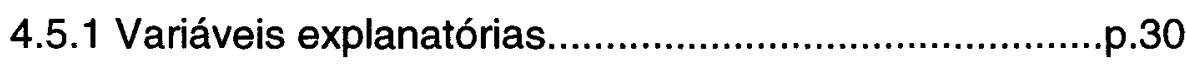

4.5.2 Variável dependente....................................................30

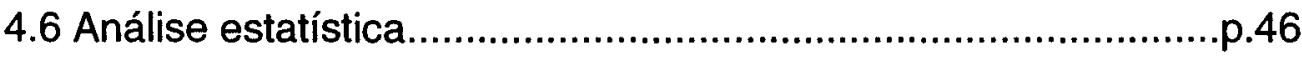

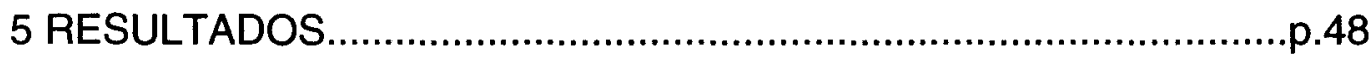

5.1 Caracterização sócio-demográfica da população.......................p.48 
5.2 Estado nutricional e fatores de risco para a desnutrição, segundo a MAN. .p.52

5.3 Análise da utilização da Mini Avaliação Nutricional. .p.60

5.4 Análise da sensibilidade, especificidade, e valores preditivos da MAN p.68

6 DISCUSSÃO. p. 86

7 CONCLUSÃO. p.136

8 RECOMENDAÇÕES p. 140

9 REFERÊNCIAS p.142

\section{ANEXOS}

ANEXO 1 - Localização geográfica de Guaratinguetá - SP A1

ANEXO 2 - Formulário de identificação e antropometria A2 ANEXO 3 - Termo de consentimento livre e esclarecido - Instituição....A3 ANEXO 4 - Termo de consentimento livre e esclarecido - Idoso. A4

ANEXO 5 - Termo de compromisso. A5

ANEXO 6 - Termo de responsabilidade. .A6 ANEXO 7 - Aprovação do Comitê de Ética em Pesquisa da FSP/USP..A7 ANEXO 8 - Short-Form Mini Nutritional Assessment. . 88

ANEXO 9 - Mini Nutritional Assessment. A9 ANEXO 10 - Valores de sensibilidade e especificidade de cada questão da MAN 


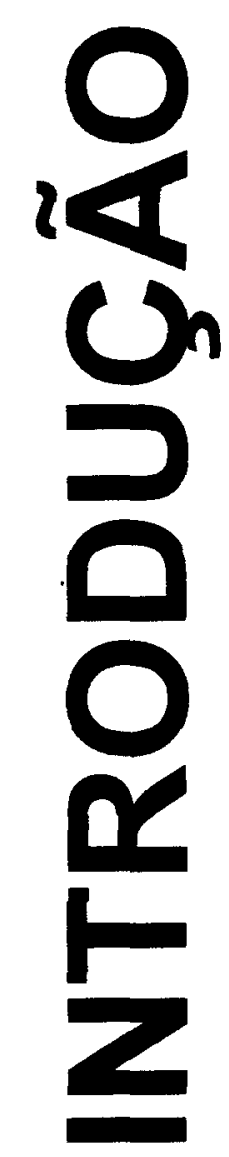




\section{INTRODUÇÃo}

\subsection{Envelhecimento populacional e a institucionalização de idosos}

A população brasileira, bem como a população mundial, a partir da segunda metade do século $\mathrm{XX}$, vem passando por um aumento da expectativa de vida que associada à queda dos coeficientes de mortalidade, tem conduzido ao envelhecimento populacional (KALACHE et al. 1987; RAMOS et al. 1987; RAMOS et al. 1993).

Está previsto que, no período de 1960 a 2025, o grupo etário menor ou igual a 15 anos terá reduzido a sua participação de $44,0 \%$ para $25,0 \%$ da população, enquanto que o segmento etário de 60 anos ou mais terá sua participação ampliada de $5,0 \%$ para $14,0 \%$ da população. Perspectivas estatísticas colocam o Brasil, no ano de 2025, em sexto lugar na lista dos países com o maior número absoluto de idosos, com cerca de 32 milhões de pessoas incluídas nesse grupo etário (RAMOS et al. 1993; KALACHE et al. 1987; RAMOS et al. 1987).

De acordo com dados do Censo de 2000 do Instituto Brasileiro de Geografia e Estatística - IBGE, a população idosa brasileira, representada por indivíduos com idade de 60 anos e mais, é de aproximadamente 15 milhões, correspondendo a $9,0 \%$ da população do país. $O$ aumento do número de idosos no Estado de São Paulo acompanha o ritmo acelerado de crescimento observado em todo país, alcançando, aproximadamente, $7,2 \%$ 
da população total (SCHOUERI JR et al. 2004). Em Guaratinguetá-SP, cidade escolhida para o desenvolvimento desse estudo, a população idosa corresponde a $9,6 \%$ dos 104.219 habitantes do municipio (IBGE 2000).

O envelhecimento da população mundial é um fato recente, universal e inexorável. Suas causas são multifatoriais e diferentes em países desenvolvidos e em desenvolvimento, mas suas conseqüências são igualmente importantes do ponto de vista social, médico e de políticas públicas (PAIXÃO JR e REICHENHEIM 2005). É uma aspiração natural de qualquer sociedade; mas tal, por si só, não é o bastante. É importante almejar uma melhoria da qualidade de vida para aqueles que já envelheceram ou que estão neste processo (DALACORTE 2002).

À medida que a população envelhece, aumenta a demanda por Instituições de Longa Permanência para Idosos (ILPI's). Os principais motivos são as dependências causadas por distúrbios cognitivos e funcionais, presença de doenças crônicas, além da miséria e do abandono (CHAIMOWICZ 1997; CHAIMOWICZ e GRECO 1999).

As ILPI's constituem alternativas de cuidados, principalmente, aos idosos mais frágeis e dependentes para executar suas tarefas básicas da vida diária que, por várias razões de ordem médico-sociais, não podem ser mantidas nas suas residências. No entanto, na maioria dos casos, a institucionalização leva os idosos ao isolamento social e à inatividade física 
em decorrência do manejo técnico inadequado e dos altos custos dos serviços sociais, que muitas vezes não contam com uma equipe multidisciplinar capaz de proporcionar atenção integral à saúde dos idosos. Estes problemas são agravados pelo inadequado consumo alimentar que, aliados às desordens sociais e emocionais, refletem diretamente no estado nutricional dos idosos favorecendo a complicações de inúmeras doenças (BORN e ABREU 1996; BRITO e RAMOS 2000).

Com o envelhecimento populacional, toma-se necessária atenção a este segmento da sociedade, sendo indispensável o conhecimento das necessidades e condições de vida desta população (COELHO FILHO e RAMOS 1999).

\subsection{Fatores de risco nutricional e a desnutrição em idosos}

Existem idosos saudáveis, desportistas, lúcidos, integrados à sociedade e, por outro lado, há os cronicamente doentes, debilitados, inativos, dependentes e institucionalizados. De acordo com MORIGUTI et al. (1998), a maior contribuição para as diferenças entre estes dois grupos tem base genética, sendo que outros fatores podem interagir, contribuindo para 0 efeito final, parecendo provável que muitas alterações ocorridas com o envelhecimento guardam estreita relação com a nutrição, especulando-se inclusive sobre a sua influência no processo degenerativo e o seu papel no envelhecimento. 
O fator de risco nutricional pode ser definido como uma característica ou ocorrência que aumenta a probabilidade de um indivíduo desenvolver distúrbios nutricionais. Os fatores de risco são freqüentemente cumulativos e inter-relacionados, com a prevalência e o grau de distúrbios nutricionais aumentando conforme aumenta o número de fatores de risco (WHITE 1994).

Idosos institucionalizados são caracterizados pelo aumento da fragilidade e vulnerabilidade. A severa incapacidade e dependência, o uso de múltiplas medicações, a presença de infecções freqüentes, a propensão ao desenvolvimento de úlceras de pressão e o próprio ambiente institucional são importantes fatores de risco para a desnutrição nestes idosos (WHITE 1994).

Independentemente destes fatores, o envelhecimento, por si só, é acompanhado por uma variedade de mudanças fisiológicas, psicológicas, econômicas e sociais que podem comprometer o estado nutricional do idoso levando à desnutrição (GARRY e VELLAS 1999).

As doenças que freqüentemente acometem os idosos comprometem seu estado de saúde, causando anorexia ao mesmo tempo em que necessitariam da elevação de suas necessidades alimentares. São eventos comuns: a doença pulmonar obstrutiva crônica, a síndrome de má absorção, o acidente vascular cerebral, a artrite, a isquemia intestinal, as doenças metabólicas e as cardiovasculares. A maior suscetibilidade às doenças leva 
os idosos a serem vítimas de outra intercorrência não menos grave que é o uso demasiado de medicamentos que, além de outros efeitos colaterais, freqüentemente interferem na digestão e absorção de alimentos e geram problemas digestivos e anorexia (MORIGUTI et al. 1998; MARUCCI e GOMES 2002).

Segundo COELHO e FAUSTO (2002), o uso de polifármacos pode ocasionar reações adversas que contribuem para a deterioração do estado cognitivo, tendo impacto significativo sobre o estado nutricional dos idosos.

O estado cognitivo alterado ou diminuído é considerado tanto um fator de risco nutricional como indicador de distúrbio nutricional, pois pode resultar em alterações do apetite e perda de peso (COELHO e FAUSTO 2002).

O distúrbio nutricional mais importante observado nos idosos é a desnutrição, sendo um problema freqüente que está associado à alta morbidade e mortalidade, à alta suscetibilidade a infecções, à maior dependência e à redução da qualidade de vida, cuja prevalência apresenta grande variação, sendo dependente do local da realização do estudo, da técnica utilizada para avaliar o estado nutricional e dos padrões de normalidade considerados. A maioria das causas da desnutrição é tratável, portanto, a detecção precoce é a chave para o seu apropriado tratamento (MORLEY e SILVER 1995; GUIGOZ et al. 1996; MORLEY 1998; PEÑA et al. 1998; MIJARES et al. 2001). 
De acordo com MORLEY (1998), a desnutrição em idosos resulta de uma variedade de condições, incluindo a anemia, úlceras de pressão, fraturas do quadril, fragilidade, dificuldades cognitivas, desidratação, hipotensão ortostática e disfunção imune.

De acordo com ABBASI e RUDMAN (1994), as causas da desnutrição, em geral, podem ser agrupadas em duas categorias: as relacionadas à ingestão alimentar (p.e.: perda de apetite, mastigação alterada, disfagia, uso de drogas anorexígenas, diminuição das percepções sensoriais e distúrbios cognitivos), e as relacionadas ao aumento das necessidades nutricionais (p.e.: presença de infecções e câncer).

A desnutrição progride mais rapidamente devido a algumas características próprias do envelhecimento. Uma delas é a anorexia fisiológica do idoso, que leva a um declínio da ingestão de alimentos ao longo da vida; também, é importante considerar o comprometimento da função gastrointestinal, causando má absorção de nutrientes, e o aumento do metabolismo decorrente de infecções e doenças crônicas (GOODWIN 1989; MORLEY 1998; WAITZBERG et al. 1999). A dentição precária, os distúrbios neuropsicológicos e a diminuição da capacidade funcional também são fatores que contribuem para o desenvolvimento da desnutrição (SOINI et al. 2004). 
Em estudos feitos em diferentes regiões do Brasil, a prevalência de desnutrição entre idosos vivendo na comunidade é de aproximadamente 10,0\% (TAVARES e ANJOS 1999), em hospitalizados, ela atinge $27,0 \%$ (SHINTAKU 2003) e, nos que vivem em Instituições de Longa Permanência para Idosos (ILPI's), ela chega a alcançar 50,0\% (MENEZES 2000). De acordo com estudos em países desenvolvidos, verifica-se que a prevalência de desnutrição em idosos morando na comunidade varia de 1,0 a 7,0\%; em hospitalizados varia de 22,0 a $59,0 \%$, e nos que vivem em instituições geriátricas varia de 10,0 a 85,0\% (GUIGOZ et al. 1996).

Conforme MORELY (1998), é estimado que a prevalência de desnutrição ocorra, aproximadamente, em 15,0\% dos idosos vivendo na comunidade, entre 10,0 e $38,0 \%$ dos pacientes ambulatoriais, entre 5,0 e $12,0 \%$ dos que recebem assistência domiciliar, entre 26,0 e 65,0 dos hospitalizados, e entre 5,0 e $85,0 \%$ dos institucionalizados.

Segundo revisão bibliográfica de SÖDERHAMN U e SÖDERHAMN O (2002), a prevalência de desnutrição entre idosos suecos institucionalizados variou de $27,0 \%$ a $33,0 \%$.

É visto, portanto, que a maior prevalência de desnutrição, tanto nacional como internacionalmente, é encontrada em idosos institucionalizados, sendo comum nesta população a realização de dietas inadequadas em energia e nutrientes, seja devido às condições em que os 
idosos estão submetidos nas instituições ou às próprias características do envelhecimento (MARUCCI 1985; KERSTETTER 1992; ROUBENOFF et al. 1996; CHARLES 1998; MENEZES 2000).

A alimentação deficiente ofertada por ILPI's contribui para o inadequado estado nutricional dos idosos. MARUCCI (1985) avaliou a dieta oferecida em 20 instituições geriátricas do município de São Paulo e verificou que todas elas apresentaram-se inadequadas para macro e micronutrientes, constatando-se que $25,0 \%$ das instituições apresentaram dietas inadequadas quanto à energia. Com relação aos idosos institucionalizados em Fortaleza - Ceará, MENEZES (2000) verificou que $61,2 \%$ apresentaram consumo alimentar com valor calórico abaixo do recomendado.

Segundo RUDMAN e FELLER (1989), menos que 5,0\% dos idosos que moram em suas residências sofrem de reservas adiposas anormais e perda de peso; enquanto a incidência é de 10 a 15 vezes maior em institucionalizados.

MORLEY (1986) também afirma que os problemas mais comuns em idosos institucionalizados são perda de peso e, concomitantemente, desnutrição protéico-calórica, a qual é endêmica e normalmente está associada à úlcera de decúbito, problemas cognitivos, infecções, anemia, doença cerebral, depressão emocional, uso de drogas anorexígenas, 
dentição precária, perda da capacidade gustativa e olfativa, bem como o ambiente que pode não ser propício para a alimentação.

Além desses fatores, indivíduos idosos enfrentam desafios que aumentam as chances de desenvolverem desnutrição, como: mobilidade prejudicada $(87,0 \%)$; dificuldade em mastigar $(35,0 \%)$; isolamento social (30,0\%); dificuldade em alimentar-se sozinho (27,0\%); problemas dentários (16\%); pobreza (15\%); dificuldades em fazer compras (11\%); deficiência visual $(8,0 \%)$; e dificuldade para preparar as refeições $(7,0 \%)$ (MORLEY 1998).

A desnutrição é um evento evitável por medidas que independem do conhecimento científico e de assistência médica, ao contrário da prevenção de óbitos por causas mais prevalentes em populações idosas, como infarto agudo do miocárdio, diabetes e acidentes cerebrovasculares, cuja abordagem é complexa (OTERO et al. 2002).

Enquanto a desnutrição é extremamente comum em idosos, a sua presença é raramente reconhecida pelos médicos e, quando é reconhecida, é raramente tratada (MORLEY 1998, WILSON et al. 1998).

Erroneamente, a desnutrição é vista como parte do processo normal de envelhecimento, sendo com freqüência ignorada (OTERO et al. 2002). 
É importante ressaltar que a obesidade também acomete os idosos, porém, é menos comum em institucionalizados. Quando ocorre, é associada à imobilidade, diminuição do estado funcional e infecções (PIERRON et al. 1990).

A promoção de um estado nutricional adequado é fundamental para a manutenção da qualidade de vida do idoso, no entanto, os numerosos fatores relacionados anteriomente fazem com que este grupo seja potencialmente suscetível ao risco para a desnutrição (DALACORTE 2002).

\subsection{Diagnóstico de desnutrição em idosos}

A deteç̧ão precoce da desnutrição deve ser realizada quando os indivíduos são admitidos nas instituições (GUIGOZ et al. 1996). No entanto, esta condição muitas vezes não é reconhecida pela falta de instrumentos específicos e validados para detectá-la em idosos, pela dificuldade em encontrar dados apropriados de referência, pelo custo elevado de equipamentos e exames, ou pela escassez de profissionais especializados para a realização da avaliação nutricional, sendo, desta forma, freqüentemente excluída da rotina dos programas de avaliação geriátrica, comprometendo a qualidade de vida dos idosos, aumentando os custos com a saúde, e dificultando o desenvolvimento de políticas de saúde (GUIGOZ et al. 1996; BECK et al. 1999). 
Se não detectada, a desnutrição pode resultar na rápida deterioração do estado de saúde do idoso e na morte (GUIGOZ et al. 1996; BECK et al. 1999; VELLAS et al. 1999; MURPHY et al. 2000).

No entanto, o diagnóstico do estado nutricional de idosos é dificultado por não existirem metodologias consideradas padrão-ouro para a sua realização nesta população (MURPHY et al. 2000).

Mesmo em hospitais, onde se acredita que o estado nutricional seja constantemente monitorado para a manutenção ou recuperação do estado de saúde dos indivíduos, WAITZBERG et al. (1999), em estudo que avaliou 4.000 pacientes internados na rede pública hospitalar brasileira, verificaram que $81,2 \%$ dos pacientes internados não tinham qualquer referência ao seu estado nutricional anotado em prontuários, possibilitando, desta forma, o agravamento das condições de saúde.

A ausência da avaliação nutricional adequada quando do ingresso na instituição e durante a estadia faz com que os idosos corram o risco de se desnutrir ao longo do tempo e os que já estavam desnutridos tendam a ter seu grau de desnutrição ainda mais agravado durante a institucionalização (WAITZBERG et al. 1999; BARRONE et al. 2003; SHINTAKU 2003).

Poucos são os serviços de saúde que incluem a avaliação do estado nutricional na avaliação geriátrica, a qual normalmente constitui, além da 
avaliação clínica, a avaliação das atividades básicas da vida diária, das atividades instrumentais da vida diária, exames para a detecção de distúrbios cognitivos e depressão (VELLAS et al. 1999).

Nas últimas duas décadas, vários instrumentos têm sido desenvolvidos para diagnosticar e tratar idosos de alto risco. Entretanto, pouca atenção tem sido dada para identificar aqueles que se beneficiariam da detecção precoce da desnutrição, ou seja, os idosos que apresentam risco para a desnutrição (VELLAS et al. 1999).

A avaliação do estado nutricional é um processo no qual vários aspectos do indivíduo são analisados, podendo compreender exames clínicos, antropométricos e bioquímicos que podem ser associados às avaliações funcionais e dietéticas que auxiliam na identificação dos riscos para a desnutrição. Como os resultados são complementares, recomenda-se o uso do maior número possível destes parâmetros na avaliação do estado nutricional do individuo (CHARLES 1998).

No entanto, a realização de todos estes métodos é custosa e dispendiosa, principalmente devido aos exames bioquímicos, dificultando a avaliação nutricional do idoso na maioria dos serviços geriátricos (MARCHINI et al. 1986). Os mesmos autores apresentaram, em estudo nacional, a rara utilização da associação destes métodos para o diagnóstico do estado nutricional dos idosos, o qual pode ter sido decorrente da falta de 
equipamentos e profissionais para a sua realização, pelo tempo restrito destinado à avaliação nutricional, ou pela falta de recursos financeiros.

Entretanto, pesquisadores têm verificado que a avaliação do estado nutricional em idosos pode ser realizada sem a necessidade destes numerosos exames (GUIGOZ et al. 1996; RUBENSTEIN et al. 2001; GUIGOZ et al. 2002).

Segundo RUBENSTEIN et al. (2001), o maior desafio encontrado pelos médicos geriatras, principalmente os de cuidado primário com a saúde, é identificar os idosos que se beneficiariam de uma intervenção dietética, sem submetê-los a todos os exames clínicos, antropométricos e bioquímicos, principalmente pelo alto custo e pelo tempo despendido para a sua realização.

De acordo com CHARLES (1998), para a avaliação nutricional ser relevante aos idosos, de forma a diagnosticar adequadamente seu estado nutricional, ela deve ser específica para esta população, não levar mais do que 10 minutos para a sua execução, ser validada, não requerer equipamentos complicados para as mensurações antropométricas, não ser invasiva e ser facilmente reproduzível.

Para GUIGOZ et al. (1996), os requisitos necessários para uma avaliação simples e rápida devem incluir: uma escala confiável com limiares 
definidos, ser compatível com a habilidade do profissional que irá realizá-la, ser aceitável pelos idosos, e econômica.

Entre alguns instrumentos desenvolvidos estão o Prognostic Nutrition Index, o Subjective Global Assessment, o Determine Checklist, o Nutritional Form for the Elderly, e o SCALES (DEMPSEY e MULLEN 1987; DETSKY et al. 1987; MORLEY 1989; WHITE et al. 1992; SÖDERHAMN U E SÖDERHAMN O 2002).

Os métodos Subjective Global Assessment (DETSKY et al. 1987) e Prognosis Nutritional Index (DEMPSEY e MULLEN 1987) objetivam avaliar o estado nutricional de pacientes hospitalizados, assim como o risco de complicações durante a hospitalização. Entretanto, estes métodos não objetivam triar idosos com risco para desnutrição, sejam eles pacientes ambulatoriais, hospitalizados ou residentes em ILPI's (DEMPSEY e MULLEN 1987; DETSKY et al. 1987; VELLAS et al. 1999).

O método "Subjective Global Assessment" foi primariamente desenvolvido para a predição de complicações associadas ao estado nutricional de pacientes sujeitos à cirurgia gastrointestinal (DETSKY et al. 1987). De acordo com BARRONE et al. (2003), o método não é altamente sensível aos idosos, não sendo possível utilizá-lo para monitorar mudanças no estado nutricional por ser subjetivo e não-quantitativo, além de não possuir bons índices de reprodutibilidade entre os avaliadores. 
O método Determine Checklist objetiva aumentar o conhecimento nutricional da população idosa, mas não é usado para diagnosticar desnutrição. É um método de auto-avaliação que foi criado para ser utilizado como a primeira ferramenta de intervenção e monitorização nutricional, visando identificar idosos com problemas nutricionais (WHITE et al. 1992). Entretanto, segundo OMRAN e MORLEY (2000), somente a sua utilização como método de diagnóstico não é recomendado. Em pacientes de risco, ele deveria ser acompanhado de exames mais específicos ou ser usado estritamente como programa de educação nutricional (OMRAN e MORLEY 2000).

O método Nutritional Form for the Elderly (NUFFE) foi desenvolvido para auxiliar enfermeiras nas ILPI's e hospitais para o diagnóstico nutricional de idosos, e envolve avaliações dietéticas e globais. É um método recente com poucos estudos, validando a sua utilização (SÖDERHAMN U e SÖDERHAMN O 2002).

O método SCALES foi desenvolvido por médicos e nutricionistas para ser utilizado como método de triagem na prática clínica para a avaliação do risco de desnutrição. Ele requer a obtenção de exames bioquímicos e acredita-se que ele deva ser utilizado como um segundo método para casos de risco nutricional identificados por outros métodos, como pelo Mini Nutrition Assessment (GUIGOZ et al. 1994; MORLEY 1989 e 1991). 
Nestes métodos, há limitada sensibilidade para identificar pessoas idosas que, embora supostamente bem nutridas, apresentam risco para desenvolver desnutrição (CHUMLEA 1999; RAMON e SUBIRÁ 2001). Muitos, também, não foram criados especificamente para a população idosa, a qual possui as suas particularidades. Por isso, toma-se importante o conhecimento prévio detalhado dos objetivos do método a ser escolhido, a sua validade e viabilidade, além da população a quem se destina.

O diagnóstico de desnutrição não é simples e requer a utilização de métodos confiáveis e profissionais experientes para a sua escolha (MORLEY 1998).

O método Mini Nutrition Assessment (GUIGOZ et al. 1994), traduzido para o português como Mini Avaliação Nutricional (MAN), foi desenvolvido especificamente para o diagnóstico de desnutrição e risco de desnutrição de idosos e tem sido utilizado como método padrão-ouro para a avaliação nutricional desta população, como nos estudos de SÖDERHAMN U e SÖDERHAMN O (2002) e THOMAS et al. (2002).

De acordo com MORLEY (1998), atualmente, a MAN parece ser o método padrão-ouro pelo qual todos os outros testes de avaliação nutricional deveriam ser julgados. 
A condição nutricional do idoso tem sido estudada internacionalmente (FRISANCHO 1981; BURR e PHILLIPS 1984; DELARUE et al. 1994; de GROOT et al. 1996, KUCZMARSKI et al. 2000; PERISSINOTTO et al. 2002), assim como no Brasil (MARUCCI 1985; MARUCCI 1992; TAVARES e ANJOS 1999; MENEZES 2000; MARUCCI e BARBOSA 2003; MASTROENI 2004; SANTOS et al. 2004; MENEZES e MARUCCI 2005), entretanto, poucos são os estudos nacionais, utilizando a MAN como método de diagnóstico (OLIVEIRA et al. 2003; DELACORTE 2004).

\subsection{Mini Avaliação Nutricional}

A Mini Avaliação Nutricional (MAN) é um método multidimensional de avaliação nutricional que permite o diagnóstico da desnutrição e do risco de desnutrição em idosos, sejam eles institucionalizados ou vivendo na comunidade, e tem sido traduzida para várias línguas (francês, inglês, alemão, espanhol, italiano, japonês, entre outras) sendo utilizada por várias instituições do mundo (GUIGOZ et al. 1996).

A MAN é reconhecida por ser prática e não invasiva e ter como principal objetivo avaliar, de forma rápida, a desnutrição em idosos sem requerer uma equipe de nutrição especializada e a realização de exames bioquímicos, permitindo a intervenção nutricional precoce, quando necessária. O método permite não somente avaliar o estado nutricional, mas também identificar as causas da desnutrição e os indivíduos que poderiam 
ser beneficiados pela intervenção nutricional precoce (GUIGOZ et al. 1996; GARRY e VELLAS 1999; VELLAS et al. 1999; VELLAS et al. 2000; GUIGOZ et al. 2002).

A MAN é composta por 18 ítens que na sua forma original (GUIGOZ et al. 1994) é apresentada em quatro partes: 1) avaliação antropométrica: índice de massa corporal, circunferência do braço e da panturrilha, e perda de peso; 2) avaliação global: tipo de acomodação, ingestão de medicamentos, presença de doenças agudas (incluindo estresse psicológico), mobilidade, problemas neuropsicológicos e presença de úlceras na pele ou escaras; 3) avaliação dietética: número de refeições diárias, consumo de diferentes grupos alimentares, ingestão diária de líquidos e autonomia para se alimentar; e 4) avaliação subjetiva: autopercepção do idoso em relação ao estado de saúde e nutricional. Cada questão possui de 2 a 4 alternativas como resposta que, individualmente, possuem pontuações específicas. As questões podem somar, no máximo, 30 pontos e os idosos podem ser classificados como não desnutridos, quando a pontuação for $\geq 24$, em risco de desnutrição, quando a pontuação estiver entre 17 e 23,5, ou desnutridos, quando for <17 (GUIGOZ et al. 1996).

O método foi desenvolvido pelo Departamento de Medicina Interna e Clínica Gerontológica do Hospital Universitário de Toulouse na França, pelo Programa de Nutrição Clínica da Universidade do Novo México dos Estados 
Unidos e pelo Centro de Pesquisa da Nestlé em Lausanne na Suiça. A MAN foi extensivamente validada com idosos saudáveis e frágeis, apresentando sensibilidade de $96,0 \%$, especificidade de $98,0 \%$ e valor preditivo positivo de 97,0\% (GUIGOZ et al. 1996; VELLAS et al. 1999).

Em Toulouse, na França, realizaram-se estudos para testar e validar a MAN. A avaliação do seu potencial discriminatório com idosos saudáveis e frágeis demonstrou que o método foi $92,0 \%$ e $98,0 \%$ acurado quando comparado, respectivamente, à avaliação clínica e nutricional completa (antropométrica, bioquímica e dietética), sendo estas avaliações consideradas padrão-ouro. Quando realizada a validação do método com idosos frágeis frente à avaliação clínica, bioquímica, dietética e funcional, os resultados demonstraram que não houve benefício em incluir a realização de exames bioquímicos, pois a MAN mostrou-se $88,0 \%$ e $89,0 \%$ acurada na presença e ausência de exames bioquímicos, respectivamente. Ao realizar o potencial de classificação da MAN com dados destes dois estudos, verificouse que, aproximadamente, $75,0 \%$ dos idosos foram classificados corretamente. De 25,0 a $30,0 \%$ deles estavam situados na zona intermediária (por volta de 19 pontos). Estes indivíduos eram idosos com risco de desnutrição e necessitaram de avaliações mais precisas para a determinação do estado nutricional. Estes resultados indicaram que 70,0 a $75,0 \%$ dos individuos poderiam ser diretamente classificados como não desnutridos ou desnutridos, usando a MAN sem a realização de exames bioquímicos (GUIGOZ et al. 1996). 
Em Albuquerque, no Novo México, a MAN foi testada em idosos saudáveis, vivendo na comunidade, participantes do estudo longitudinal New Mexico Aging Process Study. Os resultados demonstraram que cerca de $20,0 \%$ dos idosos apresentaram risco de desnutrição. A ingestão alimentar média deste grupo de pessoas estava menor do que a do grupo de bem nutridos, mas o nível de albumina e índice de massa corporal estavam normais. Estes resultados, segundo os autores, sugerem que MAN é capaz de diagnosticar idosos com risco de desnutrição antes de eles apresentaram alterações dos índices usualmente utilizados para o diagnóstico de desnutrição (GUIGOZ et al. 1996).

Estudos posteriores demonstraram que o estado nutricional, avaliado pela MAN, correlacionou-se com a ingestão de nutrientes e com os escores bioquímicos e antropométricos, sustentando a análise da sensibilidade de $96,0 \%$ e a especificidade de $98,0 \%$ do método (VELLAS et al. 1999).

Apesar de os autores da MAN a caracterizarem como um método simples e rápido de ser realizado, sua extensão estava impedindo a sua aceitabilidade, pois muitos profissionais necessitavam de treinamento para a realização das mensurações antropométricas e julgamentos subjetivos para o registro das questões, os quais demoravam a finalizá-la, comparando-se ao tempo destinado às outras avaliações geriátricas. Assim, RUBENSTEIN et al. (2001) desenvolveram uma versão da MAN, por um processo gradual de simplificação, usando a correlação de cada item ao escore total da MAN, 
a consistência interna (coeficiente alfa), e os valores de sensibilidade e especificidade.

Esta versão da MAN permaneceu com todos os itens da original, entretanto, dividida em duas etapas compreendendo, na primeira delas, uma triagem com os itens que mais se correlacionam com a MAN original (GUIGOZ et al. 1994) alteração da ingestão alimentar, perda de peso, mobilidade, presença de estresse psicológico e doenças agudas, presença de problemas neuropsicológicos e índice de massa corporal), possibilitando dois diagnósticos: idosos bem nutridos e com risco de desnutrição, sendo que no último caso, torna-se necessária a continuidade da avaliação para a confirmação do diagnóstico (RUBENSTEIN et al. 2001).

A triagem da MAN tem como característica preservar a facilidade com a qual estes dados podem ser obtidos; a confiabilidade inter-examinadores, e a correlação com a MAN original e com a avaliação clínica do estado nutricional. Esta etapa mostrou-se válida para o diagnóstico de idosos saudáveis e a MAN completa para avaliar idosos doentes ou frágeis com alta probabilidade de se desnutrir. Os 6 ítens da triagem da MAN são vistos serem tão efetivos quanto os 18 itens da MAN completa para avaliar o estado nutricional. Segundo os autores, estas duas etapas proporcionam menor esforço para a equipe de profissionais que aplicam o teste e para os idosos que são avaliados, principalmente para a população de baixo risco nutricional (RUBENSTEIN et al. 2001). 
Os benefícios da facilidade e simplicidade desta versão do método são confirmados por MURPHY et al. (2000) no estudo em que avaliaram o estado nutricional de mulheres idosas hospitalizadas.

Em recente estudo com pacientes em pré-operatório, confirmou-se a sensibilidade e a especificidade da nova versão da MAN em predizer a ausência de desnutrição na primeira etapa e a habilidade da segunda etapa em confirmar o risco para a desnutrição ou a sua presença, quando comparada com a versão original desenvolvida por GUIGOZ et al. (1994) (COHENDY et al. 2001).

BARRONE et al. (2003), da mesma forma que VELLAS et al. (1999), demonstraram a habilidade do método em avaliar idosos com risco de desnutrição antes das mudanças de peso ou níveis de albumina ocorrerem.

Estudos têm demonstrado a capacidade da MAN em avaliar alterações nutricionais ao longo de períodos de até 60 dias (BARRONE et al. 2003). Em idosos hospitalizados, ela foi preditiva dos custos com a saúde e do tempo de internação (PERTOLDI et al. 1996; BECK et al. 2001). O baixo escore da MAN também foi capaz de predizer a mortalidade nos estudos de BECK e OVESEN (1999).

As questões da MAN que auxiliam na avaliação do estado nutricional por serem considerados fatores de risco nutricional, como o tipo de 
acomodação, estado cognitivo, doenças agudas e mobilidade, foram relacionadas à morbidade e a alta dependência dos idosos quanto menor o escore da MAN (SALETTI et al. 2000).

A reprodutibilidade do método foi avaliada por BLEDA et al. (2002) e foi verificado que a MAN apresenta níveis seguros de confiabilidade entre seus avaliadores. Dos 18 itens avaliados pelo índice de Kappa, 12 (66,7\%) tiveram índices ótimos ou quase perfeitos, $5(27,8 \%)$ tiveram índices moderados ou bons, e somente 1 item $(5,6 \%)$ teve índice ruim. $O$ maior índice foi observado no item que avalia o tipo de moradia, porque todos os pacientes residiam em instituições geriátricas. O menor índice foi encontrado na questão que avalia a auto-percepção do idoso em relação à sua saúde, seguido pelo número de copos de líquidos ingeridos por dia e pelo valor da circunferência do braço. Pelos resultados encontrados, os autores sugeriram o aperfeiçoamento de algumas destas questões em vez de tentar alcançar melhores níveis de confiabilidade (BLEDA et al. 2002).

Mesmo os estudos internacionais que demonstraram a validação da MAN para idosos de diferentes locais, o que pode ser observado é que naqueles residindo em instituições geriátricas, a proporção é menor, como confirma a revisão bibliográfica apresentada por RUBENSTEIN et al. (2001).

A intervenção nutricional é dita ser mais fácil e efetiva quando implementada naqueles pacientes identificados com risco de desnutrição do 
que naqueles que já estão severamente desnutridos (VELLAS et al. 2000; BARRONE et al. 2003).

Desta forma, pretende-se com a MAN identificar precocemente o risco de desnutrição a fim de diminuir o impacto da desnutrição, uma vez que o estado nutricional deficiente tem sido amplamente encontrado em idosos institucionalizados e relacionado ao desenvolvimento e progresso de doenças crônicas que comumente os afetam e aumentam a mortalidade (BECK et al. 1999; OLIVEIRA et al. 2003).

Dados sobre o estado nutricional de idosos institucionalizados no Brasil são escassos e o conhecimento sobre o uso e avaliação da MAN é limitado. Por isso, o presente estudo pretende fornecer mais dados sobre esta população, avaliar a utilização do método, e contribuir para o seu aperfeiçoamento. 


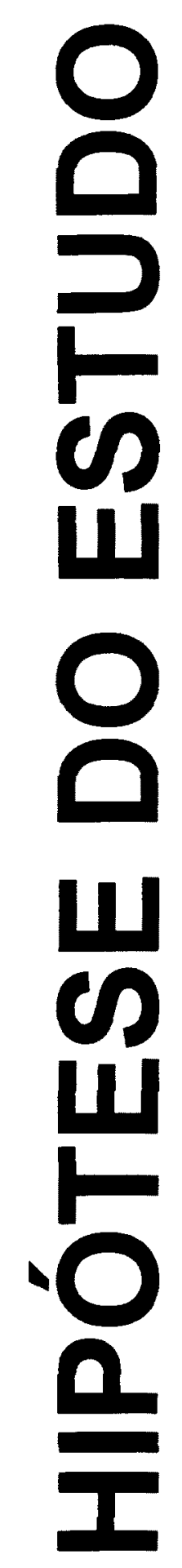




\section{HIPÓTESE DE ESTUDO}

A Mini Avaliação Nutricional é um método adequado para o diagnóstico nutricional de idosos residentes em Instituições de Longa Permanência. 


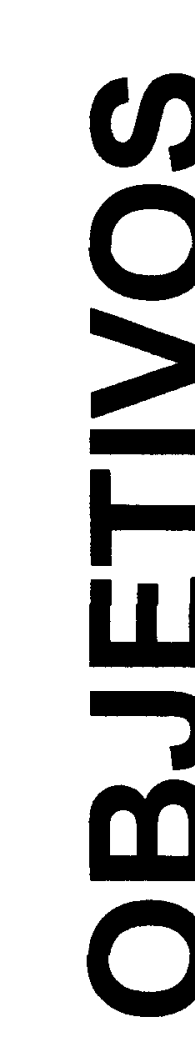




\section{OBJETIVOS}

\subsection{Objetivo geral}

Avaliar o estado nutricional e analisar a utilização do método Mini Avaliação Nutricional para o diagnóstico de desnutrição e risco de desnutrição de idosos residentes em Instituições de Longa Permanência.

\subsection{Objetivos específicos}

- Avaliar o estado nutricional dos idosos institucionalizados.

- Analisar a utilização da MAN em idosos institucionalizados.

- Verificar a sensibilidade, a especificidade e os valores preditivos da MAN. 


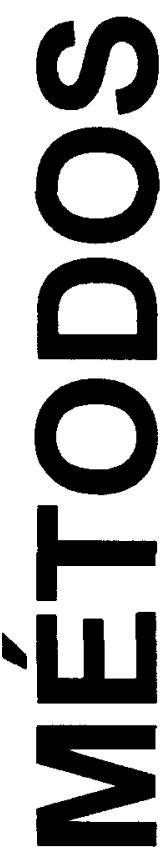




\section{METODOS}

\subsection{Delineamento e local do estudo}

O presente trabalho caracterizou-se por ser um estudo transversal, com coleta de dados primários e secundários, desenvolvido em Guaratinguetá - SP em todas as Instituições de Longa Permanência para Idosos (ILP's) do município, com funcionamento autorizado pela Vigilância Sanitária no ano de 2004.

Todas as instituições participantes desenvolviam trabalho filantrópico com auxílio do governo estadual e/ou municipal.

Guaratinguetá situa-se no Vale do Paraíba Paulista, a $180 \mathrm{~km} \mathrm{da}$ cidade de São Paulo (Anexo 1) e possui cerca de 105.000 habitantes, sendo que $10,0 \%$ da população são indivíduos com 60 anos e mais, conforme o Censo de 2000 do Instituto Brasileiro de Geografia e Estatística - IBGE.

\subsection{População}

A população de estudo compreendeu indivíduos idosos (maior ou igual a 60 anos, segundo PNI 1996), de ambos os sexos, residentes em quatro ILPI's de Guaratinguetá, sendo que uma delas atendia, exclusivamente, indivíduos do sexo masculino. Foram excluídos do estudo 
idosos sem possibilidades terapêuticas que estavam em fase terminal de doença e os que não aceitaram participar da pesquisa.

Os dados sócio-demográficos foram coletados para a descrição da população e obtidos diretamente do prontuário dos idosos e anotados em formulário específico (Anexo 2). Quando estes não constavam no prontuário, as informações foram obtidas com os funcionários das instituições.

Os dados coletados foram:

- sexo

- idade (anos)

- cor (branca, amarela, negra e parda)

- tempo de institucionalização (anos)

- procedência do idoso (rua, hospital, outra instituição, casa de familiares, casa própria, outros locais, não identificado)

- motivo da institucionalização (abandono ou ausência de cuidador, violência, ausência de familiares, opção própria, outros motivos)

A cor foi utilizada para o cálculo da estimativa do peso em idosos impossibilitados de permanecerem em pé, segundo ROSS LABORATORIES (1990). Neste caso, os indivíduos identificados como pardos foram agrupados aos negros para a utilização da fórmula. 


\subsection{Questōes éticas}

Como o estudo envolveu seres humanos, foi imprescindivel a existência de documentos que esclarecessem, tanto para as instituições como para cada idoso participante da pesquisa, os objetivos e métodos do trabalho para que todas as partes permitissem, através do consentimento esclarecido, a execução da pesquisa (SEGRE e COHEN 1995; ARCHER et al. 1996; SGRECCIA 1996).

Portanto, Termos de Consentimentos Livre e Esclarecido foram elaborados segundo a Resolução $n^{\circ} 196$ de 10 de outubro de 1996 do Conselho Nacional de Saúde (Anexos 3 e 4).

Os funcionários das instituições que participaram da pesquisa assinaram um Termo de Compromisso (Anexo 5) no qual comprometeramse a fornecer todas as informações necessárias à realização da pesquisa.

A pesquisadora, ao final do estudo, orientou os dirigentes de todas as instituições quanto à alimentação dos participantes da pesquisa, conforme diagnóstico obtido, como exposto no Termo de Responsabilidade em anexo (Anexo 6). 
Esta pesquisa foi aprovada pelo Comitê de Ética em Pesquisa (COEP) da Faculdade de Saúde Pública-da USP em 12 de março de 2004 (Anexo 7).

\subsection{Coleta de dados}

A coleta de dados ocorreu no período de abril a junho de 2004 e foi realizada pela própria pesquisadora.

\subsection{Variáveis de estudo}

\subsubsection{Variáveis explanatórias}

- sexo

- idade (anos)

\subsubsection{Variável dependente}

O diagnóstico nutricional é a variável dependente do estudo e foi analisado através do método Short-form Mini Nutritional Assessment, desenvolvido por RUBENSTEIN et al. (2001) (Anexo 8) e traduzido para o português pela Nestlé Nutrition Services como Mini Avaliação Nutricional (MAN) (Figura 1). Esta é uma versão do método Mini Nutritional Assessment, desenvolvido por GUIGOZ et al. (1994) (Anexo 9). 
NTSTLE NUTRITION STRVICES

Mini Avaliação Nutricional $^{\circledR}$
Nestlề $^{\circledR}$

\begin{tabular}{|c|c|c|c|c|}
\hline Sobrenome: & & Nome: & Sexo: & Data: \\
\hline Idade: & Peso (kg): & Altura $(\mathrm{cm})$ : & Leito: & \\
\hline
\end{tabular}

Preencher a primeira parte deste questionário, indicando a resposta. Somar os pontos da Triagem. Caso o escore seja igual ou inferior a 11, concluir o questionário para obter a avaliaçáo do estado nutricional.

\section{Triagem}

A Nos úttimos tres meses houve diminuição da ingesta alimentar devido a perda de apetite, problemas digestivos ou dificuldade para mastigar ou deglutir?

0 = diminuiçăo severa da ingesta

1 = diminuiçăo moderada da ingesta

2 = sem diminuiçăo da ingesta

B Perda de peso nos ultimos meses

0 - superior a tres quilos

1 = nåo sabe informar

2 = entre um e tres quilos

3 = semperda de peso

C Mobilidade

0 = restrito ao leito ou à cadeira de rodas

1 = deambula mas náo é capaz de sair de casa

2 = normal

D Passou por algum esstresse psicológico ou doença aguda nos últimos tres meses?

$0=\operatorname{sim} \quad 2=$ não

E Problemas neuropsicológicos

0 = demencia ou depressão graves

1 = demencia leve

2 = sem problemas psicológicos

F Indice de massa corpórea $\left(\mathrm{IMC}=\right.$ peso $[\mathrm{kg}] /$ estatura $\left.[\mathrm{m}]^{2}\right)$

$0=1 M C<19$

$1=19 \leq \mathbb{M C}<21$

$2=21 \leq \mathbb{M C}<23$

$3=\mathbb{I M C} \geq 23$

Escore de triagem (subtotal, máximo de 14 pontos)

$\begin{array}{ll}12 \text { pontos ou mais } & \begin{array}{l}\text { normal; } \\ \text { demecessário continuar a avaliaçào }\end{array} \\ 11 \text { pontos ou menos } & \text { possibitidacie de desnutriçán: } \\ & \text { contiauar a avaliaçăo }\end{array}$

\section{Avaliação global}

G O paciente vive em sua própria casa (nâo em casa geriátrica ou hospital)

$0=$ nầ

$$
1=\operatorname{sim}
$$

H Utiliza mais de tres medicamentos diferentes por dia? $0=\operatorname{sim} \quad 1=$ nào

I Lesōes de pele ou escaras?

$$
0=\operatorname{sim} \quad 1=\text { não }
$$

Ref: Guigoz Y. Vellas B and Garry PJ. 1994. Mini Nuritional Assessment: A practical assessnent tool for greding the nutritional state of elderly patients. Facts and Research in Gerontology. Supplement

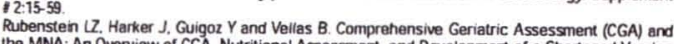
the MNA: An Overview of CGA, Nutritional Assessment, and Developmert of a Shortened Version

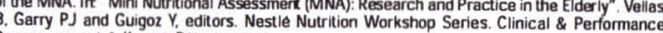
Programme, vol. 1. Karger, Bale, in press

O 1998 Societe des Produits Nestle S.A., Vevey, Switzerland, Trademark Owners
J Quantas refeiçōes faz por dia?

0 = uma refeiçăo

1 = duas refeiçōes

2 = tres refeiçōes

K O paciente consome:

- pelo menos uma porçăo diária de leite ou derivados (queijo, iogurte)? sim $\square$ não $\square$

- duas ou mais porçøes semanais de legumes ou ovos?

- carne, peixe ou aves todos os dias?

$0.0=$ nenhuma ou uma resposta $\ll$ simw

$0.5=$ duas respostas $\propto$ sim»

$1,0=$ trés respostas «sim»

L O paciente consome duas ou mais porçōes diárias de frutas ou vegetais?

0 = nâo $\quad 1=\operatorname{sim}$

M Quantos copos de liquidos (água, suco, café, chá, leite) o paciente consome por dia?

$0,0=$ menos de três copos

$0,5=$ trees a cinco copos

$1,0=$ mais de cinco copos

N Modo de se alimentar

0 = nào é capaz de se alimentar sozinho

1 = alimenta-se sozinho, porem com dificuldade

2 = alimenta-se sozinho sem dificuldade

0 paciente acredita ter algum problema nutricional?

$0=$ acredita estar desnutrido

1 = não sabe dizer

2 = acredita não ter problema nutricional

P Em comparaçāo a outras pessoas da mesma idade, como o paciente considera a sua própria saúde?

$0,0=$ nâo muito bọ

$0,5=$ nầ sabe informar

$1,0=$ boa

$2,0=$ melhor

Q Circunferencia do braço (CB) em cm

$0.0=\mathrm{CB}<21$

$0.5=21 \leq \mathrm{CB} \leq 22$

$1,0=\mathrm{CB}>22$

R Circunferencia da panturrilha (CP) em cm

$$
0=\mathrm{CP}<31 \quad 1=\mathrm{CP} \geq 31
$$

Avaliaçăo global (máximo 16 pontos)

Escore da triagem

Escore total (máximo 30 pontos)

Avaliação do Estado Nutricional

de 17 a 23.5 pontos risco de desnutricto

meros de 17 pontos desinutrido

E্রigura.io 1: Mini Avaliação Nutricional (MAN) 
Como mostrado na Figura 1, a MAN é composta por 18 questões, as quais apresentam pontuações, cujo somatório pode atingir 30 pontos. Ela é dividida em duas etapas, sendo a primeira denominada triagem, com 6 questões e pontuação máxima de 14 pontos e a segunda, avaliação global, com 12 questões e pontuação máxima de 16 pontos. Cada questão apresenta de duas a quatro alternativas como resposta, sendo que cada uma delas possui pontuação específica, podendo variar de 0 a 3 pontos. Apenas uma altemativa por questão deve ser escolhida.

Com a triagem, já é possível identificar se o indivíduo não se apresenta desnutrido. Para isso, é necessário que ele obtenha, no mínimo, 12 pontos. Se a pontuação for inferior a 12, deve-se preencher a avaliação global para definir se o indivíduo encontra-se desnutrido (menos de 17 pontos) ou com risco de desnutrição (de 17 a 23,5 pontos).

Entretanto, para que os objetivos da pesquisa fossem alcançados, a avaliação global foi realizada em todos os idosos, independentemente da pontuação da triagem. 
De acordo com a MAN, os idosos podem ser classificados da seguinte forma, conforme o estado nutricional:

\section{Desnutridos: $M A N<17$}

Risco de desnutrição: $17 \leq$ MAN $\leq 23,5$

Não desnutridos: MAN > 23,5

A Área Muscular do Braço corrigida (AMBc) foi a variável utilizada como "padrão" para o diagnóstico nutricional dos idosos. Ela é calculada, segundo sexo, de acordo com as equações de HEYMSFIELD et al. (1982):

Homens: $\begin{gathered}\mathrm{AMB}=\frac{[\mathrm{CB}(\mathrm{cm})-\pi \mathrm{PCT}(\mathrm{cm})]^{2}-10}{4 \pi} \\ \text { Mulheres: } \mathrm{AMB}=\frac{[\mathrm{CB}(\mathrm{cm})-\pi \text { PCT }(\mathrm{cm})]^{2}-6,5}{4 \pi}\end{gathered}$

As variáveis $\mathrm{CB}$ e PCT foram mensuradas da seguinte forma: 
A medida da circunferência do braço $(\mathrm{CB})$ foi realizada duas vezes do lado direito do corpo, com base nas técnicas de CALLAWAY et al. (1988). A medida foi realizada com fita métrica inextensivel com extensão de 1,5 m, com os idosos em pé e braço direito estendido ao longo do tronco. Para a determinação do local onde a fita deveria ser circundada, foi marcado o ponto médio entre o osso acrômio e o olécrano com o braço fletido a $90^{\circ}$. No caso de idosos impossibilitados de permanecerem em pé, a medida foi realizada na posição sentada ou deitada. Neste último caso, adotou-se a posição de decúbito lateral esquerdo. A leitura foi realizada no $0,1 \mathrm{~cm}$ mais próximo.

A medida da prega cutânea tricipital (PCT) foi realizada três vezes com base nas técnicas de HARRISON et al. (1988). A mensuração foi feita com os idosos em posição ereta, com o braço direito estendido ao lado do tronco e os ombros relaxados, utilizando-se o paquímetro Lange, o qual possui pressão constante de $10 \mathrm{~g} / \mathrm{mm}^{2}$. Para a obtenção da medida, a pele e o tecido adiposo foram pinçados com o dedo indicador e polegar a mais ou menos um centímetro acima do ponto médio entre o acrômio e o olécrano e a leitura da medida feita no equipamento após 2 a 3 segundos do pinçamento. Em idosos acamados, a medida foi realizada da mesma forma descrita anteriormente, no entanto, com estes em decúbito lateral esquerdo. 
Os valores de referência considerados para esta variável antropométrica foram os descritos por BARBOSA $A R^{\star}$, os quais são provenientes de idosos não institucionalizados do município de São Paulo.

O seguinte critério foi adotado para a avaliação do estado nutricional dos idosos:

Tabela 1: Determinação do estado nutricional pela $A M B c$, segundo distribuição em percentis. BARBOSA $\mathrm{AR}^{\star}$.

\begin{tabular}{ccc}
\hline Estado nutricional & \multicolumn{2}{c}{ AMBc $\left(\mathbf{c m}^{2}\right)$ segundo sexo } \\
& Homens & Mulheres \\
\hline Desnutrição & AMB $<32,30$ & AMB $<27,33$ \\
AMBc $<$ P5 & & $27,33 \leq$ AMB $<34,77$ \\
\hline Risco de desnutrição & $32,30 \leq$ AMB $<42,25$ & \\
P5 $\leq$ AMBc $<$ P25 & & AMB $\geq 34,77$ \\
\hline Não desnutrição & AMB $\geq 42,25$ & \\
AMBc $\geq$ P25 & & \\
\hline
\end{tabular}

Para o registro da MAN, as questões $\mathbf{A}, \mathbf{B}, \mathbf{D}, \mathbf{I}, \mathbf{J}, \mathbf{K}, \mathbf{L}, \mathbf{M}, \mathbf{N}, \mathbf{O}$ e $\mathbf{P}$ foram direcionadas aos idosos, entretanto, para aqueles incapazes de responderem às questões da MAN, devido à presença de distúrbio cognitivo,

* Dados não publicados 
estas foram respondidas pelos funcionários das instituições (com exceção das questões $\mathbf{O}$ e P), assim como realizado por BLEDA et al. (2002).

A incapacidade dos idosos para responderem às questões da MAN devido à presença de distúrbio cognitivo foi avaliada segundo a impressão subjetiva da pesquisadora e dos funcionários das instituições, da mesma forma que realizado por BECK et al. (2001) e SOINI et al. (2004). Em cada instituição o mesmo funcionário realizou esta avaliação junto à pesquisadora para todos os idosos.

As questões C, E e $\mathbf{H}$ foram direcionadas aos funcionários, enquanto as questões $\mathbf{F}, \mathbf{Q}$ e $\mathbf{R}$ foram obtidas pela pesquisadora a partir da mensuração do peso, estatura, circunferência do braço, circunferência da panturrilha e, quando necessário, da altura do joelho do idoso.

A questão $G$ foi respondida pela própria pesquisadora, já que a questão identifica se o idoso é ou não institucionalizado, não havendo necessidade de tal questionamento, visto que a pesquisa foi realizada somente em instituições. 
Figura 2: Esquema de preenchimento da MAN.

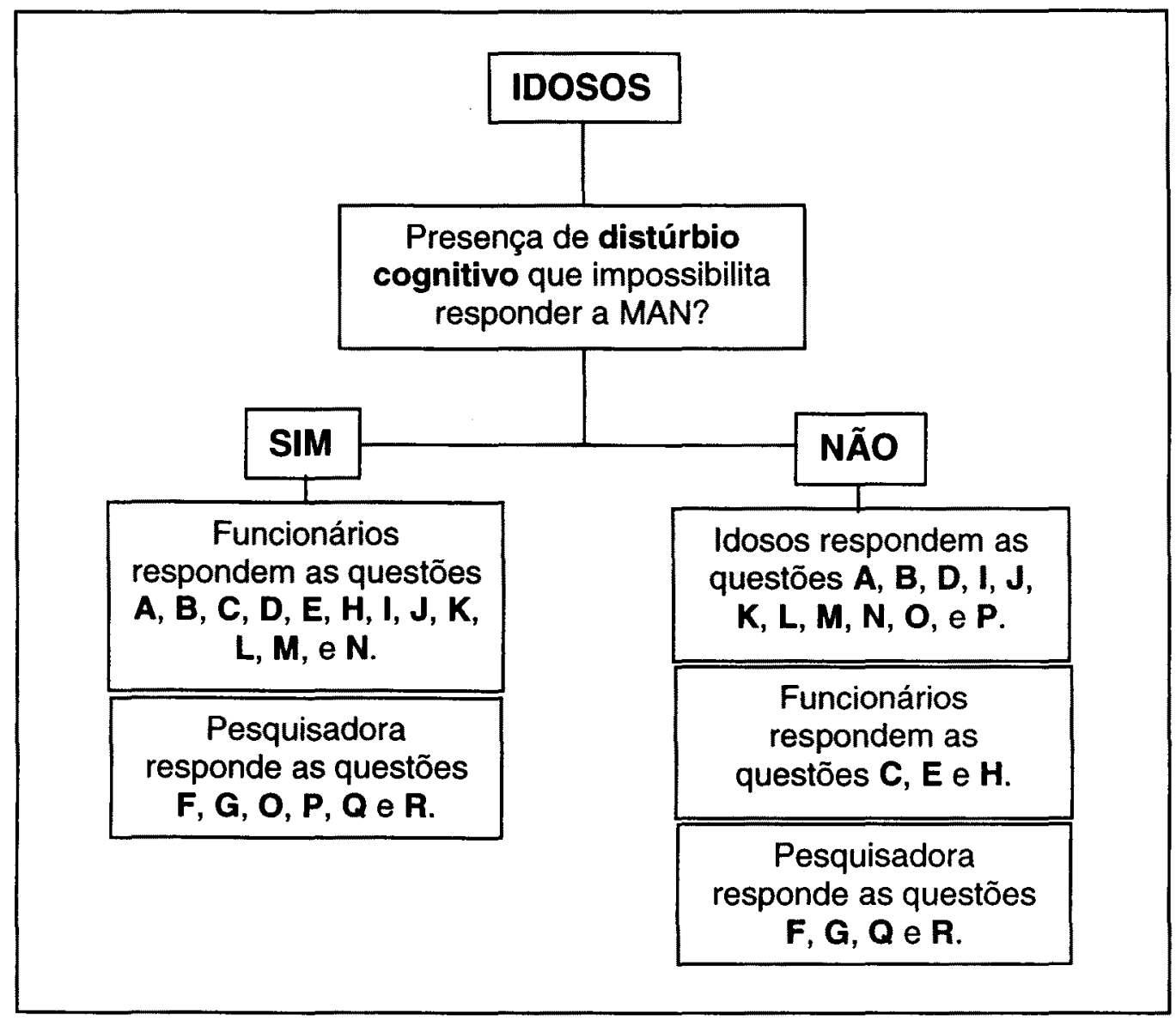

Considerações, critérios e alterações foram adotados para algumas questões da MAN a fim de facilitar o seu entendimento pelos idosos e funcionários e padronizá-las para que fossem corretamente registradas. A pontuação da MAN não foi modificada por estes fatores.

Quando as questões A, B e D foram respondidas pelos funcionários e o tempo de institucionalização do idoso foi menor que três meses, as respostas foram dadas a partir das observações atuais. 


\section{- Questão B:}

Apesar de a versão traduzida da MAN, utilizada neste estudo, não estabelecer o período a ser considerado para a perda de peso, adotou-se o mesmo critério da proposta original - Mini Nutritional Assessment de GUIGOZ et al. (1994) - , considerando-se a perda de peso nos últimos três meses antecedentes à avaliação.

\section{- Questão D:}

Considerou-se, como estresse psicológico, a hospitalização, a perda da esposa ou parente próximo ou a presença de problemas familiares nos últimos três meses, assim como no estudo de BECK et al. (1999).

\section{- Questão E:}

Como citado anteriormente, a presença e a gravidade de distúrbios cognitivos presentes nos idosos, que neste caso são referidos como problemas neuropsicológicos, foram identificados segundo a impressão subjetiva da pesquisadora e dos funcionários das instituições, como nos estudos de BECK et al. (2001) e SOINI et al. (2004). 
- Questão F:

O Índice de Massa Corporal (IMC) foi calculado a partir da seguinte fórmula:

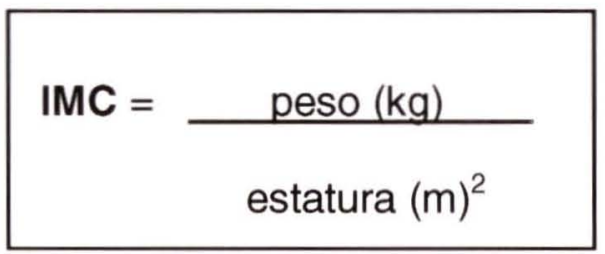

A mensuração do peso foi realizada duas vezes com base nas técnicas de GORDON et al. (1988). Os idosos permaneceram em pé, descalços, com o mínimo de vestuário e acessórios possíveis, utilizando-se balança eletrônica digital portátil, marca TANITA, com capacidade de 150 kg e sensibilidade de $200 \mathrm{~g}$ até $100 \mathrm{~kg}$ e $500 \mathrm{~g}$ de $100 \mathrm{~kg}$ a $150 \mathrm{~kg}$. Os idosos foram posicionados no centro da balança, de forma a distribuir o peso entre os pés (Figura 3).

Figura 3. Mensuração do peso.

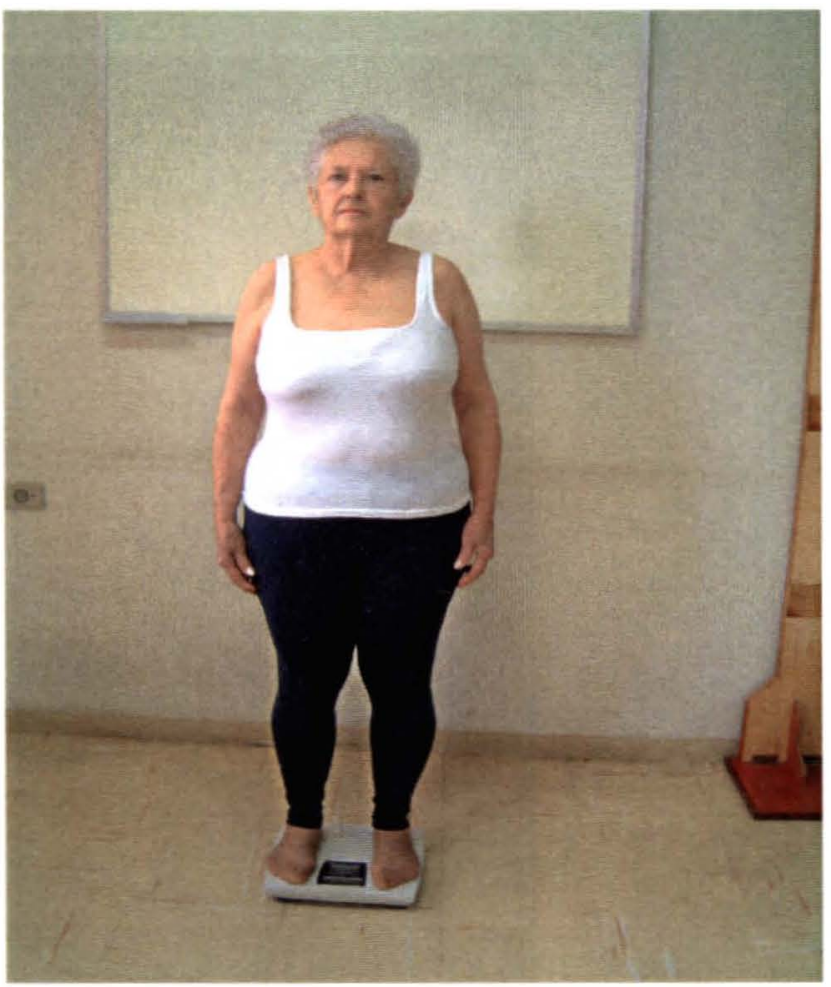


A mensuração da estatura também foi realizada duas vezes com base nas técnicas de GORDON et al. (1988). Utilizou-se o antropômetro portátil da marca SECA, com extensão de $2 \mathrm{~m}$, o qual foi fixado em uma parede sem rodapé. Os idosos foram posicionados descalços, com os pés unidos, de costas para o antropômetro, em posição ereta, olhando para frente (plano horizontal de Frankfurt). No momento da mensuração, os idosos precisavam estar com a cabeça, os ombros, as nádegas, as panturrilhas e os calcanhares encostados na parede, o que algumas vezes não foi possivel, pois alguns eram obesos ou apresentavam problemas posturais. Mesmo não sendo possível o contato de todos esses pontos, a medida foi realizada quando pelo menos 3 deles estavam em contato com a parede. A leitura foi realizada no $0,1 \mathrm{~cm}$ mais próximo (Figura 4).

Figura 4. Mensuração da estatura.

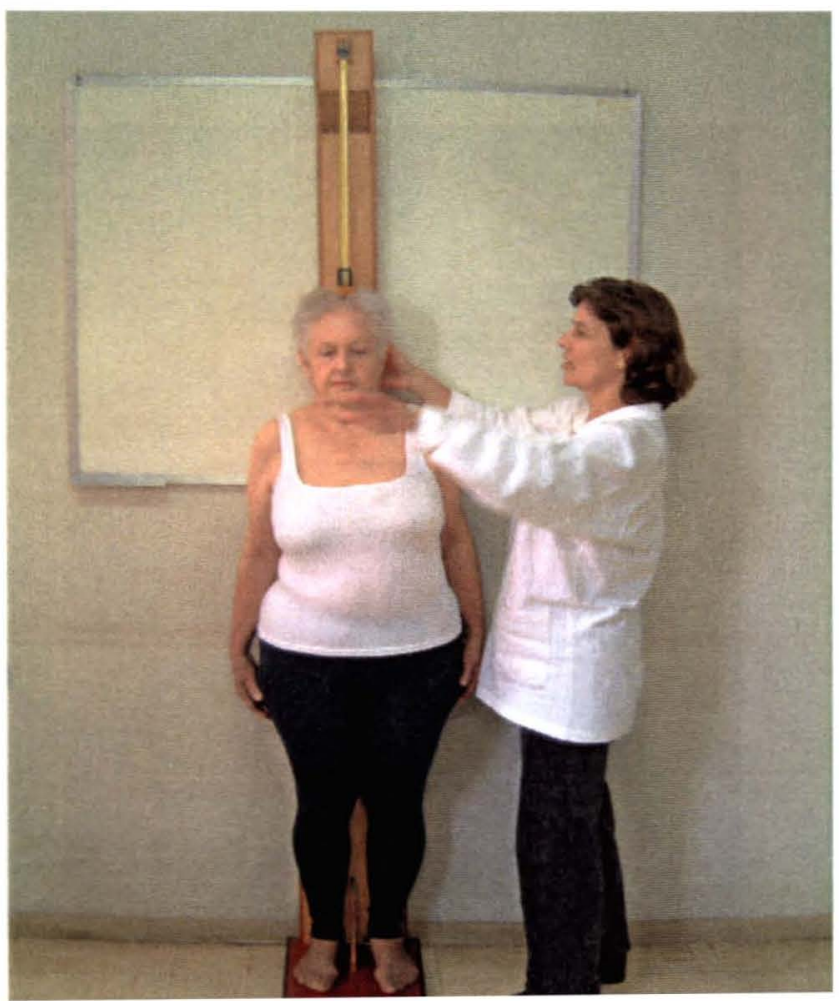


Nos casos em que não foi possível a mensuração do peso e da estatura, estes foram estimados a partir de equações que consideram a medida da altura do joelho e da circunferência do braço.

A medida da altura do joelho (AJ) foi realizada duas vezes na perna esquerda, conforme descrito por CHUMLEA et al. (1985), com um calibrador adaptado, com os idosos em posição de decúbito dorsal, e a perna formando ângulo de $90^{\circ} \mathrm{com}$ a coxa na região do joelho (Figura 5). Quando estavam sentados, a perna também foi posicionada no mesmo ângulo (Figura 6). A base inferior do equipamento foi colocada embaixo do calcanhar esquerdo, com o pé também formando um ângulo de $90^{\circ} \mathrm{com}$ a perna, e a base superior do equipamento sobre a parte posterior da patela. A leitura foi feita quando o equipamento estava paralelo a toda extensão da fíbula e a marcação feita no $0,1 \mathrm{~cm}$ mais próximo.

Figura 5. Mensuração da altura do joelho em decúbito dorsal.

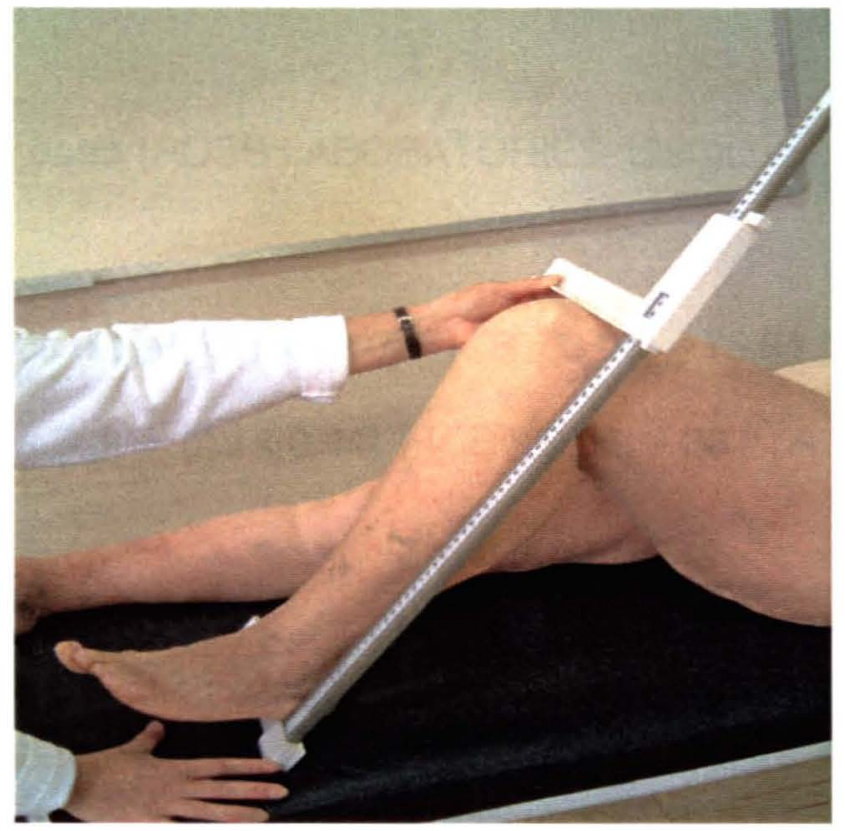


Figura 6. Mensuração da altura do joelho na posição sentada.

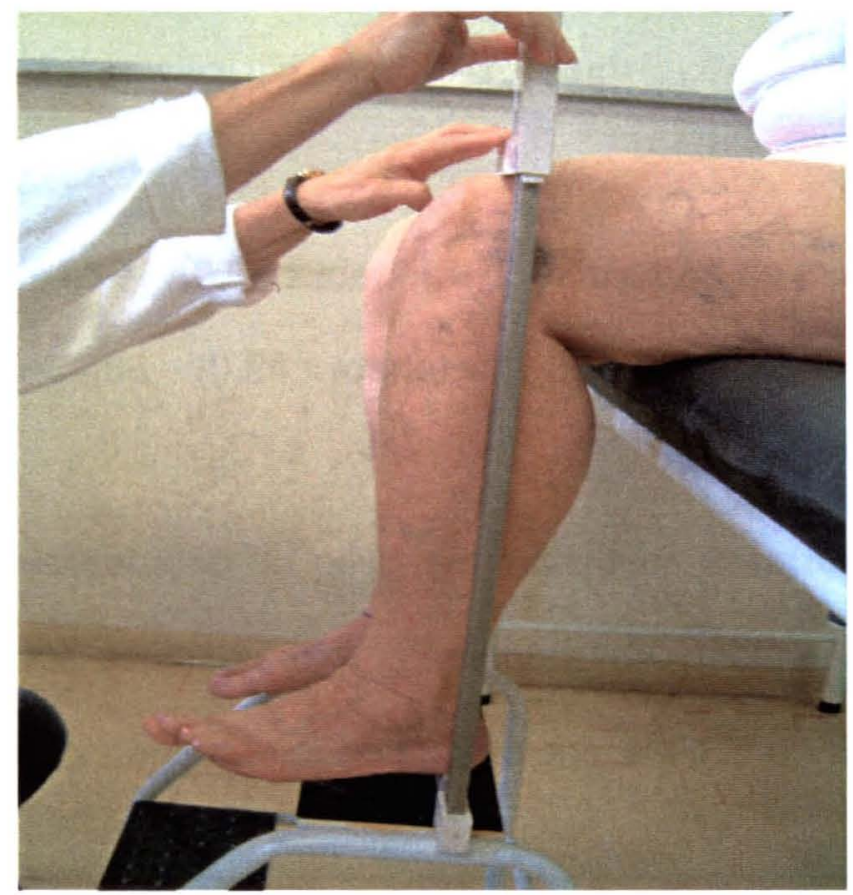

A medida da circunferência do braço $(\mathrm{CB})$ foi realizada como descrito anteriormente.

As fórmulas utilizadas para a estimativa do peso e estatura foram:

Estimativa do peso (ROSS LABORATORIES 1990):

Homens brancos $(\mathrm{kg})=[\mathrm{AJ} \times 1,10]+[\mathrm{CB} \times 3,07]-75,81$

Homens negros $(\mathrm{kg})=[\mathrm{AJ} \times 0,44]+[\mathrm{CB} \times 2,86]-39,21$ 
Mulheres brancas $(\mathrm{kg})=[\mathrm{AJ} \times 1,09]+[\mathrm{CB} \times 2,68]-65,51$

Mulheres negras $(\mathrm{kg})=[\mathrm{AJ} \times 1,50]+[\mathrm{CB} \times 2,58]-84,22$

Estimativa da estatura (CHUMLEA et al. 1985):

Homens $(\mathrm{cm})=64,19-(0,04 \times$ idade $)+(2,02 \times$ altura do joelho $)$

Mulheres $(\mathrm{cm})=84,88-(0,24 \mathrm{x}$ idade $)+(1,83 \times$ altura do joelho $)$

Para a mensuração do peso em indivíduos amputados, subtraiu-se do peso corporal estimado a porcentagem do peso correspondente ao membro amputado, conforme apresentado por GARRY e VELLAS (1999):

Peso corporal $=\frac{\text { Peso medido }(\mathrm{kg})}{100 \%-\% \text { amputação* }} \times 100$

* Porcentagem correspondente a cada segmento amputado:

Membro inferior abaixo do joelho $=6 \%$

Membro inferior até o joelho $=9 \%$

Membro inferior completo $=15 \%$

Membro superior completo $=6,5 \%$

Membro superior incompleto (antebraço) $=3,5 \%$ 


\section{- Questão G:}

Como a pesquisa foi realizada somente em indivíduos institucionalizados, esta questão teve a mesma alternativa assinalada pela pesquisadora para todos os idosos.

\section{- Questão J:}

Foi considerada uma refeição completa quando nela continha alimentos de, no mínimo, três grupos alimentares (cereais/raízes/tubérculos, carnes/leite/leguminosas, ou frutas/verduras) conforme apresentado por PHILIPPI et al. (1999).

\section{- Questāo K:}

Nesta questão, procedeu-se à substituição da opção "legumes” para “leguminosas", uma vez que este grupo de alimentos é que se caracteriza como oferta protéica, e não os legumes.

\section{- Questão L:}

Considerou-se, como uma porção de fruta, o equivalente a uma unidade (ex: banana, maçã ou laranja) ou uma fatia (ex: mamão, melão ou 
melancia) ou um copo de suco de fruta. Em relação às hortaliças, considerou-se, como uma porção, o equivalente a duas colheres de sopa.

\section{- Questão O:}

Para aqueles com distúrbio cognitivo considerados incapazes de responderem as questões, foi assinalada a alternativa "não sabe dizer".

- Questão P:

Para aqueles com distúrbio cognitivo considerados incapazes de responderem as questões, foi assinalada a alternativa "não sabe informar".

\section{- Questão Q:}

A medida da circunferência do braço foi mensurada como descrito anteriormente.

\section{- Questão R:}

A circunferência da panturrilha (CP) foi mensurada duas vezes, do lado direito do corpo, com base nas técnicas de CALLAWAY et al. (1988). A medida foi realizada com o idoso em decúbito dorsal ou sentado, com fita métrica inextensivel com extensão de 1,5 m, com a perna formando ângulo 
de $90^{\circ}$ com a coxa na região do joelho. A fita foi colocada ao redor da região mais saliente da panturrilha, sem comprimí-la. A leitura foi realizada no 0,1 cm mais próximo.

Todas as mensurações antropométricas foram realizadas pela autora do estudo, a qual foi treinada no Laboratório de Avaliação Nutricional de Populações - LANPOP do Departamento de Nutrição da Faculdade de Saúde Pública da USP.

\subsection{Análise estatística}

Para a descrição da população do estudo, assim como para a avaliação do estado nutricional dos idosos, as variáveis quantitativas (idade, tempo de permanência e MAN) foram apresentadas como médias e desviospadrão, e as variáveis qualitativas (sexo, cor, procedência do idoso e motivo da institucionalização) como porcentagens, da mesma forma que a MAN e $\mathrm{AMB}$, quando categorizadas.

No caso da MAN, as médias foram comparadas, utilizando-se o teste $t$ de Student. Quando comparadas mais de duas médias, utilizou-se o teste ANOVA. Quando a MAN foi categorizada, ela foi avaliada segundo o teste qui-quadrado. 
A sensibilidade, especificidade, valor preditivo positivo e valor preditivo negativo foram calculadas e analizadas para a MAN e suas questões, adotando, como método de referência, a avaliação do estado nutricional pela AMBc. A relação da sensibilidade e especificidade da MAN foi apresentada pela curva ROC - Receiver Operating Characteristics. A área abaixo da curva expressou o poder discriminatório do teste.

Para a adequada análise da sensibilidade e especificidade da MAN, foram considerados dois grupos de indivíduos segundo o estado nutricional, havendo o grupo dos desnutridos e dos não-desnutridos, sendo que os idosos em risco de desnutrição foram agrupados aos desnutridos, assim como no estudo de CHRISTENSSON et al. (2002).

O banco de dados foi elaborado, utilizando o aplicativo Microsoft Office Excel 7.0 e as informações estatísticas foram obtidas com o auxílio do aplicativo estatístico Epi Info 6.04 e Origin ${ }^{\circledR}$.

Neste estudo, adotou-se o nivel de significância $\alpha=5 \%$. 


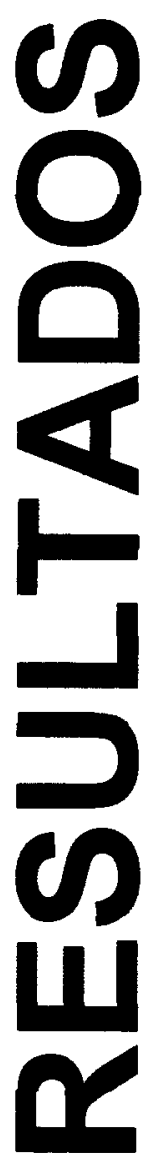




\section{RESULTADOS}

\subsection{Caracterização sócio-demográfica da população}

A Tabela 2 apresenta a distribuição dos idosos residentes em cada instituição, segundo o sexo. Este grupo de indivíduos representa, aproximadamente, $0,9 \%$ da população de idosos do município de Guaratinguetá - SP.

Tabela 2. Distribuição de idosos residentes, segundo sexo e Instituição de Longa Permanência. Guaratinguetá - SP, 2004.

\begin{tabular}{cccccccc}
\hline & \multicolumn{3}{c}{$N^{\circ}$ de idosos residentes } & \multicolumn{2}{c}{ Total } \\
\cline { 2 - 5 } Instituição & \multicolumn{3}{c}{ Masculino } & \multicolumn{2}{c}{ Feminino } & \\
& FA & FR & FA & FR & & \\
\hline 1 & 7 & 50,0 & 7 & 50,0 & 14 & 14,9 \\
2 & 20 & 74,1 & 7 & 25,3 & 27 & 28,7 \\
3 & 7 & 100,0 & 0 & 0 & 7 & 7,5 \\
4 & 25 & 54,3 & 21 & 45,7 & 46 & 48,9 \\
\hline Total & 59 & 62,8 & 35 & 37,2 & 94 & 100,0 \\
\hline FA = freqüência absoluta; & FR = freqüência relativa & & \\
\hline
\end{tabular}

Apesar destas instituições serem destinadas ao atendimento de idosos, em todas elas foram encontrados indivíduos com idade inferior a 60 anos, sendo 1 indivíduo $(6,7 \%)$ da instituição 1,1 indivíduo $(3,5 \%)$ da 
instituição 2, 3 individuos $(41,7 \%)$ da instituição 3 e 4 indivíduos $(7,7 \%)$ da instituição 4.

Nas instituições 2 e 4 , identificaram-se, respectivamente, 1 e 2 indivíduos, em cujos prontuários não constava a data de nascimento. Portanto, esses indivíduos foram excluidos do estudo.

Foram estudados 89 idosos, os quais corresponderam a $94,7 \%$ do total de idosos residentes nas instituições participantes da pesquisa. Os motivos para não participação de 5,3\% deles incluíram a recusa (3 idosos), a internação hospitalar ( 1 idoso) e a ausência de condições terapêuticas para participar do estudo (1 idoso).

Do total de participantes, $57(64,0 \%)$ eram do sexo masculino e 32 $(36,0 \%)$ eram do sexo feminino (Tabela 3$)$. 
Tabela 3. Distribuição de idosos participantes, segundo sexo e Instituição de Longa Permanência. Guaratinguetá - SP, 2004.

\begin{tabular}{|c|c|c|c|c|c|c|}
\hline \multirow{3}{*}{ Instituição } & \multicolumn{4}{|c|}{$\mathrm{N}^{\circ}$ de idosos participantes } & \multicolumn{2}{|c|}{ Total } \\
\hline & \multicolumn{2}{|c|}{ Masculino } & \multicolumn{2}{|c|}{ Feminino } & \multirow{2}{*}{ FA } & \multirow{2}{*}{ FR } \\
\hline & FA & FR & FA & FR & & \\
\hline 1 & 6 & 50,0 & 6 & 50,0 & 12 & 13,5 \\
\hline 2 & 20 & 74,1 & 7 & 25,9 & 27 & 30,4 \\
\hline 3 & 6 & 100,0 & 0,0 & 0,0 & 6 & 6,7 \\
\hline 4 & 25 & 56,8 & 19 & 43,2 & 44 & 49,4 \\
\hline Total & 57 & 64,0 & 32 & 36,0 & 89 & 100,0 \\
\hline
\end{tabular}

Como mostra a Tabela 3 , a instituição 4 contribuiu com $49,4 \%$ dos idosos participantes da pesquisa, enquanto que a instituição 3 contribuiu com apenas $6,7 \%$ dos idosos, sendo que nela reside a maior porcentagem de individuos com idade inferior a 60 anos $(41,7 \%)$ e atende apenas homens.

A idade da população estudada variou de 61 a 94 anos, e a média para ambos os sexos foi 73,7 anos (DP $=9,1)$, sendo 72,8 anos $(\mathrm{DP}=8,9$ ) para o sexo masculino e 75,3 anos $(D P=9,3)$ para o sexo feminino. 
A Tabela 4 apresenta a distribuição de idosos, segundo sexo e grupo etário. Pode-se observar maior proporção de idosos no grupo etário de 80 anos e mais.

Tabela 4. Distribuição de idosos participantes, segundo sexo e grupo etário. Guaratinguetá - SP, 2004.

\begin{tabular}{lcccccc}
\hline \multirow{2}{*}{$\begin{array}{c}\text { Grupo etário } \\
\text { (anos) }\end{array}$} & \multicolumn{3}{c}{ Masculino } & \multicolumn{2}{c}{ Feminino } \\
& FA & FR & FA & FR & FA & FR \\
\hline $\mathbf{6 0 - 6 4}$ & 11 & 19,3 & $\mathbf{6}$ & 18,8 & 17 & 19,1 \\
$\mathbf{6 5 - 6 9}$ & 16 & 28,1 & 6 & 18,8 & 22 & 24,7 \\
$\mathbf{7 0 - 7 4}$ & 9 & 15,8 & 3 & 9,4 & 12 & 13,5 \\
$\mathbf{7 5 - 7 9}$ & 6 & 10,5 & 5 & 15,5 & 11 & 12,4 \\
$\mathbf{8 0}$ e + & 15 & 26,3 & 12 & 37,5 & 27 & 30,3 \\
Total & 57 & 100,0 & 32 & 100,0 & 89 & 100,0 \\
\hline FA = freqüência absoluta; FR = freqüência relativa & &
\end{tabular}

Quanto à cor dos idosos, $67(75,3 \%)$ eram brancos, $14(15,7 \%)$ eram pardos e $8(9,0 \%)$ eram negros. Não foram encontrados indivíduos da cor amarela.

O tempo de permanência dos idosos nas instituições variou de 0 a $62,3$ anos e a média para ambos os sexos foi de 8 anos (DP $=11,4)$, sendo 
7,5 anos $(D P=11,5)$ para o sexo masculino e 8,8 anos $(D P=11,4)$ para 0 sexo feminino.

Quanto à procedência dos idosos, verificou-se que $24(27,0 \%)$ vieram da casa de familiares, $13(14,6 \%)$ de outras instituições, $11(12,4 \%)$ da própria casa, $11(12,4 \%)$ da rua e $6(6,7 \%)$ de hospitais. Os $24(27 \%)$ idosos restantes vieram de outros locais não descritos ou não identificados pelas instituições e/ou idosos.

Quanto aos motivos da institucionalização, $54(60,7 \%)$ deveram-se à ausência de cuidador ou abandono, 21 (23,6\%) por opção própria, 5 (5,6\%) devido à violência e $9(10,1 \%)$ por outros motivos não descritos ou não identificados pelas instituições e/ou idosos.

5.2 Estado nutricional e fatores de risco para a desnutrição, segundo a MAN

Na população estudada, a MAN apresentou variação de 11 a 27,5 pontos e média de 20,2 pontos $(D P=0,4)$ para ambos os sexos. Os valores médios e desvios-padrão da MAN, segundo sexo e grupo etário, estão apresentados na Tabela 5. 
Tabela 5. Valores médios e desvios-padrão da MAN de idosos residentes em ILPI's, segundo grupo etário e sexo e respectivos valores de $p$. Guaratinguetá - SP, 2004.

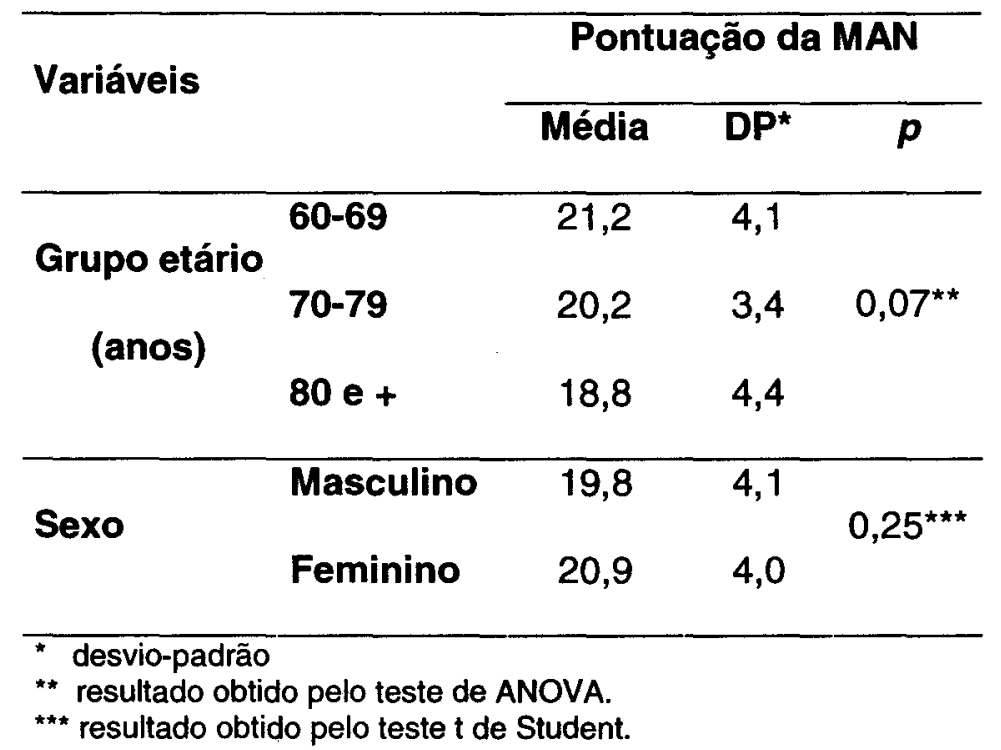

Em todas as análises, adotou-se o nível de significância $\alpha=5 \%$, entretanto, pode-se observar que a média da pontuação da MAN e os grupos etários estão no limite da significância $(p=0,07)$. Caso a população de estudo fosse maior, a relação entre as variáveis possivelmente seria demonstrada.

Quanto ao sexo, não houve diferença estatisticamente significativa entre os valores médios da MAN $(p=0,25)$.

As pontuações médias da MAN para os grupos etários e sexo estão no intervalo de risco para desnutrição (Tabela 5). 
De acordo com a avaliação do estado nutricional pela MAN, diagnosticaram-se $25(28,1 \%)$ idosos desnutridos, $45(50,6 \%)$ em risco de desnutrição e 19 (21,3\%) não desnutridos em ambos os sexos, como mostra a Figura 7.

Figura 7. Diagnóstico nutricional de idosos residentes em ILPI's, segundo a MAN. Guaratinguetá - SP, 2004.

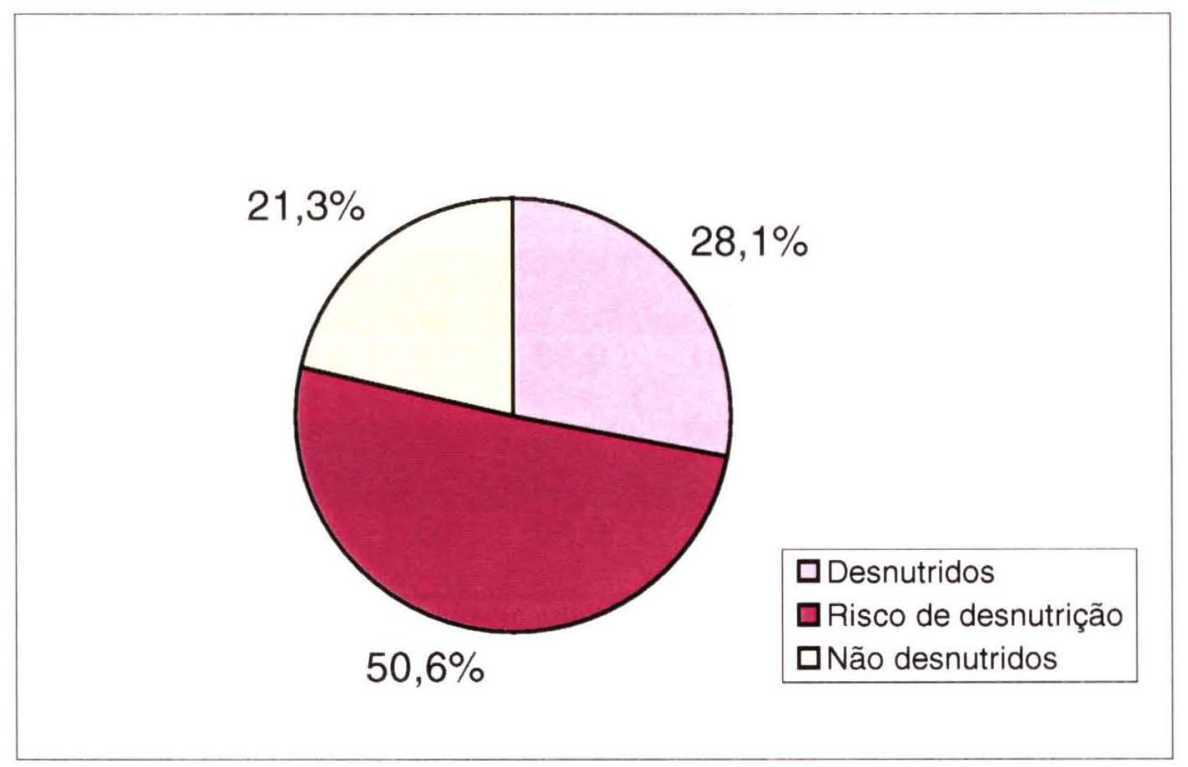

Tanto em relação ao sexo, quanto em relação aos grupos etários, o diagnóstico nutricional que mais prevaleceu foi o risco de desnutrição (Tabelas 6 e 7).

O sexo masculino foi mais prevalente nos três grupos de diagnóstico nutricional segundo a MAN: desnutridos, risco de desnutrição e não desnutridos. Entre os idosos desnutridos, o grupo etário de 80 anos e mais 
para ambos os sexos teve a maior prevalência $(44,0 \%)$. Em contrapartida, entre os idosos não desnutridos, o grupo etário de 60 a 69 anos foi o que apresentou maior prevalência $(68,4 \%)$. Entre os idosos em risco de desnutrição, este grupo etário também foi o mais prevalente $(37,8 \%)$.

Tabela 6. Distribuição de idosos, segundo sexo e diagnóstico nutricional pela MAN. Guaratinguetá - SP, 2004.

\begin{tabular}{|c|c|c|c|c|c|c|}
\hline & \multicolumn{4}{|c|}{ Sexo } & \multirow{2}{*}{\multicolumn{2}{|c|}{ Total }} \\
\hline & \multicolumn{2}{|c|}{ Masculino } & \multicolumn{2}{|c|}{ Feminino } & & \\
\hline & FA & FR & FA & FR & FA & FR \\
\hline Desnutridos & 18 & 72,0 & 7 & 28,0 & 25 & 100,0 \\
\hline Risco de desnutrição & 27 & 60,0 & 18 & 40,0 & 45 & 100,0 \\
\hline Não desnutridos & 12 & 63,0 & 7 & 37,0 & 19 & 100,0 \\
\hline Total & 57 & 64,0 & 32 & 36,0 & 89 & 100,0 \\
\hline
\end{tabular}

$\mathrm{FA}=$ freqüência absoluta; $F \mathrm{R}=$ freqüência relativa $X^{2}=1,01$ 
Tabela 7. Distribuição de idosos, segundo grupo etário e diagnóstico nutricional pela MAN. Guaratinguetá - SP, 2004.

\begin{tabular}{|c|c|c|c|c|c|c|c|c|}
\hline \multirow{3}{*}{$\begin{array}{c}\text { Grupo etário } \\
\text { (anos) }\end{array}$} & \multicolumn{8}{|c|}{ Grupo etário (anos) } \\
\hline & \multicolumn{2}{|c|}{$60-69$} & \multicolumn{2}{|c|}{$70-79$} & \multicolumn{2}{|c|}{80 e mais } & \multicolumn{2}{|c|}{ Total } \\
\hline & FA & FR & FA & FR & FA & FR & FA & FR \\
\hline Desnutridos & 9 & 36,0 & 5 & 20,0 & 11 & 44,0 & 25 & 100,0 \\
\hline $\begin{array}{l}\text { Risco de } \\
\text { desnutrição }\end{array}$ & 17 & 38,0 & 15 & 33,0 & 13 & 29,0 & 45 & 100,0 \\
\hline $\begin{array}{l}\text { Não } \\
\text { desnutridos }\end{array}$ & 13 & 68,4 & 3 & 15,8 & 3 & 15,8 & 19 & 100,0 \\
\hline Total & 39 & 43,8 & 23 & 25,9 & 27 & 30,3 & 89 & 100,0 \\
\hline
\end{tabular}

Ao considerar a pontuação da triagem da MAN de cada idoso, obtiveram-se $28(31,5 \%)$ não desnutridos e $61(68,5 \%)$ com possibilidades de desnutrição. Entretanto, quando completada a MAN, apenas 19 (21,3\%) foram considerados não desnutridos (Tabela 8). Estes resultados indicam que se não fosse completada a MAN para todos os idosos, independentemente do resultado da triagem, 9 idosos seriam classificados erroneamente como não desnutridos. 
Tabela 8. Distribuição de idosos, segundo a avaliação nutricional pela Triagem e MAN. Guaratinguetá - SP, 2004.

\begin{tabular}{|c|c|c|c|c|}
\hline \multirow[t]{2}{*}{ Avaliação } & \multicolumn{2}{|c|}{ Não desnutridos } & \multicolumn{2}{|c|}{$\begin{array}{c}\text { Desnutridos e } \\
\text { Risco de } \\
\text { desnutrição }\end{array}$} \\
\hline & FA & FR & FA & FR \\
\hline Triagem & 28 & 31,5 & 61 & 68,5 \\
\hline MAN & 19 & 21,3 & 70 & 78,5 \\
\hline
\end{tabular}

Com relação aos fatores de risco para desnutrição, estes foram identificados de acordo com as respostas das questões da MAN.

A Tabela 9 apresenta a distribuição dos idosos conforme pontuação obtida nas questões da MAN. A partir destes dados, caracterizou-se a população de estudo. 
Tabela 9. Distribuição de idosos, segundo as questões respondidas e a pontuação de cada questão da MAN. Guaratinguetá - SP, 2004.

\begin{tabular}{|c|c|c|c|c|c|c|c|c|c|c|}
\hline \multirow{3}{*}{$\begin{array}{l}\text { Questões } \\
\text { da MAN }\end{array}$} & \multicolumn{10}{|c|}{$\mathrm{N}^{\circ}$ de idosos conforme pontuação } \\
\hline & \multicolumn{2}{|c|}{0} & \multicolumn{2}{|c|}{0,5} & \multicolumn{2}{|c|}{1} & \multicolumn{2}{|c|}{2} & \multicolumn{2}{|c|}{3} \\
\hline & FA & FR & FA & FR & FA & FR & FA & FR & FA & FR \\
\hline $\mathbf{A}$ & 3 & 3,4 & - & - & 17 & 19,1 & 69 & 77,5 & - & - \\
\hline B & 0 & 0 & - & - & 30 & 33,7 & 2 & 2,2 & 57 & 64,0 \\
\hline C & 31 & 34,8 & - & - & 22 & 24,7 & 36 & 40,4 & - & - \\
\hline $\mathbf{D}$ & 27 & 30,3 & - & - & - & - & 62 & 69,7 & - & - \\
\hline $\mathbf{E}$ & 18 & 20,2 & - & - & 29 & 32,6 & 42 & 47,2 & - & - \\
\hline $\mathbf{F}$ & 16 & 18,0 & - & - & 9 & 10,1 & 14 & 15,7 & 50 & 56,2 \\
\hline $\mathbf{G}$ & 89 & 100,0 & - & - & 0 & 0,0 & - & - & - & - \\
\hline$H$ & 32 & 36,0 & - & - & 57 & 64,0 & - & - & - & - \\
\hline 1 & 3 & 3,4 & - & - & 86 & 96,6 & - & - & - & - \\
\hline $\mathbf{J}$ & 2 & 2,2 & - & - & 25 & 28,1 & 62 & 69,7 & - & - \\
\hline$K$ & 5 & 5,6 & 43 & 48,3 & 41 & 46,1 & - & - & - & - \\
\hline $\mathbf{L}$ & 40 & 44,9 & - & - & 49 & 55,1 & - & - & - & - \\
\hline $\mathbf{M}$ & 10 & 11,3 & 48 & 53,9 & 31 & 34,8 & - & - & - & - \\
\hline $\mathbf{N}$ & 14 & 15,7 & - & - & 7 & 7,9 & 68 & 76,4 & - & - \\
\hline 0 & 4 & 4,5 & - & - & 40 & 44,9 & 45 & 50,6 & - & - \\
\hline $\mathbf{P}$ & 12 & 13,5 & 39 & 43,8 & 34 & 38,2 & 4 & 4,5 & - & - \\
\hline $\mathbf{Q}$ & 3 & 3,4 & 5 & 5,6 & 81 & 91,0 & - & - & - & - \\
\hline $\mathbf{R}$ & 44 & 49,4 & - & - & 45 & 50,6 & - & - & - & - \\
\hline Total & 353 & 22,0 & 135 & 8,4 & 603 & 37,6 & 404 & 25,2 & 107 & 6,7 \\
\hline
\end{tabular}


Obtiveram-se os seguintes resultados para os idosos residentes em ILPI's de Guaratinguetá:

- $22,5 \%$ tiveram redução da ingestão alimentar devido à perda de apetite, problemas digestivos ou dificuldades para mastigar ou deglutir;

- $2,0 \%$ tiveram perda de peso nos últimos 3 meses; no entanto, este valor é questionável porque em nenhuma instituição havia registro do peso dos idosos e, por isso, este valor foi estimado pelos próprios idosos ou funcionários;

- $\quad 34,8 \%$ estavam restritos ao leito ou em cadeiras de rodas;

- $\quad 30,3 \%$ passaram por algum estresse ou doença aguda nos últimos 3 meses;

- $\quad 52,8 \%$ tinham algum problema neuropsicológico;

- $\quad 43,8 \%$ tinham IMC menor que $23 \mathrm{~kg} / \mathrm{m}^{2}$;

- $100,0 \%$ eram institucionalizados;

- $36,0 \%$ utilizavam mais de 3 medicamentos diferentes por dia;

- $\quad 3,4 \%$ tinham lesões na pele ou escaras;

- $\quad 30,3 \%$ realizavam, no máximo, 2 refeições ao dia;

- $5,6 \%$ não ingeriam alimentos ricos em proteínas ou apenas uma porção ao dia ou uma porção por semana;

- $44,9 \%$ consumiam, no máximo, uma porção de frutas, verduras ou legumes ao dia;

- $\quad 11,3 \%$ ingeriam, no máximo, 2 copos de líquidos ao dia; 
- $\quad 15,7 \%$ não eram capazes de se alimentar sozinhos;

- $4,5 \%$ acreditavam estarem desnutridos; no entanto, 44,9\% não estavam em condições de responder ou não sabiam dizer;

- $13,5 \%$ consideraram sua saúde não muito boa; no entanto, $43,8 \%$ não estavam em condições de responder ou não sabiam informar;

- $3,4 \%$ tinham $\mathrm{CB}$ menor que $21 \mathrm{~cm}$;

- $49,4 \%$ tinham CP menor que $31 \mathrm{~cm}$.

\subsection{Análise da utilização da Mini Avaliação Nutricional}

Quanto às perguntas e alternativas para as respostas das questões $\mathbf{A}$, C, E, G, H, I, M, N, Q e R nenhuma consideração, correção ou alteração prévia foi necessária para viabilizar o entendimento ou adequar à população do estudo, diferentemente do ocorrido com as questões B, D, F, J, K, L, O e P, como já apresentado anteriormente.

Independentemente destas considerações, limitações e dificuldades foram encontradas no momento do registro da MAN.

Para o início da avaliação, foi necessário estabelecer se o idoso apresentava-se capaz de responder às questões da MAN. Para isso, identificou-se, através da impressão subjetiva da pesquisadora e dos funcionários, os idosos com distúrbio cognitivo considerados incapazes de 
responderem as questões. Portanto, este foi o primeiro requisito e limitação para a realização da MAN.

Entre os 89 participantes, $47(52,8 \%)$ apresentaram algum problema neuropsicológico, sendo que $38(42,7 \%)$ foram considerados com distúrbios cognitivos e incapazes de responderem às questões da MAN, sendo 24 do sexo masculino e 14 do sexo feminino (Tabela 10). Para estes idosos, o registro das questões $A, B, D, I, J, K, L, M$ e $N$ foi dependente das informações dadas pelos funcionários.

Entretanto, os funcionários não acompanhavam continuamente a rotina diária de todos os idosos, devido à sobrecarga de trabalho nas instituições, e as respostas de algumas questões foram estimadas por eles podendo, desta forma, interferir na pontuação final da MAN. 
Tabela 10. Distribuição de idosos de acordo com a presença de distúrbios cognitivos e a capacidade de responderem as questões da MAN, segundo o sexo. Guaratinguetá - SP, 2004.

Sexo

Total

Idosos

Masculino

Feminino

FA FR

FA $\quad$ FR $\quad$ FA $\quad$ FR

Com D.C. * incapazes de

responderem a MAN

$\begin{array}{llllll}24 & 42,1 & 14 & 43,7 & 38 & 42,7\end{array}$

Sem e com D.C.* capazes

de responderem a MAN

$33 \quad 57,9 \quad 18 \quad 56,3 \quad 51 \quad 57,3$

Total

$\begin{array}{llllll}57 & 100,0 & 32 & 100,0 & 89 & 100,0\end{array}$

*D.C. = distúrbio cognitivo, segundo avaliação subjetiva do pesquisador e funcionário

$F A=$ freqüência absoluta; $F R=$ freqüência relativa

A Tabela 11 apresenta o estado nutricional dos idosos avaliados pela MAN de acordo a capacidade dos mesmos em responderem às questões do instrumento. Destaca-se no grupo considerados incapazes, maior prevalência de desnutrição $(52,0 \%)$ e menor prevalência de não desnutrição $(21,1 \%)$ em comparação ao grupo de idosos que foram capazes de responderem as questões, este último grupo apresentou maior prevalência de risco de desnutrição.

Torna-se importante ressaltar que mesmo para os idosos considerados capazes de responderem as questões da MAN, algumas delas ( $C, E$ e $H$ ) foram respondidas pelos funcionários, independentemente do 
estado cognitivo do indivíduo (Figura 2). Portanto, não houve uma avaliação feita exclusivamente com as respostas dadas pelos idosos.

Tabela 11. Distribuição de idosos de acordo com a presença de distúrbios cognitivos e a capacidade de responderem as questões da MAN, segundo o estado nutricional pela MAN. Guaratinguetá - SP, 2004.

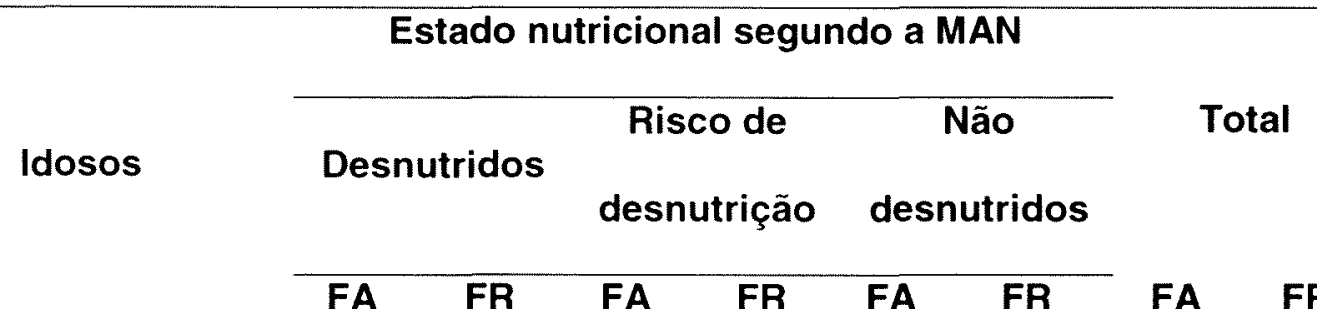

Com D.C.* incapazes

$\begin{array}{lllllllll}\text { de responderem a } & 13 & 52,0 & 21 & 46,7 & 4 & 21,1 & 38 & 42,7\end{array}$

MAN

Sem e com D.C.*

$\begin{array}{lllllllll}\text { capazes de } & 12 & 48,0 & 24 & 53,3 & 15 & 78,9 & 51 & 57,3\end{array}$

responderem a MAN

\begin{tabular}{lllllllll}
\hline Total & 25 & 100,0 & 45 & 100,0 & 19 & 100,0 & 89 & 100,0
\end{tabular}

${ }^{*}$ D.C. = distúrbio cognitivo, segundo avaliação subjetiva do pesquisador e funcionário $F A=$ frequência absoluta; $F R=$ freqüência relativa

Ainda, em relação aos funcionários, observou-se a dificuldade para o entendimento de algumas questões e alternativas da MAN, possivelmente devido à baixa escolaridade. Entre os funcionários, havia auxiliares de enfermagem e de serviços gerais. 
O fato de o registro da MAN depender das informações dadas pelos funcionários não permitiu que a ela fosse realizada na seqüência em que é apresentada, pois a rotina de trabalho dos funcionários não podia ser interrompida ao mesmo tempo em que os idosos estavam disponiveis para responderem às questões e serem medidos. Isto também prejudicou a mensuração do tempo despendido para a realização da MAN.

Por estes motivos, o registro da MAN foi realizado por etapas e sua ordem variou de acordo com a instituição.

As dificuldades encontradas no registro da MAN são descritas por questão:

- Questão A:

Nesta questão, que é relativa à diminuição da ingestão alimentar, quando houve a necessidade de os funcionários respondê-la $(42,7 \%$ dos casos), notou-se dificuldade dos mesmos em determinar a alternativa correta pelo não acompanhamento das refeições dos idosos ou pelos idosos estarem há menos de 3 meses na instituição. 


\section{- Questão B:}

A redução de peso verificada nesta questão foi estimada em todos os casos, devido à ausência de pesagem dos idosos nas instituições. Em nenhuma das 4 instituições participantes do estudo havia balança.

\section{- Questão D:}

Nenhuma dificuldade foi encontrada pela pesquisadora tendo em vista as adaptações realizadas previamente nesta questão. Entretanto, notou-se dificuldade dos idosos para identificar a presença de estresse psicológico, sendo esta ainda maior quando a resposta era dada pelo funcionário.

\section{- Questão E:}

A presença e, principalmente, o grau de problemas neuropsicológicos nos idosos - se leve ou grave - foi de difícil avaliação pela pesquisadora pelo pouco contato com os idosos avaliados. Os funcionários tiveram dificuldade em distinguir demência e depressão e classificá-las em leve ou grave. 


\section{- Questão F:}

Apesar de $34,8 \%$ dos idosos estarem restritos ao leito ou em cadeiras de rodas, $47,2 \%$ deles necessitaram que $\circ$ peso e a estatura fossem estimados para que o cálculo do IMC fosse realizado, pois haviam idosos que apresentaram dificuldade em permanecer em pé para as mensurações necessárias; deste grupo, 7,9\% eram amputados. Este fato levou ao maior dispêndio de tempo para o registro da questão, visto a necessidade de medir a altura do joelho e a circunferência do braço para o cálculo das fórmulas de estimativas de peso e estatura. Para estes casos, um funcionário auxiliou a pesquisadora para o posicionamento adequado do idoso para a obtenção das medidas.

\section{- Questão H:}

A pesquisadora optou por direcionar a questão aos auxiliares de enfermagem, pois eles sabiam com exatidão a ingestão diária de medicamentos de cada idoso, por serem responsáveis pelo controle e distribuição dos mesmos.

Para o registro destas informações, foi agendado horário com o auxiliar de enfermagem de cada instituição, o qual respondeu a questão referente a todos os idosos de uma só vez. Portanto, quando o funcionário da instituição disponibilizado para responder as questões da MAN não era 
um auxiliar de enfermagem, o mesmo era requisitado, sendo mais uma pessoa mobilizada para o registro da MAN.

\section{- Questão J:}

Nesta questão, a pesquisadora necessitou questionar os alimentos consumidos durante o dia pelos idosos para, então, classificá-los de forma a compor uma refeição, de acordo com os requisitos pré-estabelecidos na metodologia. Quanto aos funcionários, estes apresentaram dificuldade em esclarecer todos alimentos consumidos durante o dia pelos os idosos, prejudicando a definição de refeição, pelo fato de eles não acompanharem, continuamente, o momento das refeições dos idosos, portanto, não sabendo exatamente a sua composição.

\section{- Questão K:}

Como esta questão requer a identificação do consumo diário e semanal de alimentos ricos em proteínas pelos idosos, os funcionários tiveram a mesma dificuldade da questão $\mathrm{J}$.

\section{- Questão L:}

Da mesma forma que nas questões $\mathrm{J}$ e $\mathrm{K}$, os funcionários tiveram dificuldade para responder a questão. 


\section{- Questão M:}

Apesar desta questão ter sido facilmente entendida pelos idosos, a identificação da ingestão de líquidos foi de difícil mensuração devido às falhas de memória dos idosos. Para facilitar o registro da resposta, a pesquisadora questionou a ingestão de copos de líquido em cada refeição realizada pelo idoso e nos seus intervalos.

Quando a questão foi respondida por funcionários, a identificação foi ainda mais difícil, pois os mesmos não acompanhavam os idosos continuamente para saber sua ingestão de líquidos.

\section{- Questão P:}

Nesta questão, houvera idosos que apresentaram dificuldade em definir seu estado de saúde de acordo com as alternativas da questão.

A avaliação do registro da MAN, segundo o grau de dificuldade encontrado por questão pelo pesquisador, pelos idosos e pelos funcionários está apresentada na Figura 8.

Os graus de dificuldade foram definidos pela pesquisadora como: grau 0 = sem dificuldade; grau 1 = pouca dificuldade; grau 2 = média dificuldade; grau 3 = muita dificuldade. 
Figura 8. Graus de dificuldade de obtenção das respostas da MAN, segundo a ótica do pesquisador em relação a ele próprio, ao idoso e ao funcionário. Guaratinguetá - SP, 2004.

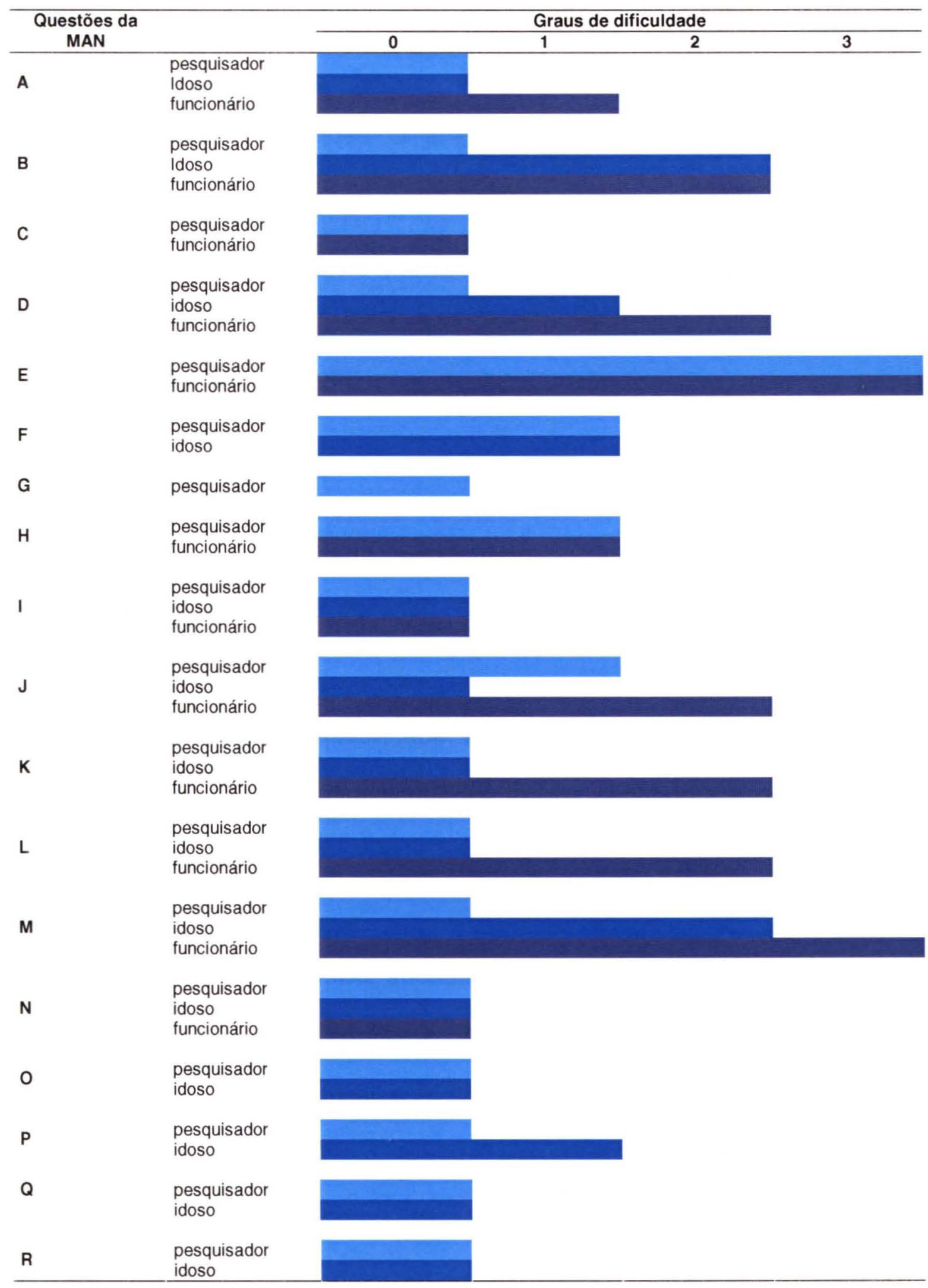


As questões C, E, G e H da MAN não apresentam a avaliação do idoso pelo fato de estas não serem direcionadas a eles. As questões $F, G, Q$ e R não apresentam a avaliação do funcionário por dependerem apenas do pesquisador para registrá-las.

No caso das questões $\mathrm{O}$ e $\mathrm{P}$, como são relacionadas à autopercepção do idoso em relação à sua saúde e estado nutricional, não foram direcionadas aos funcionários nos casos de idosos não aptos à responderem a MAN por questionarem a opinião do idoso, não podendo ser substituída pela opinião dos funcionários.

\subsection{Análise da sensibilidade, especificidade e valores preditivos da MAN}

Para a análise da sensibilidade, especificidade e valores preditivos da MAN, avaliou-se o estado nutricional dos idosos segundo a Área Muscular do Braço corrigida (AMBc).

De acordo com a $\mathrm{AMBc}$, adotando-se como referência os valores de BARBOSA AR*, diagnosticaram-se $34(38,2 \%)$ idosos desnutridos, 30 $(33,7 \%)$ em risco de desnutrição e $25(28,1 \%)$ não desnutridos em ambos os sexos (Figura 9).

\footnotetext{
* Dados não publicados
} 
Figura 9: Diagnóstico nutricional segundo a $\mathrm{AMBc}$ de idosos residentes em ILPI's. Guaratinguetá - SP, 2004.

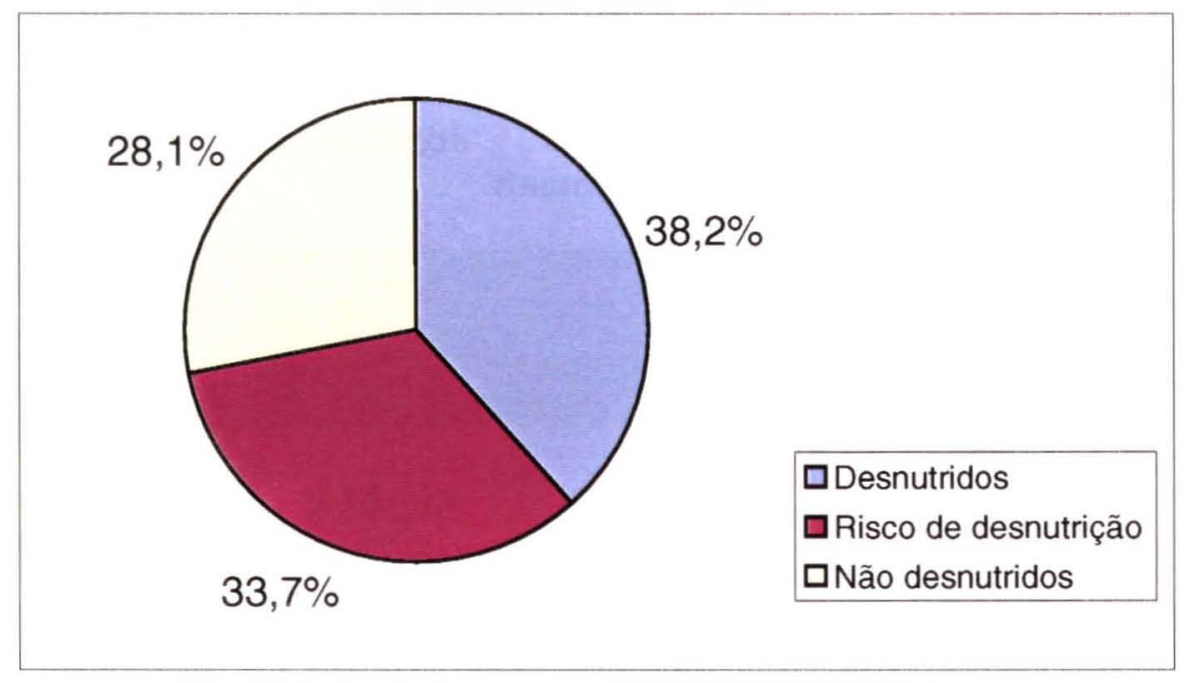

Portanto, a avaliação do estado nutricional da população do estudo é apresentada conforme os métodos de diagnóstico AMBc e MAN, sendo os idosos primeiramente classificados em desnutridos, risco de desnutrição e não desnutridos (Tabela 12) e, posteriormente, em não desnutridos e desnutridos (neste último grupo, sendo incluídos os idosos em risco de desnutrição) (Tabela 13) para que a análise da sensibilidade, especificidade e valores preditivos pudesse ser realizada. 
Tabela 12. Distribuição de idosos, segundo o diagnóstico nutricional e métodos de avaliação. Guaratinguetá - SP, 2004.

\begin{tabular}{ccccc} 
& \multicolumn{3}{c}{ AMBc } & \multirow{2}{*}{ Total } \\
\cline { 2 - 3 } & Desnutridos & Risco de & Não & \\
& & desnutrição desnutridos & \\
\hline Desnutridos & 16 & 6 & 3 & 25 \\
Risco de & 13 & 19 & 13 & 45 \\
desnutrição & & & & \\
Não & 5 & 5 & 9 & 19 \\
desnutridos & & 30 & 25 & 89 \\
\hline Total & 34 & & & \\
\hline
\end{tabular}

Tabela 13. Distribuição de idosos, segundo o diagnóstico nutricional, agrupado em 2 categorias, e métodos de avaliação. Guaratinguetá - SP, 2004.

\begin{tabular}{lccc}
\hline \multirow{2}{*}{ MAN } & \multicolumn{2}{c}{ AMBc } & \multirow{2}{*}{ Total } \\
\cline { 2 - 3 } & Desnutridos & Não desnutridos & \\
\hline Desnutridos & 54 & 16 & 70 \\
Não desnutridos & 10 & 9 & 19 \\
\hline Total & 64 & 25 & 89 \\
\hline
\end{tabular}


A partir dos dados da tabela 13, obtiveram-se os seguintes valores:

- $\quad$ sensibilidade $=0,84(84,0 \%)$

- $\quad$ especificidade $=0,36(36,0 \%)$

- $\quad$ valor preditivo positivo $=0,77(77,0 \%)$

- $\quad$ valor preditivo negativo $=0,47(47,0 \%)$

A Figura 10 apresenta a área sob a curva ROC da MAN.

Figura 10: Curva ROC da MAN. Guaratinguetá - SP, 2004.

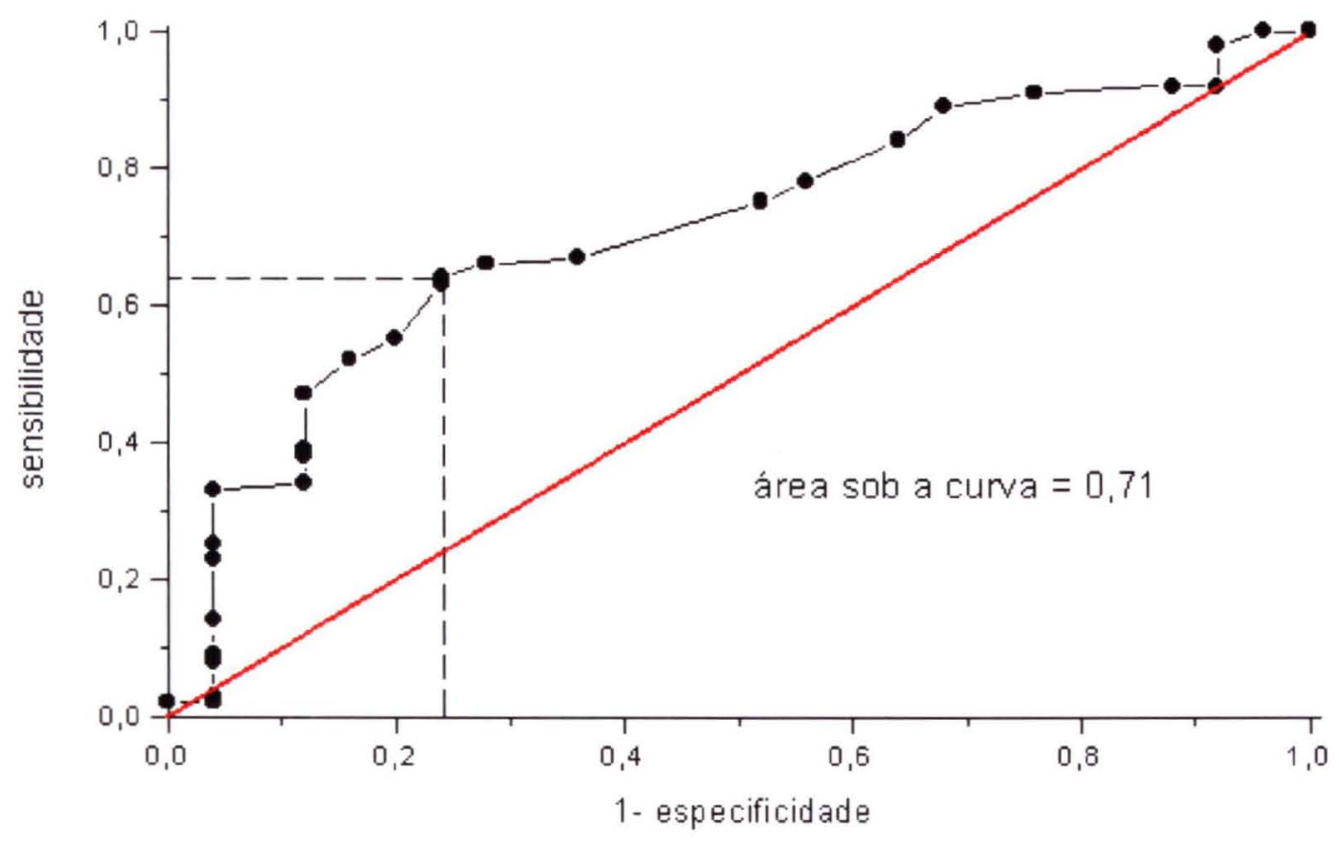


Tabela 14. Valores de sensibilidade e especificidade de cada pontuação da MAN. Guaratinguetá - SP, 2004.

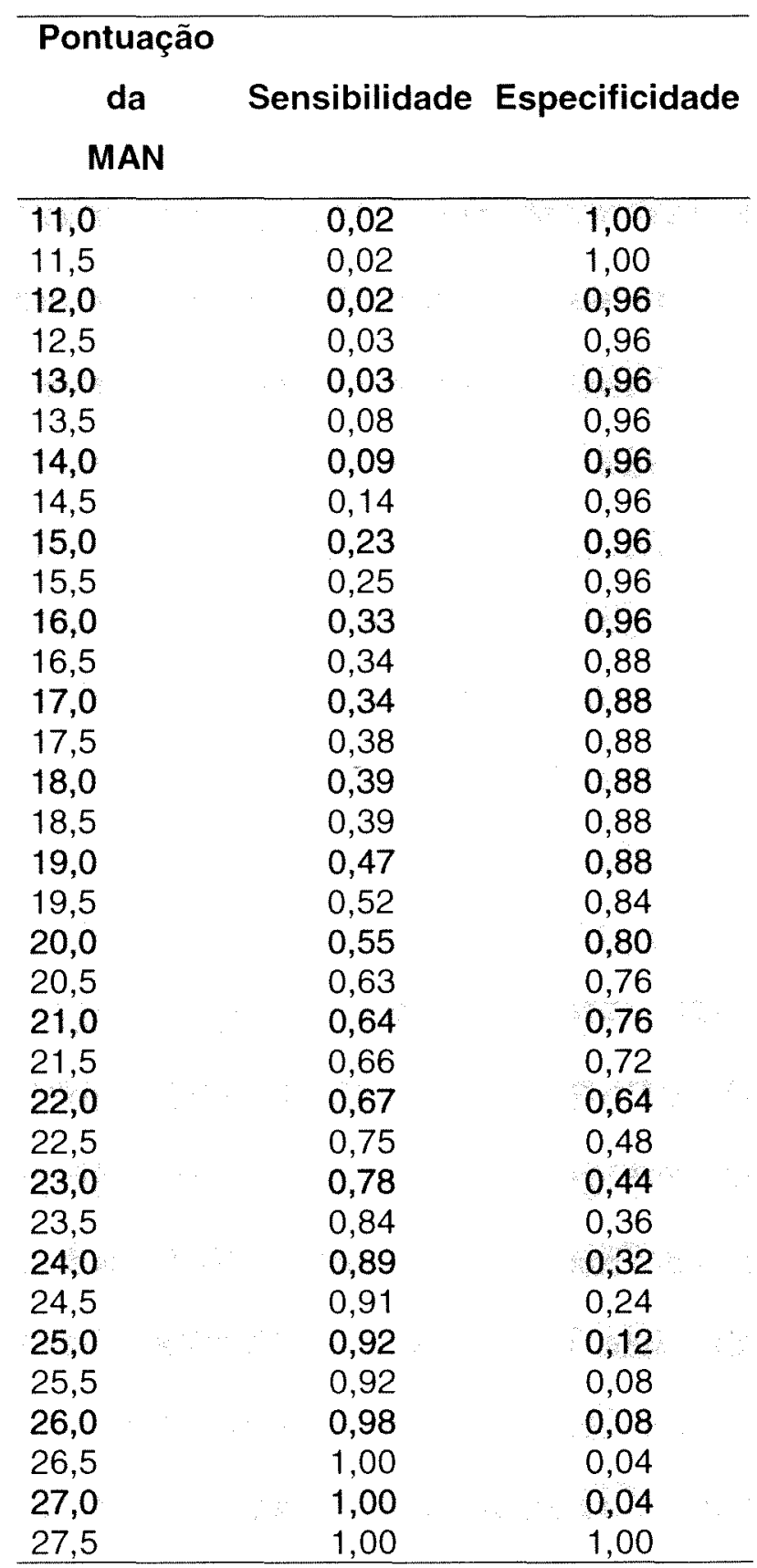


O ponto da curva ROC em que a MAN apresentou maior sensibilidade e 1 - especificidade foi a intersecção dos pontos 0,62 e 0,24, respectivamente (Figura 10). Este valor está próximo à pontuação 20,5 da MAN (Tabela 14).

Pode-se sugerir que este seja o novo ponto de corte $(20,5)$ para diagnosticar idosos em risco de desnutrição e desnutridos nesta população, em vez da pontuação 23,5 , como originalmente é apresentado.

Tabela 15. Distribuição de idosos, segundo o diagnóstico nutricional pela Triagem da MAN e pela Área Muscular do Braço corrigida (AMBc) e métodos de avaliação. Guaratinguetá - SP, 2004.

\begin{tabular}{cccc}
\hline & \multicolumn{2}{c}{ AMBc } & \\
\cline { 2 - 3 } Triagem da MAN & Desnutridos e & Não & Total \\
& Risco de desnutrição desnutridos & $(\%)$ \\
& $(\%)$ & $(\%)$ & \\
\hline Desnutridos e & 50 & 11 & 61 \\
Risco de desnutrição & & & \\
Não desnutridos & 14 & 14 & 28 \\
\hline Total & 64 & 25 & 89 \\
\hline
\end{tabular}


$\mathrm{Na}$ Tabela 15, é apresentada a distribuição dos idosos segundo a avaliação nutricional pela Triagem da MAN e a AMB. A partir destes dados obtiveram-se os seguintes valores:

- $\quad$ sensibilidade $=0,78(78 \%)$

- $\quad$ especificidade $=0,56(56 \%)$

- $\quad$ valor preditivo positivo $=0,82(82 \%)$

- $\quad$ valor preditivo negativo $=0,50(50 \%)$

A Figura 11 apresenta a área sob a curva ROC da Triagem da MAN.

Figura 11: Curva ROC da Triagem da MAN. Guaratinguetá - SP, 2004.

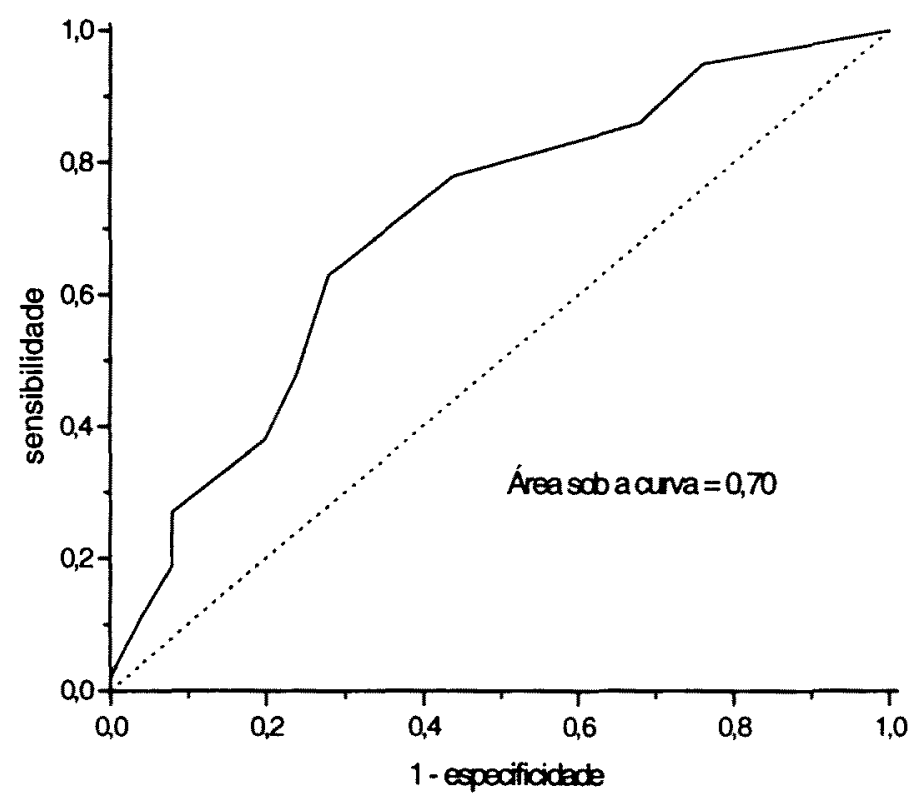


Tabela 16. Valores de sensibilidade e especificidade de cada pontuação da Triagem da MAN. Guaratinguetá - SP, 2004.

\begin{tabular}{lll}
\hline $\begin{array}{c}\text { Pontuação } \\
\text { da } \\
\text { MAN }\end{array}$ & Sensibilidade & \\
\hline 4 & & \\
5 & 0,02 & 1,00 \\
6 & 0,11 & 0,96 \\
7 & 0,19 & 0,92 \\
8 & 0,27 & 0,92 \\
9 & 0,38 & 0,80 \\
10 & 0,48 & 0,76 \\
11 & 0,63 & 0,72 \\
12 & 0,78 & 0,56 \\
13 & 0,86 & 0,32 \\
14 & 0,95 & 0,24 \\
\hline & 1,00 & 0,00 \\
\hline
\end{tabular}

O ponto da curva ROC em que a Triagem da MAN apresentou maior sensibilidade e 1 - especificidade foi a intersecção dos pontos 0,78 e 0,44, respectivamente (Figura 11). Este valor corresponde à pontuação 11 da Triagem da MAN (Tabela 16).

Esta pontuação (11) é muito próxima da originalmente apresentada para triar idosos não desnutridos e possivelmente desnutridos.

As Tabelas 17 e 18 apresentam a distribuição dos idosos com distúrbios cognitivos que foram incapazes de responderem as questões da MAN, segundo o diagnóstico nutricional e métodos de avaliação. 
Tabela 17. Distribuição de idosos com distúrbios cognitivos incapazes de responderem a MAN, segundo o diagnóstico nutricional e métodos de avaliação. Guaratinguetá - SP, 2004.

\begin{tabular}{ccccc} 
& \multicolumn{3}{c}{ AMBc } & \\
\cline { 2 - 3 } & & Risco de & Não & Total \\
& & Desnutridos & desnutrição desnutridos & \\
\hline Desnutridos & 8 & 4 & 1 & 13 \\
Risco de & 7 & 8 & 6 & 21 \\
desnutrição & & & & \\
Não & 1 & 1 & 2 & 4 \\
desnutridos & & & 9 & 38 \\
\hline Total & 16 & 13 & & \\
\hline
\end{tabular}

Tabela 18. Distribuição de idosos com distúrbios cognitivos incapazes de responderem a MAN, segundo o diagnóstico nutricional, agrupado em 2 categorias, e métodos de avaliação. Guaratinguetá - SP, 2004.

\begin{tabular}{lccc}
\hline \multirow{2}{*}{ MAN } & \multicolumn{2}{c}{ AMBc } & \multirow{2}{*}{ Total } \\
\cline { 2 - 3 } & Desnutridos & Não desnutridos & \\
\hline Desnutridos & 27 & 7 & 34 \\
Não desnutridos & 2 & 2 & 4 \\
\hline Total & 29 & 9 & 38 \\
\hline
\end{tabular}


A partir destes dados obtiveram-se os seguintes valores:

- $\quad$ sensibilidade $=0,93(93 \%)$

- $\quad$ especificidade $=0,22(22 \%)$

- $\quad$ valor preditivo positivo $=0,79(79 \%)$

- $\quad$ valor preditivo negativo $=0,50(50 \%)$

As Tabelas 19 e 20 apresentam a distribuição dos idosos com ou sem distúrbios cognitivos que foram capazes de responderem as questões da MAN, segundo o diagnóstico nutricional e métodos de avaliação.

Tabela 19. Distribuição de idosos com ou sem distúrbios cognitivos capazes de responderem a MAN, segundo o diagnóstico nutricional e métodos de avaliação. Guaratinguetá - SP, 2004.

\begin{tabular}{ccccc}
\hline \multirow{2}{*}{ MAN } & \multicolumn{3}{c}{ AMBc } & \multirow{2}{*}{ Total } \\
\cline { 2 - 4 } & Desnutridos & Não de & \\
& & desnutrição desnutridos & \\
\hline Desnutridos & 8 & 2 & 3 & 13 \\
Risco de & 5 & 11 & 7 & 23 \\
desnutrição & & & & 15 \\
Não & 5 & 4 & 6 & 51 \\
desnutridos & & 17 & 16 & \\
\hline Total & 18 & & & \\
\hline
\end{tabular}


Tabela 20. Distribuição de idosos com ou sem distúrbios cognitivos capazes de responderem a MAN, segundo o diagnóstico nutricional, agrupado em 2 categorias, e métodos de avaliação. Guaratinguetá - SP, 2004.

\begin{tabular}{lccc}
\hline \multirow{2}{*}{ MAN } & \multicolumn{2}{c}{ AMBc } & \multirow{2}{*}{ Total } \\
\cline { 2 - 3 } & Desnutridos & Não desnutridos & \\
\hline Desnutridos & 26 & 10 & 36 \\
Não desnutridos & 9 & 6 & 15 \\
\hline Total & 35 & 16 & 51 \\
\hline
\end{tabular}

A partir destes dados obtiveram-se os seguintes valores:

- $\quad$ sensibilidade $=0,93(93 \%)$

- $\quad$ especificidade $=0,22(22 \%)$

- $\quad$ valor preditivo positivo $=0,79(79 \%)$

- $\quad$ valor preditivo negativo $=0,50(50 \%)$

Para melhor visualizar os resultados encontrados, foram reunidos em uma mesma tabela os valores de sensibilidade, especificidade e valores preditivos de todos os casos analisados (Tabela 21). 
Tabela 21. Valores em porcentagem de sensibilidade, especificidade e valores preditivos da MAN. Guaratinguetá - SP, 2004.

\begin{tabular}{|c|c|c|c|c|}
\hline & $\begin{array}{c}\text { Sensibilidade } \\
(\%)\end{array}$ & $\begin{array}{c}\text { Especificidade } \\
(\%)\end{array}$ & $\begin{array}{l}\text { VPP }^{1} \\
(\%)\end{array}$ & $\begin{array}{l}V_{P N^{2}} \\
(\%)\end{array}$ \\
\hline MAN & 84 & 36 & 77 & 47 \\
\hline $\begin{array}{l}\text { MAN - idosos com D.C. } \\
\text { incapazes de responder }\end{array}$ & 93 & 22 & 79 & 50 \\
\hline $\begin{array}{l}\text { MAN - idosos com ou } \\
\text { sem D.C. }{ }^{3} \text { capazes de } \\
\text { responder }\end{array}$ & 74 & 38 & 72 & 40 \\
\hline Triagem da MAN & 78 & 56 & 82 & 50 \\
\hline
\end{tabular}

Foram realizadas análises da sensibilidade, especificidade e valores preditivos de cada questão da MAN. Os resultados estão apresentados na Tabela 22. 
Tabela 22. Valores de sensibilidade e especificidade, com os respectivos intervalos de confiança, e valores preditivos de cada questão da MAN. Guaratinguetá - SP, 2004.

\begin{tabular}{lcccc}
\hline $\begin{array}{l}\text { Questões } \\
\text { da MAN }\end{array}$ & $\begin{array}{c}\text { Sensibilidade } \\
\text { (IC 95\%) }\end{array}$ & $\begin{array}{c}\text { Especificidade } \\
\text { (IC 95\%) }\end{array}$ & $\begin{array}{c}\text { Valor } \\
\text { preditivo } \\
\text { positivo }\end{array}$ & $\begin{array}{c}\text { Valor } \\
\text { preditivo } \\
\text { negativo }\end{array}$ \\
\hline A & $0,22(0,14-0,36)$ & $0,80(0,59-0,93)$ & 0,75 & 0,29 \\
B & $0,39(0,27-0,52)$ & $0,72(0,50-0,88)$ & 0,78 & 0,32 \\
C & $0,66(0,53-0,77)$ & $0,56(0,35-0,76)$ & 0,79 & 0,39 \\
D & $0,30(0,19-0,43)$ & $0,68(0,47-0,85)$ & 0,70 & 0,27 \\
E & $0,56(0,43-0,69)$ & $0,56(0,35-0,76)$ & 0,77 & 0,33 \\
F & $0,59(0,46-0,72)$ & $0,96(0,80-1,00)$ & 0,97 & 0,48 \\
G & $1,00(0,94-1,00)$ & $0,00(0,00-0,14)$ & 0,72 & 0,00 \\
H & $0,36(0,24-0,49)$ & $0,64(0,42-0,82)$ & 0,72 & 0,28 \\
I & $0,05(0,01-0,13)$ & $1,00(0,86-1,00)$ & 1,00 & 0,29 \\
J & $0,30(0,19-0,42)$ & $0,68(0,47-0,85)$ & 0,70 & 0,27 \\
K & $0,45(0,33-0,58)$ & $0,24(0,09-0,45)$ & 0,60 & 0,15 \\
L & $0,48(0,36-0,61)$ & $0,64(0,42-0,82)$ & 0,78 & 0,33 \\
M & $0,67(0,54-0,78)$ & $0,40(0,21-0,61)$ & 0,74 & 0,32 \\
N & $0,28(0,18-0,41)$ & $0,88(0,69-0,97)$ & 0,86 & 0,32 \\
O & $0,53(0,40-0,66)$ & $0,60(0,39-0,79)$ & 0,77 & 0,33 \\
P & $0,63(0,50-0,74)$ & $0,56(0,35-0,76)$ & 0,78 & 0,37 \\
Q & $0,13(0,06-0,23)$ & $1,00(0,86-1,00)$ & 0,14 & 0,31 \\
R & $0,59(0,46-0,71)$ & $0,76(0,55-0,91)$ & 0,86 & 0,42 \\
\hline
\end{tabular}

As questões que apresentaram maior sensibilidade, ou seja, sensíveis no diagnóstico de desnutrição e risco de desnutrição, em ordem crescente, foram: G $(100,0 \%), M(67,0 \%), C(66,0 \%), P(63,0 \%), F(59,0 \%), R(59,0 \%)$, $\mathrm{E}(56,0 \%)$ e $\mathrm{O}(53,0 \%)$, as quais representam, respectivamente, a institucionalização, a ingestão de líquidos, o grau de mobilidade, a auto- 
percepção do idoso sobre sua saúde, o IMC, a circunferência da panturrilha, os distúrbios neuropsicológicos e a auto-percepção do idosos sobre seu estado nutricional.

A questão $G$ teve sensibilidade de $100,0 \%$ visto a pesquisa ter sido realizada exclusivamente em idosos institucionalizados, portanto, tendo a mesma resposta assinalada para todas as questões.

Em contrapartida, as questões que apresentaram menor sensibilidade, em ordem crescente, foram: I (5,0\%), Q (13,0\%), A $(22,0 \%), N$ $(28,0 \%), J(30,0 \%), D(30,0 \%), H(36,0 \%), B(39,0 \%), K(45,0 \%)$ e L $(48,0 \%)$, as quais representam, respectivamente, a presença de lesões ou escaras na pele, a circunferência do braço, a perda de apetite, a capacidade de alimentar-se sozinho, o número de refeições realizadas ao dia, a presença de estresse psicológico ou doença aguda, a ingestão de medicamentos, a redução do peso, a ingestão de proteínas e a ingestão de frutas.

As questões que apresentaram maior especificidade, ou seja, específicas em diagnosticar a ausência de desnutrição, em ordem crescente, foram: I (100,0\%), Q (100,0\%), F (96,0\%), N (88,0\%), A $(80,0 \%), R(76,0 \%)$, B $(72,0 \%), \mathrm{D}(68,0 \%), \mathrm{J}(68,0 \%), \mathrm{H}(64,0 \%), \mathrm{L}(64,0 \%), \mathrm{O}(60,0 \%), \mathrm{C}$ $(56,0 \%)$, $E(56,0 \%)$, e $P(56,0 \%)$, as quais representam, respectivamente, a presença de lesões ou escaras na pele, a circunferência do braço, o IMC, a capacidade de alimentar-se sozinho, a perda de apetite, a circunferência da 
panturrilha, a redução do peso, a presença de estresse psicológico ou doença aguda, o número de refeições realizadas ao dia, a ingestão de medicamentos, a ingestão de frutas, a auto-percepção do idoso sobre seu estado nutricional, o grau de mobilidade, os distúrbios neuropsicológicos e a auto-percepção do idoso sobre sua saúde.

As questões que apresentaram menor especificidade, em ordem crescente, foram: $\mathrm{G}(0,0 \%), \mathrm{K}(24,0 \%)$ e $\mathrm{M}(40,0 \%)$, as quais representam, respectivamente, a institucionalização, a ingestão de proteínas e a ingestão de líquidos.

De acordo com a classificação dos autores (GUIGOZ et al. 1994), a MAN é composta por questões que compreendem a avaliação antropométrica ( $F, Q$ e $R)$, a avaliação dietética $(A, J, K, L, M$ e $N)$, a avaliação clínica (B, C, D, E, G, H e I) e a avaliação subjetiva (O e P).

Com relação às questões que compõem a avaliação antropométrica, verificou-se que a $F$ e a $R$ apresentaram alta sensibilidade $(59,0 \%)$ e especificidade $(96,0 \%$ e $76,0 \%)$, e a questão B e Q, baixa sensibilidade (39,0\% e $13,0 \%)$ e alta especificidade $(78,0 \%$ e $100,0 \%)$.

Quanto às questões da avaliação dietética, verificou-se que todas apresentaram baixa sensibilidade, com exceção da $M$. As questões $A, L, J$ e 
$\mathrm{N}$, apresentaram alta especificidade. A questão $\mathrm{K}$ foi a única deste grupo que apresentou baixa sensibilidade e especificidade.

Entre as questões que compreendem a avaliação clínica, exceto a $\mathrm{G}$, a I, D, H e B, apresentaram baixa sensibilidade, sendo a $C$ e $E$, as que apresentaram alta sensibilidade. Todas as questões apresentaram alta especificidade.

As questões $\mathrm{O}$ e $\mathrm{P}$ pertencentes à avaliação subjetiva apresentaram alta sensibilidade e especificidade. 


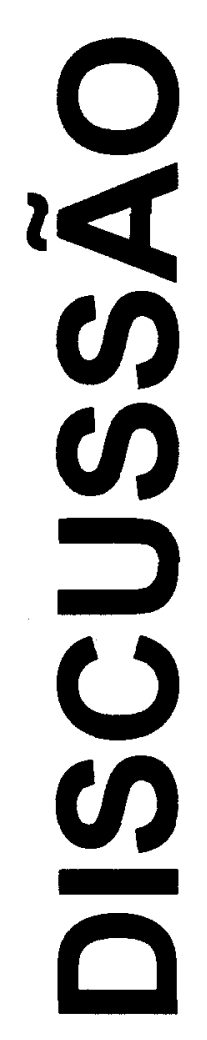




\section{DISCUSSÃO}

Dentre as quatro instituições estudadas, três são para ambos os sexos e uma é exclusivamente para homens. PILOTO et al. (1998) também identificaram maior predominância de instituições para ambos os sexos $(71,3 \%)$ no Rio de Janeiro/RJ. No caso do estudo de CHAIMOWICZ e GRECO (1999), em 40 ILPI's de Belo Horizonte/MG, houve predominância daquelas exclusivamente destinadas às mulheres $(54,0 \%)$, sendo que as instituições exclusivas para homens representaram, apenas, 3,0\%. Em ILPI's de Fortaleza/CE, MENEZES (2000) também identificou predominância de instituições exclusivas às mulheres $(66,7 \%)$ dentre as pesquisadas.

Em todas as instituições, observou-se a presença de indivíduos com idade inferior a 60 anos, correspondendo a 8,5\% dos institucionalizados de Guaratinguetá/SP. Em residentes de ILPI's da cidade de São Paulo, MARUCCI (1985) encontrou 9,1\%. CHAIMOWICZ e GRECO (1999) identificaram a mesma situação, neste caso, representando $30,7 \%$ dos homens e $15,0 \%$ das mulheres institucionalizadas.

Quanto ao sexo, houve predominância do masculino $(64,0 \%)$, semelhante ao observado no estudo de PAYETTE et al. (2000) com idosos institucionalizados de Quebéc (Canadá) $(61,0 \%)$. Entretanto, a maioria dos estudos brasileiros apresenta resultados opostos. 
BENNEMANN (2002), MENEZES (2000), CHAIMOWICZ e GRECO (1999) e MARUCCI (1985) identificaram, respectivamente, a presença das seguintes proporções de mulheres em ILPI's: 69,5\% em Bragança Paulista/SP, 69,2\% em Fortaleza/CE, 81,0\% em Belo Horizonte/MG, e 64,4\% em São Paulo/SP. Em idosos vivendo na comunidade, também foi encontrada maior prevalência do sexo feminino (MARUCCI 1992; NAJAS 1995; DELACORTE et al. 2004).

O fato de possuir uma instituição destinada exclusivamente para homens não justifica a maior proporção deste sexo entre a população estudada, visto que nesta instituição encontraram-se apenas 6 idosos. Possivelmente, a maior proporção de idosos deste sexo seja pelo fato da maioria ser solteiro ou viúvo (apesar de não ter sido registrado o estado civil dos idosos), encontrando-se sozinhos e necessitando de cuidados, o que pode ter implicado maiores casos de institucionalização. Sustentando esta hipótese, observou-se que $60,7 \%$ dos idosos foram institucionalizados devido à ausência de cuidador ou abandono.

A média de idade da população estudada foi de 73,7 anos ( $D P=9,1$ ), próxima à observada em ILPl's de Fortaleza/CE por MENEZES (2000) $(75,9$ anos). RESENDE (2001), em ILPI's de Uberlândia/MG, e BENNEMANN (2002), em ILPI's de Bragança Paulista/SP, encontraram a média de idade pouco mais elevada $(76,9$ e 77,8 anos, respectivamente). 
A maioria dos idosos apresentou 80 anos e mais $(30,3 \%)$, sendo que, entre os homens, a maior proporção foi do grupo de 65 a 69 anos $(28,1 \%)$, e entre as mulheres, foi do grupo de 80 anos e mais $(37,5 \%)$. Em idosos institucionalizados de Fortaleza/CE, MENEZES (2000) também encontrou maior proporção de idosos com 80 anos e mais $(35,1 \%)$, no entanto, entre os sexos, não foi verificada a mesma característica nesse estudo. A maior proporção de mulheres com idade superior a 80 anos pode ser justificada pela elevada expectativa de vida entre esse grupo (KALACHE et al. 1987; MENEZES 2000).

Na Suécia, SALETTI et al. (2000) também observaram maioria dos idosos residentes em ILPl's com 80 anos e mais, no entanto, a proporção foi maior $(72,0 \%)$.

Em idosos vivendo na comunidade, MENEZES (2004) e NOVAES (2003) identificaram que a maioria deles tinha entre 60 e 69 anos, enquanto que o grupo de 80 anos e mais estava presente em menores proporções.

O fato de possuir mais idosos institucionalizados com 80 anos e mais, em detrimento dos outros grupos etários, pode ser explicado pela maior necessidade de cuidados desta população, possivelmente por estarem incapazes de executarem as atividades básicas da vida diária, levando-os em maior escala à institucionalização. 
A predominância de idosos identificados como sendo de cor branca $(75,3 \%)$ foi próxima à encontrada por MARUCCI (1992) $(79,8 \%)$ com idosos ambulatoriais de São Paulo, diferentemente do encontrado em ILPI's de Fortaleza/CE onde prevaleceram idosos da cor parda (MENEZES 2000).

Similarmente ao estudo de MENEZES (2004), não foram identificados idosos da cor amarela. No estudo de MARUCCI (1992) verificou-se, apenas, 2,3\% de idosos da cor amarela, e no de NAJAS (1995), este grupo representou $4,0 \%$ da população.

O tempo de permanência dos idosos nas instituições variou de 0 a 62,3 anos e a média foi de 8 anos. A variação apresentou-se alta devido à presença de indivíduos residentes nas instituições antes delas serem destinadas exclusivamente a idosos. O tempo médio de permanência dos idosos em ILPI's verificado por BENNEMANN (2002) foi de 7,5 anos, próximo ao encontrado neste estudo.

Nos Estados Unidos, segundo COULSTON (1995), o tempo médio de permanência dos idosos nas instituições é de 2,9 anos, portanto, verifica-se que no Brasil, o tempo de permanência dos idosos nas instituições é maior.

A presença de idosos incapazes de responderem às questões da MAN devido à presença de distúrbio cognitivo esteve presente em $42,7 \%$ dos idosos estudados. Apesar de não terem sido utilizados neste estudo 
métodos específicos de diagnóstico para distúrbios cognitivos, verificou-se que o quadro encontrado foi próximo ao identificado no estudo de BENNEMANN (2002), em Bragança Paulista/SP (40,3\%), e inferior ao estudo de ENGELHARDT et al. (1998) $(52,4 \%)$, no Rio de Janeiro/RJ, todos com idosos institucionalizados e com a utilização de métodos específicos.

KELLER (1993), em estudo com idosos hospitalizados, encontrou prevalência de $27,5 \%$ de idosos com distúrbio cognitivo.

Possivelmente, a elevada prevalência de idosos com distúrbios cognitivos nas ILPI's deve-se à predominância de indivíduos com 80 anos e mais (ALMEIDA 1998; BENNEMANN 2002) e também pelo fato dos mesmos não terem condições de receber cuidados no domicílio e serem institucionalizados, já que $60,4 \%$ dos idosos residiam nas instituições pela ausência de cuidador ou abandono.

Embora o envelhecimento não seja sinônimo de doença, com o avanço da idade, aumenta o risco de comprometimento da capacidade funcional. Neste contexto, destaca-se a elevada prevalência dos distúrbios cognitivos (QUEIROZ 2000).

Dificuldades de mobilização foram encontradas em $47,2 \%$ dos idosos institucionalizados, diferentemente do identificado por DELACORTE et al. (2004) em idosos vivendo na comunidade (4,8\%). Estes resultados 
confirmam os achados de outros estudos em que a institucionalização está diretamente relacionada à incapacidade (CHAIMOWICZ e GRECO 1999; CHAIMOWICZ, 1997).

A MAN variou de 11 a 27,5 pontos e obteve média de 20,2 pontos, a qual representa "risco de desnutrição".

No Brasil, em idosos hospitalizados, a MAN apresentou pontuação mínima de 16 pontos para homens e 13,5 pontos para mulheres, e máxima de 28,5 pontos para os homens e 24 pontos para as mulheres, sendo que a pontuação média para os homens foi de 22,3 pontos e para as mulheres foi de 20,6 pontos (OLIVEIRA et al. 2003).

DELACORTE et al. (2004), em idosos vivendo na comunidade, identificaram menor variação da pontuação da MAN, e a pontuação mínima e máxima (19 a 29,5 pontos, respectivamente), assim como a média $(25,3$ pontos), foram maiores que as encontradas neste estudo; neste caso, a pontuação média representa ausência de desnutrição. Possivelmente, as pontuações mais elevadas devem-se ao fato de os pesquisadores terem avaliado idosos vivendo na comunidade, os quais apresentam melhor adequação do estado nutricional em relação aos hospitalizados e residentes em ILPI's (GUIGOZ et al. 1996). 
Na Espanha, RUIZ-LOPES et al. (2003) e BLEDA et al. (2002) avaliaram o estado nutricional de idosos em ILPI's e verificaram resultados próximos com relação à pontuação média da MAN (20,6 e 21,3, respectivamente), enquanto SALETTI et al. (2000), na Suécia, identificaram pontuação média inferior $(14,2)$.

Com relação ao estado nutricional, identificaram-se $25(28,1 \%)$ idosos desnutridos, $45(50,6 \%)$ em risco de desnutrição, e 19 (21,3\%) não desnutridos.

Estudos internacionais mostram que a prevalência de desnutrição em idosos residentes em ILPI's pode variar de 5,0 a 85,0\%. A elevada variação encontrada deve-se, principalmente, às diferenças dos métodos e critérios adotados para o diagnóstico da desnutrição (KERSTETTE 1992; MORLEY 1998).

BENNEMANN (2002), em idosos residentes em ILPl's de Bragança Paulista/SP, verificou 18,1\% de desnutrição. Em ILPI's de Uberlândia/MG, RESENDE (2001) identificou 16,0\%. MENEZES (2000), em ILPI's de Fortaleza/CE, diagnosticou 49,8\%. Nesses casos, provavelmente, a prevalência de desnutrição diferiu, principalmente, entre as instituições localizadas no Sudeste e a do Nordeste, devido às características sociais, econômicas e culturais de cada região. Comparando-se esses resultados aos deste estudo, verifica-se que há mais idosos desnutridos em instituições 
de Guaratinguetá/SP do que em Bragança Paulista/SP e Uberlândia/MG, no entanto, bem menos desnutridos que em Fortaleza/CE.

A diferença entre a prevalência de desnutrição de pacientes hospitalizados no Sudeste e Nordeste do Brasil é observada por WAITZBERG et al. (1999), que identificaram, respectivamente, $42,8 \% \mathrm{e}$ $63,9 \%$ de desnutridos em cada região.

Algumas pesquisas européias apresentaram maior prevalência de desnutrição entre idosos institucionalizados em comparação à encontrada neste estudo. Na França, LAUQUE et al. (1999) observaram a presença de $41,0 \%$ de desnutridos e, na Suécia, SALETTI et al. (2000) identificaram 36,0\%. Diferentemente, na Itália, MOLASCHI et al. (1999) verificaram menor prevalência $(21,0 \%)$.

Na Espanha, MIJARES et al. (2001) encontraram resultados próximos ao desta pesquisa para a desnutrição $(26,9 \%)$, entretanto, RUIZ-LOPES et al. (2003), RAMON e SUBIRÁ (2001) e SALVÀ et al. (1996) identificaram valores inferiores $(7,9 \%, 7,7 \%$, e $5,7 \%$, respectivamente) no mesmo país.

Em ILPI's da Venezuela, PEÑA et al. (1998) diagnosticaram 35,3\% de desnutrição, portanto, resultado superior ao deste estudo, e em ILPI's no Equador, BARCLAY et al. (1996) encontraram resultado inferior $(21,0 \%)$, assim como KELLER (1993) no Canadá (18,0\%). 
Verifica-se que os idosos desnutridos $(28,1 \%)$ prevaleceram sobre os não desnutridos $(21,3 \%)$ nesta pesquisa. Entretanto, aqueles com risco de desnutrição foram a maioria entre os três grupos $(50,6 \%)$.

É comum observar a predominância de idosos com risco de desnutrição em relação aos desnutridos e não desnutridos em ILPI's (RUIZLOPES et al. 2003; RESENDE 2001; SALETTI et al. 2000; LAUQUE et al. 1999; MOLASHI et al. 1999; PEÑA et al. 1998; BARCLAY e tal. 1996; SALVÀ et al. 1996). Isto porque os idosos institucionalizados apresentam diversos fatores que os predispõem ao risco nutricional, principalmente à desnutrição. O próprio fato da institucionalização é um potencial fator de risco para a desnutrição.

A desnutrição é freqüentemente encontrada e mais prevalente em idosos institucionalizados $(5,0$ a $85,0 \%)$ quando comparada aos hospitalizados e aos que vivem na comunidade (KERSTETTER 1992; MORLEY 1998). De acordo com a revisão bibliográfica de GUIGOZ et al. (1996), a desnutrição variou de 22,0 a 59,0\% entre os hospitalizados, e em idosos vivendo na comunidade variou de 1,0 a $7,0 \%$.

No Brasil, em idosos vivendo na comunidade, NAJAS (1995) diagnosticou 3,7\% de desnutrição, TAVARES e ANJOS (1999) identificaram, aproximadamente $10,0 \%$, DELACORTE et al. (2004) diagnosticaram 7,1\%, e NOVAES (2003), 19,6\%. Em hospitalizados, a prevalência de desnutrição foi 
de $8,8 \%$ de acordo com OLIVEIRA et al. (2003) e chegou a atingir $27,0 \%$ no estudo de SHINTAKU (2003). Em idosos residindo em ILPI's, a prevalência de desnutrição foi de $18,1 \%$ de acordo com BENNEMANN (2002), 16,0\% segundo RESENDE (2001), e alcançou $50,0 \%$ no estudo de MENEZES (2000).

Portanto, a prevalência de desnutrição encontrada nesta pesquisa $(28,1 \%)$ está entre os resultados normalmente encontrados na população de idosos institucionalizados, considerada representativa visto a maior suscetibilidade à morbimortalidade deste grupo populacional.

Neste estudo, a desnutrição foi mais prevalente entre os idosos do sexo masculino $(31,6 \%)$. Este quadro é comumente observado em outras pesquisas (NAJAS 1995; RITCHIE et al. 1997; TAVARES e ANJOS 1999, MENEZES 2000 e 2004; BENNEMANN 2002).

grupo etário de 80 anos e mais apresentou maior prevalência de desnutrição (44,0\%). BENNEMANN (2002), RESENDE (2001) e MENEZES (2000) também verificaram a mesma característica em seus estudos.

Devido à elevada prevalência de risco de desnutrição e desnutrição entre os idosos institucionalizados, a MAN pode ser considerada importante metodologia de identificação dos fatores de risco nutricional que, 
precocemente identificados e feitas as intervenções adequadas, podem prevenir a desnutrição ou evitar o seu agravo.

Portanto, considera-se como principal vantagem do método a possibilidade de identificar os fatores de risco que contribuem para o desenvolvimento da desnutrição.

Quando administrada periodicamente, a MAN permite o acompanhamento da evolução nutricional do idoso.

Se ela for utilizada em um grupo, no qual conhecidamente a prevalência de pré-obesidade e obesidade é alta, é preciso utilizar outros métodos complementares capazes de diagnosticarem estes distúrbios nutricionais, já que a MAN identifica a ausência de desnutrição, no entanto, não diferencia eutróficos de pré-obesos e obesos.

No estudo de OLIVEIRA et al. (2003), os autores observaram limitação no uso da MAN, exatamente, por utilizarem o método em idosos hospitalizados com insuficiência cardíaca, nos quais a prevalência de obesidade era alta.

A MAN tem sido utilizada para avaliar o estado nutricional de mais de 10.000 idosos em diferentes locais (comunidade, assistência domiciliar, hospitais e instituições) e países (Bélgica, Dinamarca, França, Grécia, 
Irlanda, Israel, Itália, Polônia, Espanha, Suécia, Suíça, Reino Unido, Estados Unidos, etc.) (GUIGOZ et al. 2002).

No Brasil, poucos trabalhos foram publicados com a sua utilização. Entre eles, encontrou-se o de OLIVEIRA et al. (2003) que avaliaram o estado nutricional de idosos hospitalizados no município de São Paulo, o de DELACORTE et al. (2004) que avaliaram idosos vivendo na comunidade, em Ribeirão Preto, e o de RESENDE (2001) que avaliou idosos residentes de ILPI's de Uberlândia.

Especificamente, publicações nacionais relativas ao uso da MAN em idosos residentes em ILPl's ainda são escassas, justificando a importância desta pesquisa.

Para o registro da MAN, a pesquisadora previamente adotou alguns critérios, da mesma forma que trabalhos como o de SALETTI et al. (2000), de BECK et al. (2001), de CHRISTENSSON et al. (2002), de BARONE et al. (2003) e de SOINI et al. (2004). Entretanto, cada trabalho adotou critérios pertinentes à sua população de estudo.

Neste estudo, a MAN foi realizada pela própria pesquisadora, a qual é nutricionista, da mesma forma que nos trabalhos de SALETTI et al. (2000), de BECK et al. (2001) e de BARONE et al. (2003). 
Nas pesquisas de BLEDA et al. (2002) e de SOINI et al. (2004), a MAN foi realizada por enfermeiras.

Muitos trabalhos, como de GROOT et al. (1998), de RUBENSTEIN et al. (2001), de DONINI et al. (2002), de THOMAS et al. (2002), de VISVANATHAN et al. (2003), de GERBER et al. (2003), e de DELACORTE et al. (2004), referem que a MAN foi realizada por investigadores, mas não definem quais foram esses profissionais.

GUIGOZ et al. (2002) relatam que a MAN pode ser realizada facilmente por qualquer profissional da saúde. No entanto, esta orientação é questionada pela pesquisadora, pois o método apresenta questões que exigem conhecimentos técnicos em nutrição e treinamentos específicos.

Obtido o diagnóstico nutricional de acordo com a pontuação final da MAN, mesmo ele realizado por outros profissionais da saúde, invariavelmente é o nutricionista o profissional capacitado para orientar e prescrever dietas específicas para cada indivíduo de acordo com o diagnóstico nutricional identificado.

Para o início do registro da MAN, houve a necessidade de identificar os idosos aptos a responderem suas questões. Portanto, o primeiro critério adotado foi a identificação de idosos com distúrbios cognitivos. 
Os indivíduos que apresentaram incapazes de responderem as questões da MAN devido à presença de distúrbio cognitivo também foram incluídos no estudo.

No caso destes idosos, os funcionários foram solicitados a participar da pesquisa, respondendo às questões referentes ao avaliado (com exceção das questões $O \in P$ ), da mesma forma que realizado por BLEDA et al. (2002). Esta situação pode implicar respostas e estimativas equivocadas, no entanto, não podem ser evitadas, e sim, minimizadas.

Em muitas pesquisas, idosos com distúrbio cognitivo foram excluídos (MURPHY et al. 2000; BARONE et al. 2003; OLIVEIRA et al. 2003; VISVANATHAN e al. 2003; DELACORTE et al. 2004; SOINI et al. 2004). Entretanto, o mesmo critério não foi adotado, pois este grupo de idosos é mais vulnerável à desnutrição, e por isso há questão relacionada ao tema, além de estarem em grandes proporções nas instituições de longa permanência (BENNEMANN 2002). Além disso, a questão sobre a presença de distúrbio cognitivo faz parte da MAN e contribui para a pontuação final; então, não seria adequado excluí-la, pois isto interferiria no diagnóstico.

O diagnóstico da presença de distúrbio cognitivo foi realizado subjetivamente pela pesquisadora com o auxílio dos funcionários, assim como nos estudos de SOINI et al. (2004) e de BECK et al. (2001). No 
entanto, a pesquisadora encontrou dificuldade para o diagnóstico, devido ao fato de o momento do registro da MAN ser o único contato da mesma com o idoso avaliado. Com relação aos funcionários, apesar de eles conhecerem e conviverem com os idosos há mais tempo, apresentaram dificuldade em distinguir os demenciados dos depressivos, e se o distúrbio cognitivo era grave ou leve. Por isso, considerou-se esta etapa da pesquisa como a mais difícil e, ao mesmo tempo, a mais importante por definir os idosos que necessitariam de outras pessoas para responder, por eles, as questões da MAN.

Um funcionário de cada instituição realizou o diagnóstico junto à pesquisadora, desta forma, minimizando possíveis variações na impressão subjetiva sobre as condições cognitivas dos idosos.

A opção pela não utilização de métodos específicos para a identificação de distúrbios cognitivos foi feita para que não interferisse em um dos objetivos da pesquisa, o qual era de avaliar a utilização da MAN, incluindo a verificação de suas vantagens, limitações e dificuldades.

Entretanto, outros estudos com a MAN utilizaram previamente testes como: Berger Scale, Mini-Mental State Examination, Red Cross Cognitive Scale, Abbreviated Mental Test, Short Portable Mental Status Questionnaire, entre outros (de GROOT et al. 1998; DONINI et al. 2000; MURPHY et al. 
2000; SALETTI et al. 2000; VELLAS et al. 2000; RESENDE 2001; DONINI et al. 2002; RUIZ-LOPES et al. 2003; VISVANATHAN e al. 2003).

Levando em consideração que uma das vantagens da MAN, descritas pelos seus autores (GUIGOZ et al. 1994) sobre outros métodos de avaliação nutricional, é ser prática e rápida, a utilização de outra metodologia como requisito para a sua realização, a descaracterizaria. No entanto, mesmo adotando como critério de avaliação a impressão subjetiva da pesquisadora e dos funcionários das instituições, o preenchimento da MAN despendeu mais tempo do que o proposto pelos seus autores (GUIGOZ et al. 1994), apesar do mesmo não ter sido registrado. A mesma situação foi encontrada por RESENDE (2001).

Os fatos que levaram a demora do preenchimento da MAN, além do diagnóstico de indivíduos com distúrbio cognitivo, foram: a necessidade de estimar o peso e a estatura para $47,2 \%$ dos idosos, a dependência da disponibilidade do auxiliar de enfermagem para informar sobre os medicamentos utilizados pelos idosos, e o relato de todos os alimentos consumidos pelos idosos durante o dia para classificá-los em refeições.

Para que a identificação de distúrbios cognitivos, necessária à realização da MAN, não dificulte a sua utilização em idosos residentes em ILPI's e continue a manter sua característica de praticidade, os prontuários 
médicos deveriam incluir o diagnóstico relativo à presença de distúrbios cognitivos.

De acordo com RESENDE (2001), é comum nas ILPI's haver registros precários da situação da saúde dos idosos, não havendo prontuários padronizados.

Infelizmente, como esta não é e, talvez, não será a realidade de muitas instituições, o diagnóstico subjetivo de distúrbios cognitivos, com todas as suas dificuldades e limitações, continuará sendo a altemativa para a realização da MAN.

Devido à necessidade de definição da condição cognitiva dos idosos para o registro da MAN, a primeira questão a ser realizada foi a $E$, a qual questiona a presença de problemas neuropsicológicos nos idosos.

Considera-se este fato como o primeiro indicativo de que a MAN deve sofrer alterações em sua estrutura, ou seja, na ordem em que as questões são apresentadas, visando sua praticidade quando utilizada em institucionalizados.

Outro indicativo da necessidade de alteração da estrutura do método é a dependência, para o registro da MAN, das informações dos funcionários em $100 \%$ dos casos para as questões $\mathrm{C}, \mathrm{E}$ e H, e em $42,7 \%$ dos casos para 
as questões $A, B, D, I, J, K, L, M$ e $N$ para aqueles com distúrbio cognitivo incapazes de responderem as questões. Isto resultou no preenchimento de todas as questões que dependiam das informações dos funcionários em um mesmo momento, visto o restrito tempo disponível dos mesmos nas instituições decorrente da sobrecarga de trabalho. Esta condição sugere possíveis vícios nas respostas, o qual poderá ter refletido nas pontuações das questões, interferindo no diagnóstico nutricional dos idosos. Entretanto, na maioria das instituições, um mesmo funcionário respondeu as questões da MAN para todos os idosos. Outro fator que também pode ter interferido nas respostas da MAN foi a falta de informação dos funcionários relativa aos idosos e a possível dificuldade de compreensão de algumas questões e alternativas por ambos.

Devido à rotina diária dos idosos nas instituições, as mensurações antropométricas também foram realizadas em um mesmo momento, de forma que os mesmos foram abordados uma única vez para que não fossem interrompidas suas atividades. Para os acamados, também houve a necessidade do auxílio de um funcionário para posicionar os idosos para a execução adequada das medidas.

Diante destas análises, verifica-se a impossibilidade da realização da MAN por apenas um profissional e o registro das questões na ordem em que são apresentadas. 
A versão Short-Form Mini Nutritional Assessment (RUBENSTEIN et al. 2001), traduzida para o português e utilizada neste estudo, propõe triar em apenas 6. das 18 questões, os idosos não desnutridos, desta forma, otimizando o tempo gasto para identificar este grupo de idosos e excluindo a necessidade da continuidade do registro das questões do método. No entanto, como os idosos e, principalmente, os institucionalizados constituem um potencial grupo para o desenvolvimento da desnutrição, o registro de todas as questões da MAN torna-se importante para o acompanhamento dos fatores de risco para desnutrição.

A questão $A$, referente à redução da ingestão alimentar devido à perda de apetite, problemas digestivos ou dificuldades para mastigar ou deglutir, não apresentou qualquer dificuldade no seu registro e toda a revisão bibliográfica realizada também apresentou o mesmo resultado. Apenas no caso da resposta ter sido dada pelo funcionário, verificaram-se alguns casos em que os mesmos apresentaram dificuldade em determinar a alternativa correta para o idoso avaliado devido ao não acompanhamento regular das atividades diárias dos idosos. As mesmas considerações são feitas para as questões $\mathrm{J}, \mathrm{K}$ e $\mathrm{L}$, as quais identificam, respectivamente, o número de refeições, a ingestão de alimentos ricos em proteínas e a ingestão de frutas ou vegetais. 
É importante que o motivo da perda de apetite seja especificado para que condutas adequadas possam ser tomadas. Para isto, basta que no momento do registro da questão, seja assinalado o motivo de tal alteração.

Observaram-se $22,5 \%$ de idosos com redução da ingestão alimentar. Nos estudos de SALETTI et al. (2000) e de RUIZ-LOPEZ et al. (2003), também com idosos institucionalizados, foram identificados valores superiores $(29,0 \%$ e $38,8 \%$, respectivamente). Em contrapartida, SOINI et al. (2004), em estudo com idosos sob assistência domiciliar, identificaram apenas $10,0 \%$.

No estudo de SIGULEM (1998) é discutido que muitas das causas de desnutrição não são necessariamente o resultado da ingestão alimentar deficiente, mas decorrente da alteração nos processos de digestão, absorção e utilização dos alimentos e nutrientes.

A questão B identifica a perda de peso nos três últimos meses antecedentes ao registro da MAN. Em 100\% dos casos não havia registros de pesagem dos idosos e todas as informações obtidas foram estimadas pelos idosos ou funcionários. Porém, esta situação não foi encontrada exclusivamente nos idosos residentes em ILPI's de Guaratinguetá/SP; ela também foi presenciada em $100,0 \%$ dos idosos no estudo de RESENDE (2001), em 70,0\% dos idosos no estudo de SALETTI et al. (2000), e em 
$44,0 \%$ dos idosos no estudo de CHRISTENSSON et al. (2002), todos institucionalizados.

WAITZBERG et al. (1999), em pesquisa com 4.000 pacientes internados na rede pública hospitalar brasileira, verificaram que $81,2 \%$ dos pacientes não tinham qualquer referência de pesagem anotado em seus prontuários.

No estudo de BECK et al. (2001), foi adotada a estimativa de peso e estatura pelos idosos e/ou funcionários para o registro desta questão e para o cálculo de IMC, pois os autores consideraram ser um método confiável.

Enquanto alguns idosos apresentaram dificuldade para estimar a perda de peso e quantificá-la devido à ausência de pesagem, os funcionários a apresentaram em um grau ainda mais elevado, principalmente, para aqueles institucionalizados há menos de 3 meses.

Em apenas 2,0\% dos idosos verificou-se a perda de peso nos últimos três meses antecedentes à avaliação, sendo que esta perda foi de 1 a 3 quilos. Não houve casos relatados de perda de peso superior a 3 quilos. Sugere-se que o resultado encontrado seja devido aos idosos e funcionários necessitarem estimar o peso neste período, não identificando, dessa forma, qualquer alteração que pudesse ocorrer, apesar de que no estudo de RUIZLOPEZ et al. (2003) foi verificada porcentagem ainda menor $(1,1 \%)$. 
SOINI et al. (2004), em idosos sob assistência domiciliar, observaram $12,0 \%$ de casos com perda de peso superior a 3 quilos nos 3 últimos meses antecedentes à avaliação.

A perda de peso é um dos indicadores mais sensíveis de indivíduos com risco para desenvolverem desnutrição (MORLEY 1998).

A questão C não apresentou problemas para o seu registro, tanto para o pesquisador como para os funcionários, ao avaliar o grau de mobilidade dos idosos, sendo considerada de fácil preenchimento.

Estavam restritos ao leito ou à cadeira de rodas, $34,8 \%$ dos idosos. SALETTI et al. (2000) também verificaram resultados semelhantes para idosos institucionalizados $(30,0 \%)$. Em idosos vivendo na comunidade, verificou-se, nesta situação, apenas $4,8 \%$ de idosos no estudo de DELACORTE et al. (2004), e 4,9\% no estudo de BECK et al. (2001). Este quadro de imobilidade ligado à dependência pode contribuir para o risco de desnutrição, conforme VISVANATHAN et al. (2003).

A questão D identifica a presença de estresse psicológico e doença aguda nos últimos 3 meses. O estresse psicológico foi definido como a hospitalização, a perda da esposa ou parente próximo, ou a presença de problemas familiares, assim como no estudo de BECK et al. (1999). 
Mesmo previamente definido quais situações seriam consideradas como estresse psicológico, alguns idosos apresentaram dificuldade em responder a questão. Acredita-se que seja devido às falhas de memória e à perda da noção de temporalidade, principalmente para a identificação do estresse psicológico. No caso dos funcionários, a dificuldade encontrada foi ainda maior pelo fato de não saberem da história de vida de todos idosos, principalmente para aqueles institucionalizados há menos de 3 meses.

Em $30,3 \%$ dos idosos identificou-se a presença de estresse psicológico ou doença aguda nos últimos três meses antecedentes à avaliação. SOINI et al. (2004), em idosos sob assistência domiciliar, identificaram $36,0 \%$, no entanto, os critérios definidos foram diferentes.

Em idosos vivendo na comunidade, de GROOT et al. (1998) observaram maior porcentagem de casos $(80,0 \%)$, no entanto, os autores não definiram, no estudo, o quê foi considerado como estresse psicológico.

BECK et al. (2001) e CHUMLEA (1999) ainda criticam a questão D por ela não definir o quê é considerado como doença aguda e a sua gravidade.

Mesmo assim, esta questão mostra-se importante, pois a presença de doenças é um potencial fator de risco para a desnutrição por poder 
ocasionar a redução da ingestão alimentar, a má absorção de nutrientes, e o aumento do metabolismo (MORLEY 1998).

A presença de infecções em idosos institucionalizados é um fator comum e pesquisas têm demonstrado que de 15,0 a $20,0 \%$ destes idosos possuem uma infecção ativa no trato urinário, respiratório, na pele ou nos olhos (ABBASI e RUDMAN 1994).

A questão $E$ avalia a presença de problemas neuropsicológicos e, como discutido anteriormente, o seu registro foi dificultado, pois adotou-se como critério de avaliação a impressão subjetiva da pesquisadora e dos funcionários, diferentemente de outros estudos que adotaram metodologias específicas para a determinação de demência e depressão (de GROOT et al. 1998; DONINI et al. 2000; MURPHY et al. 2000; SALETTI et al. 2000; VELLAS et al. 2000; RESENDE 2001; DONINI et al. 2002; RUIZ-LOPES et al. 2003; VISNANATHAN et al. 2003).

Em 52,8\% dos idosos identificou-se algum problema neuropsicológico, ou seja, demência ou depressão. VELLAS et al. (2000), em idosos vivendo na comunidade e em idosos hospitalizados, identificaram resultado próximo ao deste estudo $(56,0 \%)$. Já SOINI et al. (2004), em idosos sob assistência domiciliar, de GROOT et al. (1999) e BECK et al. (2001), em idosos vivendo na comunidade, verificaram resultados inferiores 
$(12,0 \%, 20,0 \%$, e $13,1 \%$, respectivamente). SALETTI et al. (2000), também em idosos institucionalizados, observaram valores superiores $(64,0 \%)$.

O estado cognitivo alterado é considerado tanto um fator de risco nutricional como indicador de distúrbio nutricional, pois pode resultar em alterações do apetite e perda de peso (COELHO e FAUSTO 2002).

THOMAS et al. (2002) confirmaram em seu estudo que a depressão é altamente associada à desnutrição. MORLEY e KRAENZLE (1994) concluíram que a depressão é a causa mais comum de perda de peso em idosos institucionalizados, porém, potencialmente tratável.

De acordo com MORLEY (1998), a causa mais comum da desnutrição parece ser a depressão, sendo as próximas mais comuns, o uso de dietas terapêuticas e o câncer.

Como já verificado em outros estudos (BENNEMANN 2002 e THOMAS et al. 2002), a maior prevalência de desnutrição foi verificada no grupo de idosos com distúrbios cognitivos $(52,0 \%)$, que neste caso também eram incapazes de responderem a MAN.

Através da questão $F$, identificou-se que $43,8 \%$ dos idosos apresentaram IMC inferior a $23 \mathrm{~kg} / \mathrm{m}^{2}$. De acordo com a Organização Pan- 
Americana de Saúde (OPAS), citado por MARUCCI e BARBOSA (2003), estes idosos são classificados como de baixo peso.

SALETTI et al. (2000) observaram que $70,0 \%$ dos idosos vivendo em ILPI's apresentaram IMC menor que $23 \mathrm{~kg} / \mathrm{m}^{2}$. SOINI et al. (2004) identificaram, apenas, $20,2 \%$ naqueles sob assistência domiciliar, e RUIZLOPES et al. (2003) observaram 15,5\% também em residentes em ILPI's.

BARONE et al. (2003) propõem novos intervalos de classificação de IMC para esta questão da MAN. Os valores apresentados variam de 22 a 27 $\mathrm{kg} / \mathrm{m}^{2}$, como proposto pelo NSI (1994).

Nesta versão da MAN, idosos com IMC $\geq 23 \mathrm{~kg} / \mathrm{m}^{2}$ recebem a maior pontuação ( 3 pontos), seguido por aqueles com $21 \leq \mathrm{IMC}<23 \mathrm{~kg} / \mathrm{m}^{2}$ (2 pontos), depois aqueles com $19 \leq \mathrm{IMC}<21 \mathrm{~kg} / \mathrm{m}^{2}$ (1 ponto) e, por último, os idosos com IMC $<19 \mathrm{~kg} / \mathrm{m}^{2}$ (0 ponto). Sabe-se que para a determinação dos intervalos de classificação do IMC para a questão $F$, os autores utilizaram o valor do IMC do percentil 10 de idosos franceses, com 80 anos e mais, como ponto de corte, de acordo com estudo de VELLAS et al. (1992) citado por GUIGOZ et al. (1997).

Em $47,2 \%$ dos casos foi necessário estimar o peso e a estatura devido à presença de idosos acamados ou em cadeira de rodas, fazendo com que esta questão apresentasse dificuldade no seu registro, visto a 
necessidade da mensuração da altura do joelho e o cálculo das fórmulas para estimativa do peso e da estatura, levando mais tempo para registrá-la.

CHARLES (1998) afirma encontrar limitação no uso da MAN, visto a necessidade do avaliador possuir habilidades no uso de técnicas antropométricas adequadas e base de cálculos para os casos de se estimar a estatura e o peso, além da obtenção do IMC.

O fato de todos os idosos participantes desta pesquisa serem institucionalizados (questão G) já implica risco para desnutrição. De acordo com GOODWIN (1989), idosos institucionalizados apresentam maior prevalência de desnutrição do que aqueles que vivem na comunidade, pois é comum nesta população a ocorrência de múltiplas infecções e doenças crônicas que aumentam as necessidades de energia dos indivíduos, as quais muitas vezes não são supridas pela alimentação ofertada nas instituições.

MARUCCI (1985) avaliou a dieta oferecida em 20 ILPI's no município de São Paulo e verificou que todas elas apresentaram-se inadequadas para macro e micronutrientes, constatando-se que $25,0 \%$ das instituições apresentaram dietas insuficientes quanto à energia. Com relação a idosos institucionalizados em Fortaleza/Ceará, MENEZES (2000) verificou que $61,2 \%$ apresentaram consumo alimentar com valor calórico abaixo do recomendado. 
A questão $\mathrm{H}$ verifica a ingestão diária de medicamentos pelos idosos. Neste grupo de estudo, observou-se que $36,0 \%$ dos idosos ingeriam mais de 3 medicamentos diferentes ao dia. SOINI et al. (2004), em estudo com pacientes em assistência domiciliar, identificaram a mesma ingestão de medicamentos em $82,0 \%$ dos idosos, e DELACORTE et al. (2004), em idosos vivendo na comunidade, identificaram $45,2 \%$.

É possível que a quantidade de idosos com ingestão superior a 3 medicamentos diferentes ao dia $\left(36,0^{\prime \prime}\right)$, neste estudo, seja devido a necessidade das instituições em limitar e priorizar a medicação para idosos mais debilitados pela falta de recursos financeiros.

A polifarmácia é considerada um fator de risco nutricional para os idosos e pode levar à desnutrição (MORLEY 1998; MARUCCI e GOMES 2002; RUIZ-LOPES et al. 2003).

Para o registro desta questão foi necessário recorrer aos auxiliares de enfermagem das instituições que, muitas vezes, não eram os cuidadores, para fornecerem as informações corretas relativas ao uso de medicamentos pelos idosos. Este fato dificultou o registro da questão, despendendo maior tempo para o seu registro.

A questão I identifica a presença de escaras ou lesões na pele e, neste estudo, elas estavam presentes em $3,4 \%$ dos idosos. RUIZ-LOPES et 
al. (2003) identificaram resultado próximo ao deste estudo nos idosos institucionalizados avaliados (5,0\%). Em idosos sob assistência domiciliar, SOINI et al. (2004) verificaram 15,0\%. Esta questão não apresentou qualquer dificuldade para o seu registro.

Visto que $34,8 \%$ dos idosos são acamados ou estão em cadeiras de rodas, $28,1 \%$ são desnutridos, e as instituições possuem limitações quanto ao número de funcionários para atenderem aos idosos, esperava-se encontrar maior porcentagem de idosos com escaras ou lesões na pele. Felizmente, não foi o quadro encontrado.

A questão $\mathrm{J}$ refere-se ao número de refeições realizadas ao dia pelos idosos. Verificou-se que $30,3 \%$ deles realizavam no máximo duas refeições ao dia. Também em idosos institucionalizados, SALETTI et al. (2000) encontraram $58,0 \%$ com a mesma ingestão. Já RUIZ-LOPES et al. (2003) verificaram que $100,0 \%$ realizavam três refeições diárias. As diferenças entre estes estudos podem estar relacionadas com os critérios considerados para classificar as refeições.

Para o registro desta questão, determinou-se que cada refeição deveria conter alimentos de, no mínimo, três grupos alimentares (cereais/tubérculos/raizes, carnes/leite/ovos/leguminosas, frutas/verduras/ legumes) de acordo com o proposto por PHILIPPI et al. (1999) para que não ficasse a critério do idoso ou funcionário a informação sobre o número de 
refeições realizadas sem o conhecimento de sua composição. Esta conduta fez com que o registro da questão levasse mais tempo para ser concluída.

A questão $\mathrm{K}$ identifica a ingestão de alimentos ricos em proteínas. Neste grupo, 5,6\% não ingeriam alimentos ricos em proteínas diariamente ou no mínimo uma vez por semana. No estudo de SOINI et al. (2004), 11,0\% dos idosos apresentaram a mesma característica.

Em $94,4 \%$ dos idosos havia a ingestão mínima de uma porção diária de alimentos ricos em proteínas. No estudo de RUIZ-LOPES et al. (2003), $100,0 \%$ dos idosos realizavam o mesmo consumo.

A questão $L$ identifica a ingestão diária de frutas, verduras e legumes. Entre os idosos entrevistados, $44,9 \%$ consumiam, no máximo, uma porção ao dia desses alimentos. RUIZ-LOPES et al. (2003), também em idosos institucionalizados, encontraram apenas $0,5 \%$ deles com o mesmo consumo. Em idosos sob assistência domiciliar, verificou-se $30,0 \%$ com as mesmas características (SOINI et al. 2004).

A questão $M$ identifica a ingestão de líquidos através do número de copos com líquidos. Dos idosos entrevistados, $11,3 \%$ ingeriam no máximo 2 copos com líquido ao dia. No estudo de BECK et al. (2001) com idosos vivendo na comunidade, apenas $1,6 \%$ tinham a mesma ingestão. 
Os idosos apresentaram dificuldade em mensurar a ingestão de líquidos durante um dia pelas falhas de memória. No entanto, a dificuldade foi ainda maior quando a questão foi direcionada aos funcionários por eles não acompanharem os idosos continuamente.

A questão $\mathrm{N}$ identifica a dependência do idoso para se alimentar. Em $15,7 \%$ dos idosos ela foi presenciada. RUIZ-LOPES et al. (2003), em idosos institucionalizados, encontraram resultado inferior (4,5\%). Diferentemente, BECK et al. (2001) identificaram que 100,0\% dos idosos que viviam na comunidade, participantes do estudo, alimentavam-se sozinhos.

De acordo com SIEBENS et al., citado por ABBASI e RUDMAN (1994), por volta de 40,0\% dos idosos residentes em ILPI's requerem ajuda para se alimentar. Esta condição é considerada pelos autores como o maior fator de risco para a desnutrição em idosos institucionalizados (ABBASI e RUDMAN 1994).

As questões $\mathrm{O}$ e $\mathrm{P}$ identificam, respectivamente, a impressão subjetiva do idoso a respeito do seu estado nutricional e de sua saúde. Acreditavam estar desnutridos $4,5 \%$ dos idosos e $13,5 \%$ consideravam sua saúde não muito boa. No estudo de SOINI et al. (2004), 13,0\% se consideravam desnutridos e $17,0 \%$ consideravam sua saúde não muito boa. 
Enquanto neste estudo $44,9 \%$ e $43,8 \%$, respectivamente, não sabiam avaliar o seu estado nutricional e sua saúde, no estudo de SOINI et al. (2004) resultados inferiores foram encontrados para ambas questões (15,0\% e $37,0 \%$, respectivamente), entretanto, também considerados elevados pelos autores.

A grande proporção de respostas "não sabe dizer" para as questões subjetivas também foi relatada por RUBENSTEIN et al. (2001).

RUIZ-LOPES et al. (2003) consideram estas avaliações subjetivas importantes para a avaliação do estado nutricional do idoso e CHRISTENSSON et al. (2002) demonstraram que elas possuem alto valor preditivo.

DONINI et al. (2002), ao encontrarem baixa especificidade da MAN e muitos casos falso-positivos, sugerem que as avaliações subjetivas tenham grande contribuição para este resultado.

A questão $Q$ registra o valor da medida da circunferência do braço (CB) e, em 3,4\% da população de estudo, ele foi menor que $21 \mathrm{~cm}$. Em outro estudo com idosos institucionalizados, menos de $15,0 \%$ tinham CB menor que $21 \mathrm{~cm}$ (RUIZ-LOPES et al 2003). 
O valor da medida da $\mathrm{CB}$, assim como o da circunferência da panturrilha $(\mathrm{CP})$, estimam a reserva muscular e são consideradas bons indicadores de desnutrição em idosos e têm sido recomendados como medidas sensiveis da perda de massa muscular nesse grupo, especialmente se a redução se dá em função da diminuição da atividade física (WHO 1995).

A questão R registra o valor da medida da CP. Em $49,4 \%$ dos idosos a CP foi menor que $31 \mathrm{~cm}$. No estudo de RUIZ-LOPES et al. (2003), também com idosos institucionalizados, foi verificado $30,3 \%$ de idosos com CP menor que $31 \mathrm{~cm}$.

ROLLAND et al. (2003) verificaram que a CP menor que $31 \mathrm{~cm}$ em idosos foi associada à incapacidade física.

O ponto de corte para as variáveis antropométricas $C B$ e CP da MAN foi definido a partir do percentil 10 de idosos franceses com 80 anos e mais (GUIGOZ et al. 1997).

No estudo de BARBOSA $A R^{\star}$, com idosos residentes no município de São Paulo, os valores da CP no percentil 10 de idosos com 80 anos e mais foi de $28 \mathrm{~cm}$ para as mulheres e $29 \mathrm{~cm}$ para os homens, portanto, ambos valores inferiores aos apresentados na MAN. Para a $C B$, o valor no

\footnotetext{
* Dados não publicados
} 
percentil 10 para idosos com 80 anos e mais foi de $23 \mathrm{~cm}$ para ambos os sexos. Neste caso, o valor foi superior aos apresentados na MAN.

BARONE et al. (2003) fizeram ajustes nos valores da CB (questão Q), por sexo, para a utilização da MAN em idosos australianos. Da mesma forma que identificado por BARBOSA $\mathrm{AR}^{*}$ no Brasil, esses autores também encontraram valores superiores para a CB. Quanto à CP (questão R), não foi feita alteração (BARONE et al. 2003).

Atendendo a um dos objetivos específicos desta pesquisa, calculouse a sensibilidade, a especificidade e os valores preditivos da MAN na população de estudo.

Inúmeros trabalhos têm avaliado a sensibilidade e a especificidade da MAN em diferentes contextos, adotando-se vários métodos como padrão de referência por ainda não haver um consenso do melhor a ser utilizado para o diagnóstico nutricional de idosos (MURPHY et al. 2000; OMRAN e MORLEY 2000).

De acordo com URTEAGA et al. (2001), é preciso considerar que estudos que exploram a concordância entre métodos de diagnósticos nutricionais pela sensibilidade e especificidade enfrentam problemas em definir o método e respectivas referências consideradas "padrão-ouro" para 
as análises. Por isso, cada estudo adota um método, não havendo padronização das avaliações (URTEAGA et al. 2001).

Neste caso, adotou-se a área muscular do braço corrigida (AMBc) como método padrão de referência para o diagnóstico nutricional dos idosos. A escolha dessa variável antropométrica deveu-se ao fato de ela não ser invasiva, ser de baixo custo, de fácil execução e válida para a avaliação da desnutrição, inclusive em idosos (BURR e PHILLIPS 1984; FRISANCHO 1981; LANDI et al. 1999; KUCZMARKI et al. 2000; PERISSINOTTO et al. 2002).

Conforme SHINTAKU (2003), o esforço científico para escolha de métodos mais fidedignos para interpretações e diagnósticos em idosos é muito importante e a antropometria tem sido uma metodologia utilizada pelos pesquisadores para encontrar meios mais eficientes para suas interpretações e diagnósticos. No entanto, por ser um indicador de diagnóstico único e objetivo, não permite a identificação de fatores de risco para a desnutrição.

Vários estudos têm demonstrado a associação do índice de massa corporal (IMC) à mortalidade em idosos (AGARWAL et al. 1988; LANDI et al. 1999). Porém, o IMC possui limitações para identificar a desnutrição, já que não determina o tipo de massa corporal predominante. Assim, os 
indicadores de estoque protéico, como a $\mathrm{AMBc}$, são considerados os melhores para a estimativa de desnutrição protéica (ANSELMO 1987).

BANNERMAN e GHOSH (2003) avaliaram o estado nutricional de pacientes a partir de medidas antropométricas como peso, estatura, circunferência do braço, prega cutânea tricipital e área muscular do braço. Esta última medida se mostrou relevante no que se refere ao delineamento prognóstico de aumento da mortalidade e parâmetro útil para identificar risco nutricional.

A área museular do braço tem sido a variável antropométrica mais utilizada, mais do que o peso e variáveis bioquímicas, sendo preditora de mortalidade e morbidade (FRISANCHO 1984; FRIEDMAN 1991; HEYMSFIELD e CASPER 1987; LANSEY et al. 1993; POTTER et al. 1995; MILLER et al. 2002).

Apesar de, recentemente, terem sido publicados dados antropométricos, distribuídos em percentis, de idosos residentes em ILPI's de Fortaleza-CE (MENEZES 2005), a escolha dos valores antropométricos apresentados por BARBOSA $\mathrm{AR}^{*}$ como referência para a $\mathrm{AMBc}$, ainda que referentes a idosos vivendo na comunidade, deveu-se ao fato dos dados serem coletados no município de São Paulo, mais próximo de Guaratinguetá/SP. Os dados do estudo de MENEZES (2005) foram coletados em Fortaleza/CE e os idosos desta região apresentam 
características distintas. Esta escolha segue a orientação do Expert Committe of the World Health Organization (WHO 1995), o qual não recomenda a utilização de dados universais.

O uso de testes mais simples como substitutos dos mais elaborados e mais exatos no estabelecimento da presença da doença (neste caso, da desnutrição e do risco de desnutrição) é feito com o entendimento de que isto resulta em um certo risco de diagnóstico incorreto. Tal risco é justificado pela segurança e conveniência do teste mais simples (FLETCHER et al. 1996). Por isso, previamente à coleta dos dados, a pesquisadora realizou treinamento de mensurações antropométricas para a execução de técnicas adequadas e mais próximas da precisão, e escolheu como padrão de referência para a análise da $\mathrm{AMBc}$ dados disponiveis obtidos de população similar à deste estudo.

Quanto ao desempenho diagnóstico da MAN, a sensibilidade foi de $84,0 \%$ e a especificidade foi de $36,0 \%$. Possivelmente, o agrupamento dos idosos desnutridos e com risco de desnutrição tenha sido uma das causas para a baixa especificidade da MAN.

DONINI et al. (2000) sugerem que a baixa especificidade pode estar relacionada à ausência de respostas de várias questões para muitos idosos, ás quais foram atribuidas a pontuação "0". Tal afirmação também pode ser 
um dos motivos que contribuíram para a baixa especificidade neste estudo, visto que $22,0 \%$ das respostas da MAN obtiveram pontuação "0".

A MAN apresentou melhores resultados em predizer a desnutrição e o risco de desnutrição $(77,0 \%)$ do que a ausência destes casos $(47,0 \%)$. Como a intenção é garantir que os idosos com desnutrição e risco de desnutrição sejam identificados, a MAN atende aos objetivos propostos.

Visto o elevado número de idosos com distúrbios cognitivos impossibilitados de responderem a MAN (42,7\%), funcionários das instituições necessitaram contribuir com a pesquisa respondendo as questões pertinentes a este grupo. No entanto, muitas das respostas necessitaram serem estimadas.

Avaliando a sensibilidade, especificidade e valores preditivos da MAN neste grupo e comparando os valores encontrados com o grupo de idosos que foram capazes de responderem ao questionário, identificou-se que o primeiro foi mais sensivel $(93,0 \%)$ que o segundo $(74,0 \%)$. No entanto, o segundo grupo foi mais específico $(38,0 \%)$ que o primeiro $(22,0 \%)$, porém, ambos com baixa especificidade. Este resultado é similar a análise da MAN quando não subdivida nos dois grupos.

Quanto à capacidade do método em predizer a presença de desnutrição ou risco de desnutrição, os dois grupos apresentaram valores 
aceitáveis (o primeiro, $79,0 \%$ e o segundo, 72,0\%). Já a capacidade do método em predizer a ausência de desnutrição e risco de desnutrição apresentou valores inferiores $(50,0 \%$ e $40,0 \%$, respectivamente), mas também aceitáveis visto as características do grupo estudado e o objetivo do método.

Considera-se favorável a sensibilidade da MAN ser mais elevada no grupo de idosos em que as respostas foram dadas pelos funcionários, já que é comum a ocorrência desta situação em ILPl's pela elevada prevalência de indivíduos com distúrbios cognitivos, como já demonstrado por BENNEMANN (2002).

Sugere-se a possível superestimação, pelos funcionários, dos fatores de risco para desnutrição nos idosos, identificados através das questões da MAN. Diante desta possibilidade, o uso do método neste grupo garante, ao menos, o diagnóstico de todos os idosos realmente desnutridos e com risco de desnutrição.

De qualquer forma, a sensibilidade de $74,0 \%$ encontrada para o grupo de idosos que foram capazes de responderem a MAN, é aceitável.

Pesquisas de validação da MAN, realizadas por GUIGOZ et al. (1994) através da comparação com avaliações clínica, bioquímica, antropométrica e dietética dos idosos, demonstraram resultados superiores (sensibilidade de 
$96,0 \%$ e especificidade de $98,0 \%$ ). Da mesma forma que verificado por RUBENSTEIN et al. (2001), frente à avaliação clínica ao avaliar a sensibilidade $(99,0 \%)$ e a especificidade $(94,0 \%)$ da Short-Form Mini Nutritional Assessment.

DELACORTE et al. (2004), ao avaliarem a sensibilidade e especificidade da MAN através de avaliações antropométrica, bioquímica e dietética em idosos brasileiros vivendo na comunidade, também encontraram resultados superiores $(100,0 \%$ e $74,0 \%$, respectivamente). Ao avaliarem a sensibilidade e especificidade do mesmo grupo, comparando-se com o diagnóstico nutricional obtido somente pelo IMC e níveis séricos de albumina, verificaram sensibilidade de $38,0 \%$ e especificidade de $73,0 \%$.

Diferentemente, CHRISTENSSON et al. (2002) encontraram resultado inferior para a especificidade $(26,0 \%)$, e superior para sensibilidade $(96,0 \%)$, quando utilizadas como referência variáveis antropométricas e bioquímicas de idosos institucionalizados da Suécia.

DONINI et al. (2000) também observaram baixa especificidade $(16,0 \%)$ em comparação à este estudo e alta sensibilidade $(98,0 \%)$ ao compararem com avaliações antropométricas e bioquímicas de idosos institucionalizados na Itália. 
Em estudo com idosos europeus vivendo na comunidade, de GROOT et al. (1998) encontraram valores ainda menores para sensibilidade ao compararem aos idosos com baixo IMC $(12,0 \%)$ e perda de peso $(8,0 \%)$.

MURPHY et al. (2000), em idosos hospitalizados da Inglaterra, também verificaram sensibilidade inferior à deste estudo quando utilizaram como padrão métodos bioquímicos $(27,0 \%)$ e dietéticos $(57,0 \%)$, no entanto, observaram resultados superiores para especificidade $(66,0 \%$ e $94,0 \%$, respectivamente). Entretanto, os autores agruparam os idosos em risco de desnutrição aos eutróficos, e não aos desnutridos como neste estudo.

Embora um método possa ser considerado perfeito, ou seja, com bom poder discriminatório, quando a sua sensibilidade e especificidade estão próximos de 1,0, há situações em que se espera que o método seja mais sensivel em detrimento da sua especificidade (FLETCHER et al. 1996), como nesta pesquisa.

Neste caso, é preferível que a MAN seja altamente sensível para que possa diagnosticar corretamente idosos desnutridos e em risco de desnutrição para que profissionais da saúde possam atuar sobre os casos detectados, prevenindo riscos de morte e outras complicações e promovendo qualidade de vida ao idoso. 
Segundo FLETCHER et al. (1996), deve-se escolher um teste sensivel quando a penalidade por deixar de diagnosticar uma doença é grave. Portanto, é importante que a MAN tenha alta sensibilidade para evitar a possibilidade de diagnosticar idosos desnutridos ou em risco de desnutrição como eutróficos (não desnutridos).

CHRISTENSSON et al. (2002) relatam que quando um método com baixa especificidade é usado, é importante que a população comumente apresente a doença em questão, entretanto, muitos diagnósticos falsospositivos poderão ocorrer.

Como a desnutrição é altamente freqüente em idosos institucionalizados (KESTETTER 1992), a afirmação de CHRISTENSSON et al. (2002) justifica a reduzida especificidade da MAN neste estudo. Portanto, é mais importante que o método seja altamente sensível (DEMPSEY e MULLEN 1987).

Tendo em vista os estudos citados anteriormente, a pesquisadora considera aceitável o valor da sensibilidade encontrada nesta pesquisa $(84,0 \%)$ e justificável a baixa especificidade $(36,0 \%)$.

Adicionalmente a todas considerações feitas, possivelmente, se a população do estudo fosse maior, melhores resultados seriam encontrados. Além disso, deve-se considerar todas as limitações e dificuldades 
encontradas no registro da MAN que podem ter contribuído para o diagnóstico nutricional distinto do verificado pela $\mathrm{AMBc}$.

De acordo com FLETCHER et al. (1996), usualmente os valores de sensibilidade e especificidade são estimados a partir de observações de amostras relativamente pequenas de pessoas com e sem a doença em questão. Nestes casos, a sensibilidade e a especificidade do teste podem não representar fidedignamente os valores verdadeiros, mesmo que não haja vícios no estudo. No entanto, os valores observados são compativeis com uma faixa de valores verdadeiros, caracterizada tipicamente pelo “intervalo de confiança de 95\%". A amplitude desta gama de valores define o grau de precisão das estimativas de sensibilidade e especificidade (FLETCHER et al. 1996).

Considerando o posterior aprimoramento do método, frente às análises realizadas, e o teste realizado em uma população maior, espera-se o aumento da sua sensibilidade, bem como da especificidade.

A MAN foi capaz de predizer a desnutrição e o risco de desnutrição em $77,0 \%$ dos casos. Como a prevalência destes diagnósticos nesta população é alta (GUIGOZ et al. 1996; KESTETTER 1992), realmente esperava-se um valor preditivo positivo alto. 
Na Itália, DONINI et al. (2000), em estudo com idosos de ILPI's, também verificaram elevada capacidade preditiva positiva da MAN $(83,0 \%)$. Diferentemente, DELACORTE et al. (2004) verificaram valor preditivo positivo baixo $(23,0 \%)$; esta situação ocorreu justamente por se tratar de idosos provenientes da comunidade onde, conhecidamente, a prevalência de desnutrição e risco de desnutrição é baixa (GUIGOZ et al. 1996).

A capacidade da MAN em diagnosticar a ausência de desnutrição na população de estudo foi de $47,0 \%$. DELACORTE et al. (2004) identificaram valor preditivo negativo de $100,0 \%$. Nestes dois casos, provavelmente a diferença dos valores preditivos devem-se aos grupos populacionais serem distintos, ou seja, de idosos de ILPI's e da comunidade, respectivamente.

DONINI et al. (2000 e 2002) encontraram valor preditivo negativo mais elevado em seu estudo $(62,5 \%)$ com idosos de ILPI's quando comparado ao obtido nesta pesquisa.

A área sob a curva ROC analisada $(0,71)$ através da relação dos valores de sensibilidade e 1-especificidade da MAN foi próxima à encontrada por CHRISTENSSON et al. (2002) $(0,74)$. Estes valores mostram a severidade do contrabalanço entre a sensibilidade e a especificidade de um teste podendo ser usado para auxiliar a decidir onde se localiza o melhor ponto de corte para o diagnóstico em questão (FLETCHER et al. 1996). Neste caso, o ponto da curva que apresentou maior sensibilidade e 
especificidade foi o correspondente à pontuação 20,5 e não a pontuação 23,5 originalmente estabelecida na MAN.

CHRISTENSSON et al. (2002), adotando novo ponto de corte para a MAN de acordo com os resultados obtidos da sua população, elevou a especificidade de $26,0 \%$ para $70,0 \%$, no entanto, a sensibilidade diminuiu de $96,0 \%$ para $76,0 \%$

Portanto, a partir de novas propostas para pontos de corte da MAN, serão necessários mais estudos para a verificação de sua adequação.

A área sob a curva ROC também representa a acurácia de um teste. Quanto maior a área, melhor o teste. O valor máximo que a área sob a curva pode atingir é 1,00 (FLETCHER et al. 1996). Neste estudo, a MAN mostrouse $71,0 \%$ acurada.

Além das análises feitas para MAN, também realizaram-se as mesmas para a Triagem da MAN adotando-se, da mesma forma, a AMBc como método de referência. Neste caso, a Triagem apresentou sensibilidade de $78,0 \%$ e especificidade de $56,0 \%$. Seu valor preditivo positivo foi de $82,0 \%$ e o valor preditivo negativo foi de $50,0 \%$, ambos superiores aos encontrados pela MAN. 
Ao contrário dos dados anteriormente apresentados para MAN, a Triagem da MAN foi menos sensível, no entanto, mais específica.

Diferentemente da MAN, espera-se que a Triagem da MAN seja altamente específica em diagnosticar idosos não desnutridos a fim de cumprir seu objetivo, ou seja, através de apenas 6 questões (em vez de 18) triar idosos não desnutridos, otimizando o tempo gasto para a diagnóstico nutricional do idoso. É preciso considerar que, na classificação de não desnutrição, podem estar incluídos idosos obesos.

RUBENSTEIN et al. (2001) encontraram resultados superiores aos deste estudo quando compararam a Triagem da MAN com a avaliação clínica. A sensibilidade foi de $98,0 \%$ e a especificidade de $94,0 \%$ (RUBENSTEIN et al. 2001).

Estes resultados novamente levam a sugerir a utilização do método inicialmente apresentado por GUIGOZ et al. (1994), no qual a MAN é dividida por grupos de avaliação: avaliação global, avaliação antropométrica, avaliação dietética e avaliação subjetiva; em vez do proposto por RUBENSTEIN et al. (2001).

A análise da sensibilidade e especificidade também foi realizada individualmente para cada questão da MAN; no entanto, ainda são poucas as publicações que apresentam estas análises para comparação. 
Identificaram-se apenas dois estudos apresentando tais resultados: o de RUBENSTEIN et al. (2001), que trabalhou com grupos de idosos hospitalizados e vivendo na comunidade, e o de DONINI et al. (2000), que pesquisou idosos de ILPI's (Anexo 10).

As sensibilidades das questões F $(59,0 \%), G(100,0 \%)$ e $L(48,0 \%)$ que correspondem, respectivamente, ao IMC, a institucionalização, e a ingestão de frutas ou vegetais, foram próximas às identificadas no estudo de DONINI et al. (2000), e a questão P $(63,0 \%)$, que avalia a auto-percepção do idoso sobre sua saúde, foi próxima à identificada no estudo de RUBENSTEIN et al. (2001).

A questão $\mathrm{C}$, que identifica o grau de mobilidade, apresentou sensibilidade inferior (66,0\%), apenas, ao estudo de RUBENSTEIN et al. (2001), e as questões $\mathrm{J}$ e R, que identificam o número de refeições e a circunferência da panturrilha, apresentaram sensibilidade inferior $(30,0 \%$ e $59,0 \%$, respectivamente), somente, ao estudo de DONINI et al. (2000).

Excluindo estes casos, as questões A, B, D, E, H, I, K, N, O e Q apresentaram valores de sensibilidade inferiores tanto aos dados observados por DONINI et al. (2000) como aos de RUBEINSTEIN et al. (2001). 
Nesta pesquisa, as questões que apresentaram maior e menor sensibilidade, respectivamente, foram as questões $G(100,0 \%)$ e I $(5,0 \%)$, que correspondem a institucionalização e a presença de escaras e lesões na pele, da mesma forma que no estudo de DONINI et al. (2000).

No estudo de RUBENSTEIN et al. (2001), as questões que apresentaram maior e menor sensibilidade (questão D e J, respectivamente) não coincidiram com as deste estudo.

Além da questão G que apresentou a maior sensibilidade $(100,0 \%)$, as questões $C, E, F, M, O, P$ e $R$ apresentaram sensibilidade superior a $50,0 \%$ em diagnosticar a desnutrição e o risco de desnutrição na população estudada, as quais correspondem, respectivamente, a imobilidade, a presença de problemas neuropsicológicos, ao IMC, a ingestão de líquidos, a auto-percepção do idoso sobre seu estado nutricional, a auto-percepção do idoso sobre sua saúde, e a circunferência da panturrilha.

As especificidades das questões $F(96,0 \%)$ e $G(0,0 \%)$ (IMC e institucionalização) foram próximas às verificadas no estudo de DONINI et al. (2000), e a questão I (100,0\%) (lesões na pele ou escaras) próxima à verificada no estudo de RUBENSTEIN et al. (2001). A especificidade da questão Q $(100,0 \%$ ) (circunferência do braço) foi próxima aos dois estudos. Excluindo esses casos, as questões $\mathrm{C}, \mathrm{J}, \mathrm{K}$ e $\mathrm{L}$ apresentaram especificidade inferior a ambos estudos. 
As questões $A, B, D, E, H, M, N, O, P$ e $R$ apresentaram especificidade inferior, apenas, às verificadas no estudo de RUBENSTEIN et al. (2001), e a questão C, ao estudo de DONINI et al. (2000).

Entre as questões da MAN, as que apresentaram maior especificidade neste estudo foram às questões I $(100,0 \%)$ e $Q,(100,0 \%)$ (lesões na pele ou escaras e circunferência do braço) e a que apresentou menor especificidade foi a questão $G(0,0 \%)$ (institucionalização), semelhantes aos dois estudos citados.

Além das questões I e Q que apresentaram maior especificidade, as questões $A, B, C, D, E, F, H, J, L, N, O, P$ e $R$ apresentaram especificidade superior a 50,0\% em diagnosticar a ausência de desnutrição e risco de desnutrição. No estudo de RUBENSTEIN et al. (2001), todas as questões da MAN apresentaram esta característica.

O fato de as questões da MAN apresentarem maior capacidade preditiva positiva, provavelmente, está relacionada à prevalência de desnutrição e risco de desnutrição na população estudada.

Os dados obtidos neste estudo referem-se a uma população idosa específica que possui características próprias e que devem ser consideradas ao extrapolar os resultados encontrados para outros grupos populacionais. 
A MAN, como um método de diagnóstico de desnutrição e risco de desnutrição, atende amplamente as necessidades de identificação destes distúrbios, além do que, o diagnóstico de desnutrição realizado precocemente e os fatores de risco identificados permitem intervenções adequadas e favorecem a qualidade de vida do idoso.

Este estudo abre oportunidades para novas pesquisas com a MAN, considerando as limitações identificadas e os critérios e alterações adotadas necessárias para a sua realização em idosos institucionalizados, a fim de aperfeiçoar o método. 


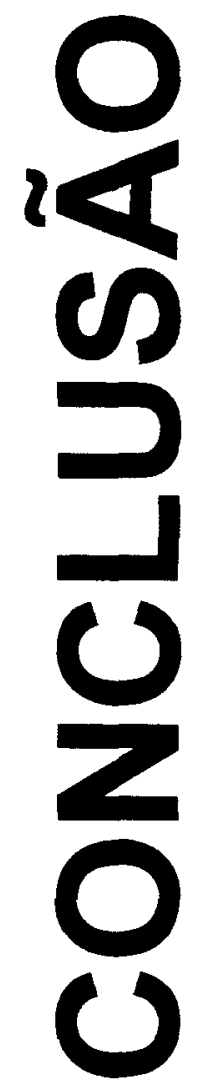




\section{CONCLUSÃO}

Os resultados obtidos neste estudo permitem as seguintes conclusões:

Quanto ao estado nutricional dos idosos

- $28,1 \%$ são desnutridos, $50,6 \%$ estão em risco de desnutrição, e $21,3 \%$ são não desnutridos, segundo a MAN.

- $\quad$ em relação aos desnutridos, o grupo etário de 80 anos e mais teve a maior prevalência $(44,0 \%)$.

- $\quad$ em relação aos em risco de desnutrição, o grupo etário de 60 a 69 anos teve a maior prevalência $(37,8 \%)$.

- $\quad$ em relação aos não desnutridos, o grupo etário de 60 a 69 anos teve a maior prevalência $(68,4 \%)$.

Quanto ao uso da MAN

- a MAN é um método adequado para o diagnóstico de desnutrição e risco de desnutrição em idosos, apresentando vantagens, dificuldades e limitações. 
Vantagens do método

- a MAN possibilita a identificação dos fatores de risco para desnutrição, permitindo a prevenção precoce da desnutrição.

- a MAN é sensível no diagnóstico de desnutrição e risco de desnutrição.

Dificuldades do método

- a MAN não se mostrou tão prática como descrito por seus autores, pois não pôde ser realizada na ordem em que é apresentada, despendendo maior tempo para sua realização do que é sugerido.

- necessidade de estimar o peso e a estatura para $47,2 \%$ dos idosos.

- dependência da disponibilidade dos funcionários para obtenção das informações necessárias ao registro da MAN.

- necessidade em obter informações de todos os alimentos consumidos pelos idosos durante o dia para, então, classificá-los em refeições.

Limitações do método 
- necessidade de se diagnosticar, previamente ao registro da MAN, idosos com distúrbios cognitivos, visto não haver disponíveis tais informações nos prontuários médicos.

- a MAN não diferencia idosos eutróficos de pré-obesos e obesos.

- não havia qualquer registro do valor do peso dos idosos nos prontuários para identificação de possiveis perdas de peso.

- $\quad$ em idosos considerados incapazes de responderem a MAN, conforme definido pelos funcionários, cujo tempo de institucionalização é menor que 3 meses, é prejudicada a utilização da MAN devido os funcionários ainda não possuírem percepção adequada das condições do idoso.

- falhas de memória dos idosos e funcionários favorecendo as estimativas como resposta.

Quanto à sensibilidade, especificidade e valores preditivos

- a MAN mostrou-se sensível $(84,0 \%)$ no diagnóstico de idosos desnutridos e em risco de desnutrição, no entanto, pouco específica $(36,0 \%)$ para a identificação de idosos não desnutridos. 
- a MAN foi capaz de predizer a desnutrição e o risco de desnutrição no grupo de idosos estudados $(77,0 \%)$, no entanto, pouco preditiva no diagnóstico de não desnutrição $(47,0 \%)$. 


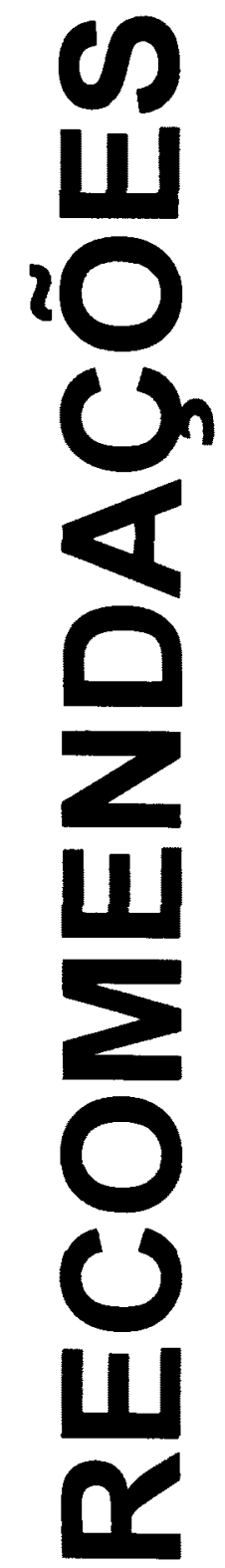




\section{RECOMENDAÇÕES}

As seguintes recomendações são propostas:

- realização de um manual de orientação para o registro da MAN, anexado em todos os impressos, incluindo no seu conteúdo os critérios que devem ser adotados para o seu registro verificados neste estudo, fórmulas para o cálculo do IMC, equações para estimativa de peso e estatura, e formas de mensuração das variáveis antropométricas para que haja padronização e o diagnóstico seja fidedigno.

- realização da MAN por nutricionistas, pois o método apresenta questões que exigem conhecimentos técnicos em alimentação e nutrição e treinamentos específicos.

- uso da proposta original da MAN, apresentada por GUIGOZ et al. (1994), traduzida para o português, por agrupar questões referentes a um mesmo tipo de avaliação (antropométrica, dietética, global e subjetiva) em um mesmo momento, e não possuir a triagem, a qual descarta a possibilidade da identificação de fatores de risco para a desnutrição em idosos diagnosticados como não desnutridos.

- realização de novos estudos para o aperfeiçoamento da MAN para que os resultados encontrados possam ser extrapolados para os idosos 
institucionalizados do Brasil e verdadeiramente representem a sensibilidade e especificidade da MAN nesta população. 


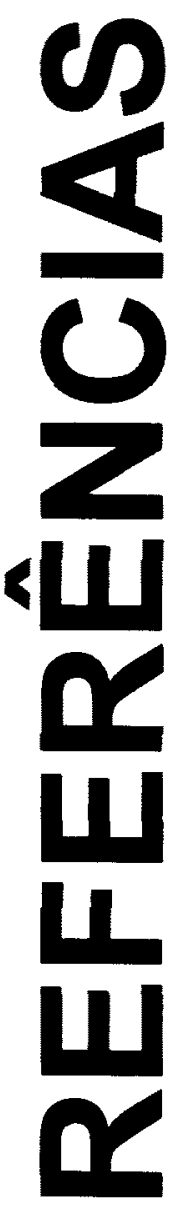




\section{REFERÊNCIAS}

1. Abbasi $A A$ e Rudman D. Undernutrition in the nursing home: prevalence, consequences, causes and prevention. Nutr Rev 1994; $52(4): 113-122$.

2. Almeida OP. Mini Exame do Estado Mental e o diagnóstico de demência no Brasil. Arq Neuropsiquiatr 1998; 56 (3-b): 605-612.

3. American Academy of Family Physicians. The American Dietetic Association. National Council on the Aging: Inc. Incorporating Nutrition Screening and Interventions into Medical Practice: A monograph for physicians. 1994.

4. Archer L, Bisaia J, Oswald W. Bioética. São Paulo: Verbo; 1996.

5. Barclay DV, Heredia L, Gil-Ramos J, Montalvo MM, Lozano R, Mena $M$ et al. Nutritional status of institutionalized elderly in Ecuador. Arch Latin Am Nutr 1996; 46 (2): 122-127.

6. Barone L, Milosavljevic M, Gazibarich B. Assessing the older person: Is the MNA a more appropriate nutritional assessment tool than the SGA? J Nutr Health Aging 2003; 7 (1): 13-17. 
7. Beck AM, Ovesen L, Osler M. The Mini Nutritional Assessment (MNA) and the Determine Your Nutritional Health Checklist (NSI Checklist) as predictors of morbibity and mortality in an elderly Danish population. Brit J Nutr 1999; 81: 31-36.

8. Beck AM, Ovesen L, Schroll M. A six months' prorpective follow-up of $65+-y$-old patients from general practice classified accordin to nutritional risk by the Mini Nutrition Assessment. Eur $\mathbf{J}$ Clin Nutr 2001; 55: 1028-1033.

9. Bennemann RM. Avaliação do estado nutricional de idosos com e sem distúrbios cognitivos, residentes em instituição geriátrica do município de Bragança Paulista - Estado de São Paulo. São Paulo; 2002. [Dissertação de Mestrado - Faculdade de Saúde Pública da USP].

10. Bleda MJ, Bolibar I, Parés R, Salvà A. Reliability of the Mini Nutritional Assessment (MNA) in institutionalized elderly people. J Nutr Health Aging 2002; 6 (2): 134-137.

11. Born T, Abreu CMG. O cuidado ao idoso em instituições de longa permanência. Gerontologia 1996; 4(4): 7-14. 
12. Brasil. Decreto $n^{\circ} 1948$ de 3 de julho de 1996. Política Nacional do Idoso. Diário Oficial.

13. Brito FC, Ramos LR. Serviços de atenção à saúde do idoso. In: Papaléo Netto M. Gerontologia: a velhice e o envelhecimento em visão globalizada. $2^{\circ}$ ed. São Paulo: Atheneu; 2000.

14.Burr ML, Phillips KM. Anthropometric norms in the elderly. Brit $\mathbf{J}$ Nutr $1984 ; 51: 165-9$.

15. Callaway CW, Chumlea WC, Bouchard C, et al. Circunferences. In: Lohman TG, Roche AF, Martorell R. Anthropometric standardization reference manual. Champaign, Illinois: Human Kinetics Books; 1988. p. 39-53.

16. Chaimowicz F. A saúde dos idosos às vésperas do século $X X I$ : problemas, projeções e alternativas. Rev Saúde Pública 1997; 31(2): 184-200.

17. Chaimowicz F e Greco DB. Dinâmica da institucionalização de idosos em Belo Horizonte, Brasil. Rev Saúde Pública 1999; 33 (5): p. 454460. 
18. Charles RP. Nutrition assessment methods for the older Irish adult in the clinical and community settings. Proc Nutr Soc 1998; 57: 599602.

19. Christensson L, Unosson M, Ek AC. Evaluation of nutritional assessment techniques in elderly people newly admitted to municipal care. Eur J Clin Nutr 2002; 56: 810-818.

20. Chumlea WC, Roche AF, Steinbaugh ML. Estimating stature from knee height for persons 60 to 90 years of age. J Am Geriatric Soc 1985; 33(2): 116-120.

21. Chumlea WC. The state of the Mini Nutritional Assessment? Nutrition 1999; $15(2): 159-161$.

22. Coelho AK e Fausto MA. Avaliação pelo nutricionista. In: Maciel A. Avaliação multidisciplinar do paciente geriátrico. Rio de Janeiro: Editora Revinter; 2002. p.121-154.

23. Coelho Filho JM, Ramos LR. Epidemiologia do envelhecimento no Nordeste do Brasil: resultados de inquérito domiciliar. Rev Saúde Pública 1999; 33(5): 445-53. 
24. Cohendy R, Rubenstein LZ, Eledjam JJ. The Mini Nutritional Assessment - Short Form for preoperative nutritional evaluation of elderly patients. Aging Clin Exp Res 2001; 13: 293-297.

25. Coulston AM. Nutrition management in nursing home. In: Morley JE, Glick Z e Rubentein LZ. Geriatric nutrition. 2 nd. New York; 1995. p. 295-301.

26. Dalacorte RR. Uso da Mini Avaliação Nutricional como um método de avaliação de risco de desnutrição em idosos de uma comunidade de Ribeirão Preto - SP. Ribeirão Preto; 2002. [Dissertação de Mestrado - Faculdade de Medicina de Ribeirão Preto da USP].

27.Delacorte RR, Moriguti JC, Matos FD, Pfrimer K, Marchini JC, Ferrioli E. Mini Nutritional Assessment score and the risk for undernutrition in free-living older persons. J Nutr Healht Aging 2004; 8 (6): 531-534.

28. Delarue J, Constans T, Malvy D, Pradignac A, Couet C, Lamisse F. Anthromopetric values in an elderly French population. Brit $\mathbf{J}$ Nutr $1994 ; 71: 295-302$.

29.Dempsey DT e Mullen JL. Prognostic value of nutritional indices. JPEN 1987; 11: 109S-14S. 
30. Detsky AS, McLaughlin JR, Baker JP et al. What is subjective global assessment of nutritional status? JPEN 1987; 11:8-13.

31.Donini LM, de Felice MR, Tagliaccica A, Palazzotto A, Bernardini L, Cannella C. Valeur prédictive du Mini Nutritional Assessment en Long Séjour Gériatrique. Age \& Nutrition 2000; 11(1): 3-11.

32. Donini LM, Felice MR, Tani L, Bernardini L, Pinto A, Giusti AM et al. A "proportional and objective score" for the Mini Nutritional Assessment in long-term geriatric care. J Nutr Health Aging 2002; 6 (2): 141-146.

33. Engelhardt E, Laks J, Rozenthal M, Marinho VM. Idosos institucionalizados: rastreamento cognitivo. Rev Psiquiatr Clin 1998; 25 (2): 74-9.

34. Fletcher RH, Fletcher SW, Wagner EH. Epidemiologia clínica: elementos essenciais. 3 ed. Artes Médicas: São Paulo; 1996. p. 5283.

35. Frisancho AR. New norms of upper limb fat and muscle areas for assessment of nutritional status. Am J Clin Nutr 1981; 34: 25402545. 
36. Garry PJ, Vellas BJ. Practical and validated use of the Mini Nutritional Assessment in geriatric evaluation. Nutr Clin Care 1999; 2 (3): 146154.

37. Gerber V, Krieg MA, Cornuz J, Guigoz Y, Burckhardt. Nutritional status using the Mini Nutrition Assessment questionnaire and its relationship with boné quality in a population of institutionalized elderly women. J Nutr Health Aging 2003: 7 (3): 140-145.

38. Goodwin JS. Social, psychological and physical factors affecting the nutritional status of elderly subjects: separating cause and effect. Am J Clin Nutr 1989; 50: 1201-1209.

39. Gordon CC, Chumlea WC, Roche AF. Stature, recumbent lenght, and weight. In: Lohman TG, Roche AF, Martorell R. Anthropometric standardization reference manual. Champaign, Illinois: Human Kinetics Books; 1988. p. 3-8.

40. de Groot LCPGM, Beck AM, Schroll M, van Staveren WA. Evaluating the DETERMINE Your Nutritional Health Checklist and the Mini Nutritional Assessment as tools to identify nutritional problems in elderly Europeans. Eur J Clin Nutr 1998; 52: 877-883. 
41. Guigoz Y, Vellas BJ, Garry PJ. Mini Nutritional Assessment: a practical assessment tool for grading the nutritional state of elderly patients. Facts Research in Gerontology 1994; 4 (suppl 2): 15-59.

42. Guigoz Y, Vellas BJ, Garry PJ. Assessing the nutritional status of the elderly: the Mini Nutritional Assessment as part of the geriatric evaluation. Nutr Rev 1996; 54(1): (II)S59-S65.

43. Guigoz Y, Vellas BJ, Garry PJ. Mini Nutritional Assessment: a practical assessment tool for grading the nutritional state of elderly patients. Facts Research and Intervention in Geriatrics 1997; (suppl 4): 11-60.

44. Guigoz $\mathrm{Y}$, Lauque S, Vellas BJ. Identifying the elderly at risk for malnutrition the Mini Nutritional Assessment. Clin Geriatr Med 2002; 18: 737-757.

45. Harrison GG, Buskirk ER, Carter JEL. Skinfold thicknesses and measurement technique. In: Lohman TG, Roche AF, Martorell R. Anthropometric standardization reference manual. Champaign, Illinois: Human Kinetics Books; 1988. p. 55-70. 
46. Heymsfield SB, Mc Manus C, Smith J et al. Anthropometric measurement of muscle: revised equations for calculating bone-free arm muscle area. Am J Clin Nutr 1982; 36: 680-690.

47. Instituto Brasileiro de Geografia e Estatística (IBGE). Censo demográfico 2000. Disponivel em <: http://www.ibge.gov.br. [2004 julho 21].

48. Kalache A, Veras RP, Ramos LR. O envelhecimento da população mundial: um desafio novo. Rev Saúde Pública 1987; 21(3): 200-10.

49. Keller HH. Malnutrition in institutionalized elderly: how and why? J Am Geriatr Soc 1993: 41: 1212-1218.

50. Kerstetter $\mathrm{HH}$. Malnutrition in the institutionalized older adult. J Am Diet Assoc 1992; 92: 1109-16.

51. Kuczmarski MF, Kuczmarski RJ, Najjar M. Descriptive anthropometric reference data for older Americans. J Am Diet Assoc 2000; 100(1): 59-66.

52. Landi F, Zucalla G, Gambassi G, Incalzi RA, Manigrasso L, Pagano F, Carbonin PU, Bernabei R. Body mass index and mortality among 
older people living in the community. J Am Geriatr Soc 1999; 47: 1072-1076.

53. Lauque S, Guyonnet S, Nourhashemi F, et al. Nutritional status of institutionalized elderly persons with or without dementia. Rev Geriatr 1999; $24: 115-9$.

54. Marchini JS, Anselmo MAC, Burini RC. Avaliação nutricional de pacientes hospitalizados. Rev Soc Bras Nutr Parenter 1986; 3 (7): 25-29.

55. Marucci MFN. Avaliação das dietas oferecidas em instituições para idosos localizadas no município de São Paulo. São Paulo; 1985. [Disseração de Mestrado - Faculdade de Saúde Pública da USP].

56. Marucci MFN. Aspectos nutricionais e hábitos alimentares de idosos matriculados em ambulatório geriátrico. São Paulo; 1992. [Tese de Doutorado - Faculdade de Saúde Pública da USP].

57. Marucci MFN e Gomes MMBC. Interação droga-nutriente em idosos. In: Papaléo Netto M. Gerontologia. São Paulo: Editora Atheneu; 2002. p. 273-283. 
58. Marucci MFN e Barbosa AR. Estado nutricional e capacidade física. In: Lebrão ML e Duarte YAO (org.). SABE - Saúde, Bem-estar e Envelhecimento. $O$ projeto SABE no município de São Paulo: uma abordagem inicial. Brasília: OPAS; 2003. p. 95-117.

59. Mastroeni MF. Estado nutricional e consumo de macronutrientes de idosos da cidade de Joinville - SC. São Paulo; 2004. [Tese de Doutorado - Faculdade de Saúde Pública da USP].

60. Menezes TN. Avaliação antropométrica e do consumo alimentar de idosos residentes em instituições geriátricas da cidade de Fortaleza - Ceará. São Paulo; 2000. [Dissertação de Mestrado Faculdade de Saúde Pública da USP].

61. Menezes TN. Estado nutricional, valor energético da alimentação dos idosos de Fortaleza - CE e sua associação com sexo, grupo etário e nível sócio-econômico. São Paulo; 2004. [Tese de Doutorado - Faculdade de Saúde Pública da USP].

62. Menezes TN, Marucci MFN. Antropometria de idosos residentes em instituições geriátricas, Fortaleza - CE. Rev Saúde Pública 2005; 39 (2): 169-175. 
63. Mijares AH, Taberner RR, Triguero MLM, Fandos JG, Garcia AL, Suárez-Varela MMM. Prevalencia de malnutricion entre ancianos institucionalizados en la Comunidad Valenciana. Med Clin $2001 ; 117(8): 289-94$

64. Miller MD, Crotty M, Giles LC, Bannerman E, Whitehead C, Cobiac L, Daniels LA, Andrews G. Corrected arm muscle area: an independent preditor of long-term mortality in community-dweling older adults. J Am Geriatr Soc 2002; 50: 1272-1277.

65. Molaschi M, Massaia M, Pallavicino di Ceva A, et al. Mini Nutritional Assessment in nursing home residents. In: Vellas B, Garry PJ, Guigoz Y. Nestle Nutr Workshop Ser Clin Perform Programme. Basel: S. Karger AG; 1999. p. 159.

66. Moriguti JC, Lucif Jr N, Ferrioli E. Nutrição no idoso. In: Dutra-deOliveira LE, Marchini JS. Ciências nutricionais. Ed. Sarvier: São Paulo; 1998. p. 239-50.

67. Morley JE. Nutritional status of the elderly. Am J Med 1986; 81: 67995.

68. Morley JE. Death by starvation. A modern American problem? J Am Geriatr Soc 1989; 37: 184. 
69. Morley JE. Why do physicians fail to recognize and treat malnutrition in older person? J Am Geriatr Soc 1991; 39: 1139-1140.

70. Morley JE, Kraenzle D. Causes of weight loss in a community nursing home. J Am Geriatr Soc 1994; 42: 583-585.

71. Morley JE, Silver AJ. Nutritional issues in nursing home care. Ann Inter Med 1995; 123: 850-59.

72. Morley JE. Protein-energy malnutrition in older subjects. Proc Nutr Soc 1998; 57: 587-592.

73. Murphy MC, Brooks CN, New SA, Lumbers ML. The use of the MiniNutritional Assessment (MNA) tool in elderly orthopaedic patients. Eur J Clin Nutr 2000; 54: 555-562.

74. Murphy MC, Lumbers M, Sinclair AJ, Nayak USL. A guide to completing the Mini Nutritional Assessment - MNA. Nestlè Clinical Nutrition. Disponível em <URL: http://www.mna-elderly.com/clinicalpractice.htm > [2004 maio 15].

75. Najas MS. Avaliação do estado nutricional de idosos a partir da utilização da medida do comprimento da perna - "knee height" como método preditor da estatura. São Paulo; 1995. [Dissertação de Mestrado - Universidade Federal de São Paulo]. 
76. Novaes VLSS. Relação do estado nutricional, níveis séricos de colesterol, frações e triglicérides com o consumo alimentar de gorduras e fibras em idosos. São Paulo; 2003. [Tese de Doutorado Faculdade de Saúde Pública da USP].

77. Oliveira A, Cardoso E, Isosaki M. Avaliação do risco de desnutrição de idosos com insuficiência cardíaca internados em hospital especializado em cardiologia. Rev Bras Nutr Clin 2003; 18 (1): 21 25.

78. Omran ML, Morley JE. Assessment of protein energy malnutrition in older people persons, Part 1: history, examination, body composition, and screening tools. Nutrition 2000; 16: 50-63.

79. Organização Pan-Americana de Saúde (OPAS). XXXVI Reunión del Comitê Asesor de Investigaciones en Salud - Encuesta Multicêntrica - Salud Bienestar y Envejecimiento (SABE). Disponivel em < URL: http://www.opas.org/program/sabe.htm> [2005 maio 10].

80. Otero UB, Rozenfeld S, Gadelha AMJ, Carvalho MS. Mortalidade por desnutrição em idosos, região Sudeste do Brasil, 1980-1997. Rev Saúde Pública 2002; 36(2): 141-8. 
81. Paixão Jr. CM, Reichenheim ME. Uma revisão sobre instrumentos de avaliação do estado funcional do idoso. Cad Saúde Pública 2005; 21(1): 7-19.

82. Payette H, Coulombe C, Boutier V, Gray-Donald K. Nutrition risk factors for institutionalization in a free-living functionally dependet elderly population. J Clin Epidemiol 2000; 53: 579-587.

83. Peña EP, Solano LR, Portillo Z, Rodriguez LM. Estado nutricional de adultos mayores institucionalizados. Valencia, Estado Carabobo, Venezuela. Arch Latin Am Nutr 1998; 48 (2): 104-111.

84.Perissinotto E, Pisent C, Sergi G, Grigoletto F, Enzi G. Anthropometric measurement in the elderly: age and gender differences. Brit $\mathbf{J} \mathbf{N u t r}$ 2002; 87: 177-86.

85. Pertoldi W, Fragiacomo $\mathrm{C}$, Rapin $\mathrm{CH}$, et al. The Mini Nutritional Assessment a predictor of costs in geriatric patients. J Am Geriatric Soc 1996; 44: P230.

86. Philippi ST, Laterza AR, Cruz ATR, Ribeiro LC. Pirâmide alimentar adaptada: guia para escolha dos alimentos. Rev Nutr 1999; 12(1): 6580. 
87. Pierron RL, Perry HM III, Grossberg G, Morley JE, Mahon G, Stewart T. The aging hip. J Am Geriatric Soc 1990; 38: 1339-52.

88. Piloto AA, Nunes ATGL, Assis M, Frias SR. O asilo na cidade do Rio de Janeiro. Gerontologia 1998; 6(1): 07-12.

89. Queiroz Z. Cuidando do idoso: uma abordagem social. O Mundo da Saúde 2000; 24 (4): 246-248.

90. Resende CHA. Desnutrição em idosos institucionalizados em asilos. Ribeirão Preto; 2001. [Tese de Doutorado - Faculdade de Medicina de Ribeirão Preto da USP]. 126p.

91. Ramon JM e Subirá C. Prevalência de malnutrición en la población anciana española. Med Clin (Barc) 2001; 117: 766-70.

92. Ramos LR, Veras RP, Kalache A. Envelhecimento populacional: uma realidade brasileira. Rev Saúde Pública 1987; 21(3): 211-21.

93. Ramos LR, Rosa TE, Oliveira ZM, Medina MCG, Santos FRG. Perfil do idoso em área metropolitana na região sudeste do Brasil: resultados de inquérito domiciliar. Rev Saúde Pública 1993; 27: 8794. 
94. Ritchie CS, Burgio KL, Locher JL, Cornwell A, Thomas D, Hardin M, et al. Nutritional status of urban homebound older adults. Am J Clin Nutr 1997; 66: 815-8.

95. Rolland Y, Cances VL, Cournot M, Nourhashémi F, Reynish W, Rivière D et al. Sarcopenia, calf circunference, and physical function of elderly women: a cross-sectional study. Am Geriatr Soc 2003; 51 : $1120-1124$

96. Ross Laboratories. Division of Abbott Laboratories - USA. Estimating weight from knee height. Columbus, Ohio; 1990.

97. Roubenoff R, Giacoppe J, Richardson SH, Hoffman P. Nutrition assessment in long-term care facilities. Nutr Rev 1996; 54(1): (II)S40S42.

98. Rubenstein LZ, Harker JO, Salva A, Guigoz Y e Vellas B. Screening for undernutrition in geriatric practice: developing the Short-form Mini Nutritional Assessment (MNA-SF). J Ger Med Sci 2001; 56 (6): M366M372.

99. Rudman D e Feller AG. Protein-calorie undernutrition in the nursing home. J Am Geriatr Soc 1989; 37: 173-83. 
100. Ruiz-López MD, Artacho R, Oliva P, Moreno-Torres R, Bolãnos J, Teresa C, López MC. Nutritional risk in institutionalized older women determined by the Mini Nutritional Assessment test: what are the main factors? Nutrition 2003; 19: 767-771.

101. Saletti A, Lindgren EY, Johansson L, Ceterholm T. Nutritional status according to mini nutritional assessment in an institutionalized elderly population in Sweden. Gerontology 2000; 46: 136-45.

102. Salvà A, Bolibar I, Muhoz M, Sacristàn V. Um nuevo instrumento para la valoracion nutricional em geriatria: el "Mini Nutritional Assessment" (MNA). Rev Gerontol 1996; 6: 319-328.

103. Santos JL, Albala C, Lera L, Garcia C, Arroyo P, Pérez-Bravo F, et al. Anthropometric measurements in the elderly population of Santiago, Chile. Nutrition 2004; 20 (5): 452-457.

104. Schoueri Jr. R, Ramos LR, Papaléo Netto M. Crescimento populacional: aspectos demográficos e sociais. $2^{\mathrm{a}}$ ed. In: Carvalho Filho ET, Papaléo Netto M. Geriatria: fundamentos, clínica e terapêutica. São Paulo: Editora Atheneu; 2004. p. 9-29.

105. Segre M e Cohen C. Bioética. São Paulo: EDUSP; 1995. 
106. Sgreccia E. Manual de bioética: fundamentos e ética biomédica. São Paulo: Edição Loyola; 1996.

107. Shintaku RCO. Estado nutricional de idosos internados em um hospital público geral do Estado de São Paulo. São Paulo; 2003. [Dissertação de Mestrado - Faculdade de Saúde Pública da USP].

108. Sigulem DM. Desnutrição energético-protéica: nomenclatura e classificação. In: Nóbrega FJ. Distúrbios da nutrição. Rio de Janeiro: Editora Revinter; 1998. p. 47-49.

109. Söderhamn U e Söderhamn O. Reliability and validity of the nutritional form for the elderly (NUFFE). J Adv Nur 2002; 37(1): 2834.

110. Soini H, Routasalo P, Lagström H. Characteristics of the MiniNutritional Assessment in elderly home-care patients. Eur J Clin Nutr 2004; 58: 64-70.

111. Tavares EL e Anjos LA. Perfil antropométrico da população idosa brasileira. Resultados da pesquisa nacional sobre saúde e nutrição. Cad Saúde Pública 1999; 15(4): 759-68. 
112. Thomas DR, Zdrowski CD, Wilson MM, Conright KC, Lewis C, Tariq S et al. Malnutrition in subacute care. Am J Clin Nutr 2002; 75: 308313.

113. Urteaga CR, Ramos RIH, Atalah ES. Validación del criterio de evaluación nutricional global del adulto mayor. Rev Méd Chile 2001; 129: 871-876.

114. Vellas B, Guigoz Y, Garry PJ, Nourhashemi F, Bennahum D, Lauque $S$ e Albarede J. The nutritional assessment (MNA) and its use in grading the nutritional state of elderly patients. Nutrition 1999; 15: 116-122.

115. Vellas B, Guigoz Y, Baumgartner M, Garry PJ, Lauque S, Albadere JL. Relationships between nutritional markers and the mini-nutritional assessment in 155 older persons. Am Geriatric Soc 2000; 48: 13001309.

116. Visvanathan $R$, Macintosh $C$, Callary $M$, Penhallm R, Horowitz $M$, Chapman I. The nutritional status of 250 older australian recipients of domiciliary care services and its association with outcomes at 12 months. J Am Geriatr Soc 2003; 51: 1007-1011. 
117. Waitzberg DL, Caiaffa WT, Correia MITD. Inquérito Brasileiro de Avaliação Nutricional Hospitalar (Ibanutri). Rev Bras Nutr Clin 1999; 14(2): 121-34.

118. White JV, Dwyer JT, Posner BM, Ham RJ, Lipschitz DA, Wellman NS. Nutrition sreening initiative: development and implementation of the public awareness checklist and screening tools. J Am Diet Assoc 1992; $92: 163-167$.

119. White JV. Risck factors for poor nutritional status. Primary Care $1994 ; 21(1): 19-31$.

120. Wilson MMG, Vaswani S, Lui D, Morley JE, Miller DK. Prevalence and causes of undernutrition in out patients. $J$ Medicine 1998; 104: 56-63.

121. World Health Organization (WHO). Physical status: the use and interpretation of anthropometry. Geneva: Worl Health Organization; 1995. p. 375-409. (Technical Report Series, 854). 


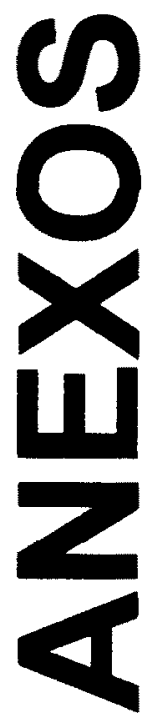


LOCALIZAÇÃO GEOGRÁFICA DE GUARATINGUETÁ-SP

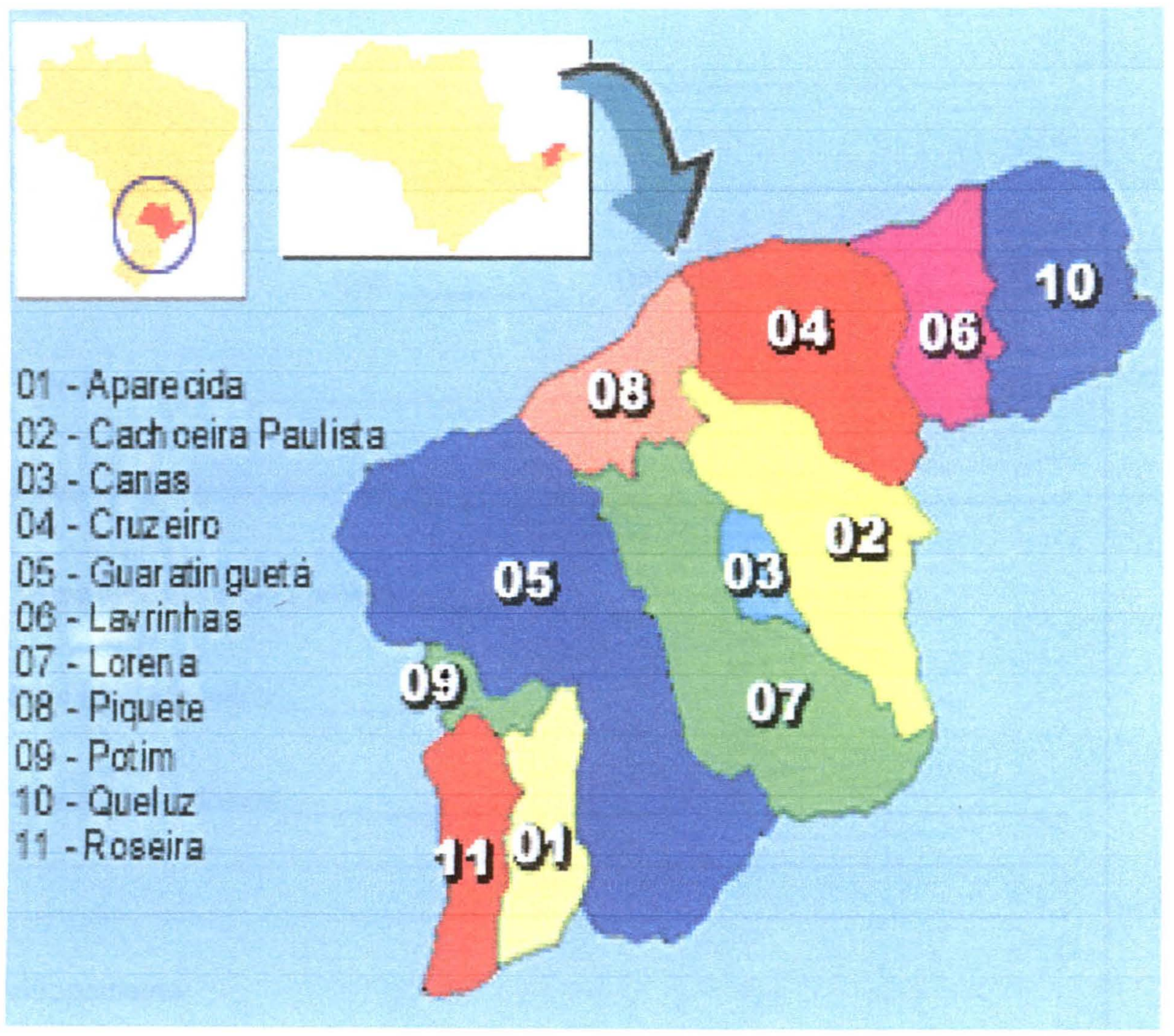




\section{FORMULÁRIO DE IDENTIFICAÇÃO E ANTROPOMETRIA}

Data:

$1+1$

$n^{\circ}$ de ordem

Instituição

Nome:

Sexo: $M \square F \square$

Cor:

Data de nascimento:

Procedência:

Motivo da institucionalização:

Tempo de internação (meses):

$N^{\circ}$ de medicamentos:

Diagnósticos clínicos:

Antropometria:

MEDIDAS

$1^{a}$ medida $2^{a}$ medida $3^{a}$ medida

Média

Peso $(\mathrm{kg})$

Estatura (m)

Altura do joetho (cm)

Circ. da panturrilha $(\mathrm{cm})$

Circ do 1 raco $(\mathrm{cm})$

Prega cutânea triciptal (mm) 


\section{TERMO DE CONSENTIMENTO LIVRE E ESCLARECIDO}

(De acordo com a resolução n 196, de 10 de outubro de 1996,

do Conselho Nacional de Saúde)

Eu (nome do responsável pela instituição),

responsável pela instituição

aceito livremente participar do estudo "Uso da Mini Avaliação Nutricional (MAN) como método de diagnóstico do estado nutricional de idosos institucionalizados" sob a responsabilidade dos seguintes pesquisadores: Maria de Fátima Nunes Marucci, docente da Faculdade de Saúde Pública (FSP) da Universidade de São Paulo (USP) e Luciana Silva Ferreira, mestranda do curso de Pós-graduação em Saúde Pública da FSP/USP.

Objetivo do estudo: Avaliar a utilização da "Mini Avaliação Nutricional" para o diagnóstico nutricional de idosos institucionalizados, de forma a proporcionar uma ferramenta útil no diagnóstico precoce da desnutrição neste grupo populacional.

Participação: Como responsável pela instituição, estou ciente que, concordando em participar do estudo, fornecerei qualquer esclarecimento ou informação a respeito do que seja necessário à pesquisa. Serão realizadas medidas de peso, estatura, circunferência do braço, circunferência da panturrilha, altura do joelho e prega cutânea tricipital; e entrevista com idosos utilizando a Mini Avaliação Nutricional para o registro dos dados, a qual envolve questōes relacionadas ao estado nutricional, ingestão alimentar, saúde e estilo de vida.

Riscos: Este estudo não trará riscos para a integridade moral e física do idoso.

Benefícios: As informações obtidas neste estudo poderão ser úteis cientificamente e contribuir para a melhoria das condições de saúde e nutrição 
dos idosos participantes da pesquisa e de outras instituiçōes, tendo em vista, que poderá diagnosticar, precocemente, o estado nutricional destes indivíduos e, assim, promover intervenção adequada, também, precocemente.

Privacidade: Os dados compilados neste estudo poderão ser divulgados em publicaçōes e congressos sem, no entanto, identificar os participantes e a instituição. A participação, tanto da instituição quanto dos idosos é voluntária, sendo que qualquer um poderá desistir de participar do estudo, a qualquer momento, sem qualquer prejuizo.

Guaratinguetá, de de 2004. 


\section{TERMO DE CONSENTIMENTO LIVRE E ESCLARECIDO}

(De acordo com a resolução $n^{\circ} 196$, de 10 de outubro de 1996, do Conselho Nacional de Saúde)

$\mathrm{Eu}$, aceito livremente participar do estudo "Uso da Mini Avaliação Nutricional (MAN) como método de diagnóstico do estado nutricional de idosos institucionalizados" sob a responsabilidade dos seguintes pesquisadores: Maria de Fátima Nunes Marucci, docente da Faculdade de Saúde Pública (FSP) da Universidade de São Paulo (USP) e Luciana Silva Ferreira, mestranda do curso de Pósgraduação em Saúde Pública da FSPIUSP.

Objetivo do estudo: Avaliar a utilização da "Mini Avaliação Nutricional" em idosos institucionalizados, de forma a proporcionar uma ferramenta útil no diagnóstico precoce da desnutrição neste grupo populacional.

Participação: Estou ciente de que concordando em participar do estudo, fornecerei qualquer esclarecimento ou informação que seja necessária à pesquisa. Serão realizadas medidas de peso, estatura, circunferência do braço, circunferência da panturrilha, altura do joelho e prega cutânea tricipital; será realizada, também, uma entrevista utilizando a "Mini Avaliação Nutricional" para o registro dos dados, a qual envolve questōes relacionadas ao estado nutricional, ingestão alimentar, saúde e estilo de vida. Nenhuma das avaliaçōes envolverá métodos invasivos.

Riscos: Este estudo não trará riscos para a sua integridade moral e física.

Beneficios: As informações obtidas neste estudo poderão ser úteis cientificamente e contribuir para a melhoria das condiçōes de saúde e nutrição dos idosos participantes da pesquisa e de outras instituições, tendo em vista que poderá diagnosticar, precocemente, o estado nutricional destes individuos e, assim, promover intervenção adequada, também, precocemente. 
Privacidade: Os dados compilados neste estudo poderão ser divulgados em publicações e congressos sem, no entanto, identificar os participantes e a instituição. A participação, tanto da instituição quanto dos idosos é voluntária, sendo que qualquer um poderá desistir de participar do estudo, a qualquer momento, sem qualquer prejuizo.

Guaratinguetá, de de 2004. 
Eu,

$R G n^{\circ}$ (cargo)

da instituição

aceito livremente participar do estudo "Uso da Mini Avaliação Nutricional (MAN) como método de diagnóstico do estado nutricional de idosos institucionalizados" comprometendo-me a fornecer todas as informações e esclarecimentos necessários à sua realização.

Guaratinguetá, de de 2004 .

Assinatura do funcionário (a) 


\section{TERMO DE RESPONSABILIDADE}

Eu, Luciana Silva Ferreira, mestranda da Faculdade de Saúde Pública da Universidade de São Paulo responsável pela pesquisa "Uso da Mini Avaliação Nutricional (MAN) como método de diagnóstico nutricional de idosos institucionalizados" me responsabilizo em entregar à instituição cópia da Mini Avaliação Nutricional juntamente com impresso explicativo para a sua adequada utilização, caso seja confirmada a hipótese do estudo. Aos individuos identificados como desnutridos ou com risco de desnutrição, orientações nutricionais serão realizadas, visto a inexistência de nutricionistas nas instituições. No mais, coloco-me à disposição para eventuais dúvidas e esclarecimentos.

\section{Luciana Silva Ferreira}

RG 30586409-9

CPF 290415018-86

Telefone para contato: (12) 97780479 


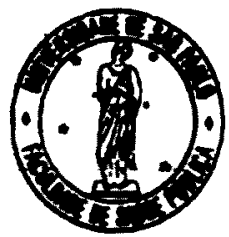

\section{Universidade de São Paulo}

Faculdade de Saúde Pública

COMTEE DE ÉTICA - COEP

Av. Dr. Amaldo, 715 - CEP 01246-904 - São Pauio - Brasil

Telefones: (55-11) 3066- 7779 - fone/fax (55-11) 3064 -7314 - e-mail: mdgracas@usp.br

\section{OL.COEP/023/04}

12 de março de 2004

Pelo presente, informo que o Comitê de Ética em Pesquisa da Faculdade de Saúde Pública da Universidade de São Paulo-COEP, analisou e aprovou, de acordo com os requisitos da Resolução CNS/196/96, o Protocolo de Pesquisa n. ${ }^{\circ} 1083$, intitulado: "USO DA MINI AVALIAÇÃO NUTRICIONAL (MAN) COMO MÉTODO DE DIAGNÓSTICO DO ESTADO NUTRICIONAL DE IDOSOS INSTITUCIONALIZADOS", apresentado pela pesquisadora Luciana Silva Ferreira.

Atenciosamente,

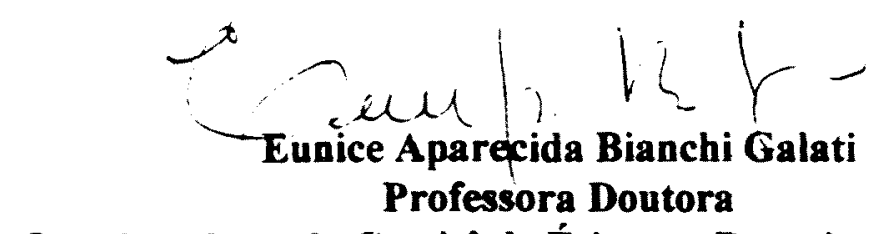

Coordenadora do Comitê de Ética em Pesquisa da FSP-COEP 


Mini Nutritional Assessment
MNA
Nestle

\begin{tabular}{llll} 
Last name: & First name: & Sex: & Date: \\
\hline Age: & Weight, kg: & Height, $\mathrm{cm}:$ & I.D. Number: \\
\hline
\end{tabular}

Complete the screen by filling in the boxes with the appropriate numbers. Add the numbers for the screen. If score is 11 or less, continue with the assessment to gain a Malnutrition Indicator Score.

\section{Screening}

A Has food intake declined over the past 3 months due to loss of appetite, digestive problems, chewing or swallowing difficulties?

$0=$ severe loss of appetite

1 = moderate loss of appetite

2 = no loss of appetite

B Weight loss during the last 3 months

$0=$ weight loss greater than $3 \mathrm{~kg}$ (6.6 lbs)

1 = does not know

2 = weight loss between 1 and $3 \mathrm{~kg}$ ( 2.2 and $6.6 \mathrm{lbs}$ )

$3=$ noweight loss

C Mobility

$0=$ bed or chair bound

1 = able to get out of bed/chair but does not go out

2 = goes out

D Has suffered psychological stress or acute disease in the past 3 months
0 = yes

$$
2=\text { no }
$$

E Neuropsychological problems

$0=$ severe dementia or depression

1 = mild dementia

2 = nopsychological problems

F Body Mass Index (BMI) (weight in $\mathrm{kg}$ )/ (height in $\mathrm{m}^{2}$

$0=$ BMl less than 19

$1=$ BMI 19 to less than 21

2 = BMI 21 to less than 23

$3=\mathrm{BMI} 23$ or greater

Screening score (subtotal max. 14 points)

12 points or greater Normal - not at risk - no need to complete assessment

11 points or below Possible malnutrition - continue assessment

\section{Assessment}

G Lives independently (not in a nursing home or hospital)

$0=$ no 1 = yes

H Takes more than 3 prescription drugs per day

0 = yes $\quad 1=$ no

I Pressure sores or skin ulcers

$0=$ yes $\quad 1=$ no

zef.: Guigoz Y. Vellas B and Garry PJ. 1994. Mini Nutritional Assessment: A practical assessment tool for grading the nutritional stale of elderly patients. Facts and Research in Gerontology. Supplemen

Rubenstein LZ, Harker J, Guigoz Y and Vellas B. Comprehensive Geriatric Assessment (CGA) and the MNA. In: "Mini Nutritional Assessment (MNA) Resepre PJ and Guigoz Y, editors. Nestlé Nutrition Workshop Series. Clinical \& Performance Programme vol 1. Karger, Bale, in press

(c) Nestle, 1994, Revision 1998. N67200 12/99 10M

\begin{tabular}{|c|c|}
\hline J & $\begin{array}{l}\text { How many full meals does the patient eat daily? } \\
\begin{aligned} 0=1 \text { meal } \\
1=2 \text { meals } \\
2=3 \text { meals }\end{aligned}\end{array}$ \\
\hline K & $\begin{array}{l}\text { Selected consumption markers for protein intake } \\
\text { - At least one serving of dairy products } \\
\text { (milk, cheese, yogurt) per day? yes } \square \text { no } \square \\
\text { - Two or more servings of legumes } \\
\text { or eggs per week? } \\
\text { - Meat, fish or poultry every day yes } \square \text { no } \square \\
0.0=\text { if } 0 \text { or } 1 \text { yes } \\
0.5=\text { if } 2 \text { yes } \\
1.0=\text { if } 3 \text { yes }\end{array}$ \\
\hline L & $\begin{array}{l}\text { Consumes two or more servings } \\
\text { of fruits or vegetables per day? } \\
0=\text { no } \quad 1=\text { yes }\end{array}$ \\
\hline$M$ & $\begin{array}{l}\text { How much fluid (water, juice, coffee, tea, milk...) is consur } \\
0.0=\text { less than } 3 \text { cups } \\
0.5=3 \text { to } 5 \text { cups } \\
1.0=\text { more than } 5 \text { cups }\end{array}$ \\
\hline $\mathrm{N}$ & $\begin{array}{l}\text { Mode of feeding } \\
\begin{array}{ll}0=\text { unable to eat without assistance } \\
1=\text { self-fed with some difficulty } \\
2=\text { self-fed without any problem }\end{array}\end{array}$ \\
\hline 0 & $\begin{array}{l}\text { Self view of nutritional status } \\
\begin{aligned} 0 & =\text { views self as being malnourished } \\
1 & =\text { is uncertain of nutritional state } \\
2 & =\text { views self as having no nutritional problem }\end{aligned}\end{array}$ \\
\hline$P$ & $\begin{array}{l}\text { In comparison with other people of the same age, } \\
\text { how does the patient consider his/her health status? } \\
0.0=\text { not as good } \\
0.5=\text { does not know } \\
1.0=\text { as good } \\
2.0=\text { better }\end{array}$ \\
\hline Q & $\begin{array}{l}\text { Mid-arm circumference }(\mathrm{MAC}) \text { in } \mathrm{cm} \\
0.0=\text { MAC less than } 21 \\
0.5=\text { MAC } 21 \text { to } 22 \\
1.0=\text { MAC } 22 \text { or greater }\end{array}$ \\
\hline$R$ & $\begin{array}{l}\text { Calf circumference }(\mathrm{CC}) \text { in } \mathrm{cm} \\
0=\mathrm{CC} \text { less than } 31 \quad 1=\mathrm{CC} 31 \text { or greater }\end{array}$ \\
\hline \multicolumn{2}{|r|}{ Assessment (max. 16 points) } \\
\hline \multicolumn{2}{|c|}{ Screening score } \\
\hline \multicolumn{2}{|r|}{ Total Assessment (max. 30 points) } \\
\hline \multicolumn{2}{|r|}{ Malnutrition Indicator Score } \\
\hline Less & s than 17 points \\
\hline
\end{tabular}




\section{MINI NUTRITIONAL ASSESSMENT MNA $^{\text {"W }}$}

$10 *$ First Name: M.I. Sex

Date:

Last Mame:

Whight $\mathrm{kg}$ :

Heighte cm:

Knee Hejognt. $\mathrm{cm}$ :

Comptete the form by writing the numbers in the boxes. Add the numbers in the bexes and compare the total assessment to the Malnutrition indicator Scere.

\begin{tabular}{|c|c|}
\hline \multicolumn{2}{|l|}{ ANTHROPOMETRIC ASSESSMENT } \\
\hline $\begin{array}{l}\text { 1. Body Mass index (BMI) (waight in } \mathrm{kg} \text { ) / (height in } \mathrm{m} \text { ): } \\
\begin{array}{ll}\text { 2. BMI }<19 & =0 \text { points } \\
\text { 0. BMI } 19 \text { to }<21 & =1 \text { Doimt } \\
\text { c. BMI } 21 \text { to }<23 & =2 \text { Donts } \\
\text { d. BMI } 223 & =3 \text { Donts }\end{array}\end{array}$ & Points \\
\hline $\begin{array}{l}\text { 2. Mid-arm carcumterence (MAC) in em } \\
2 \text { MAC }<21=0.0 \text { points } \\
\text { b. MAC } 21 \leq 22=0.5 \text { points } \\
\text { c. MAC }>22=1.0 \text { points }\end{array}$ & \\
\hline 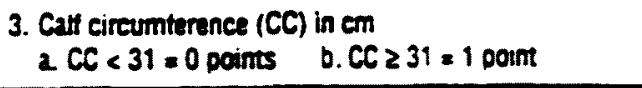 & \\
\hline 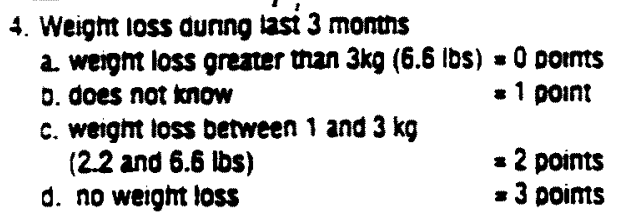 & \\
\hline
\end{tabular}

\section{GENERAL ASSESSMENT}

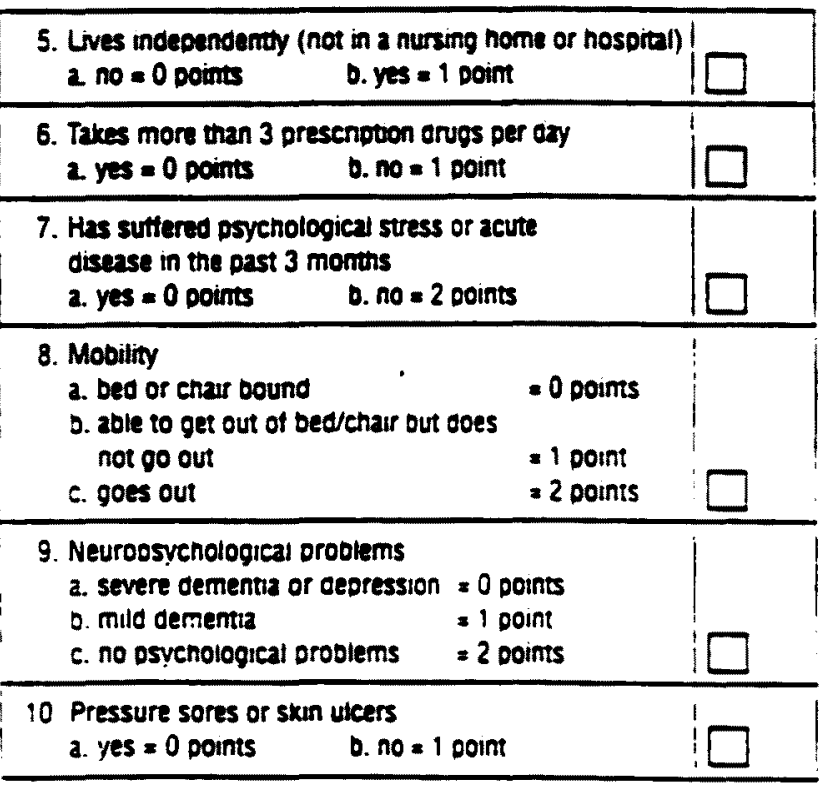

DIETARY ASSESSMENT

11. How many tuli meats ooes the patient eat darly? a. 1 meal $=0$ points

๖. 2 meais $=1$ point

c 3 meals $=2$ ooints

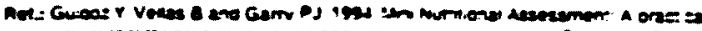

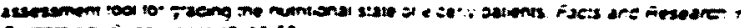

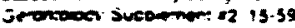

Olga Mestec Lta iNesthe Aesearen CentervClintec Nutrition Company

Figure 1. The Mini Nutritional Assessment Form.

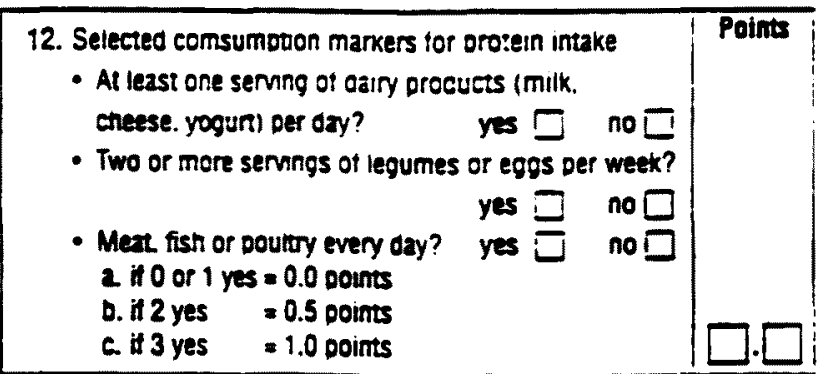

13. Consumes two or mare servings of trutrs or vegerables der day?

$\begin{array}{ll}\text { a. no }=0 \text { oounts } & \text { b. yes }=1 \text { Doint }\end{array}$

14. Has food intre cecined over the oast unree montus oue to loss ot aboetns. digestrve orodiems. chewning of swallowing ortticulties?

a. severe loss of appeute $=0$ points

b. moderate loss of appetute $=1$ point

c. no loss of apdetre

$=2$ Doimts

15. How much thio (water. juice. cottee. tea. milk....)

is consumeo der day? ( 1 cup $=8$ az)

2. less than 3 cups $=0.0$ poins

b. 3 to 5 cups $=0.5$ points

c. more than 5 aups $=1.0$ points

16. Mode of teeding

a. Unable to ext without assistance $=0$ points

b. setf-fed with some gifficulty $\quad=1$ point

c. sall-fed whout any brootem $=2$ ooints

\section{SELF ASSESSMENT}

17. Do they vew themserves as raving nutnoonal oroolems?
a. major mainutrion
-0 Doints

b. coes not know or mocerate matnurntion $=1$ Doim

c. no nutntioral orodiem

$=2$ points

18. In companson amth otner deods of the same age. now do iney consicer their neann stans?

a. not as goo0 $=0.0$ oonts

b. coes not krout $=0.5$ oornts

c. $259000=1.0$ ooints

c. Better $=2.0$ ooints

ASSESSMENT TOTAL I max. 30 DOIn:S):

\begin{tabular}{|c|c|}
\hline \multicolumn{2}{|c|}{ MALNUTRTION INDICATOR SCORE } \\
\hline$\geq 24$ points & well-nounsned \\
\hline 171023.5 poins & at nsk of mainutntion \\
\hline$<17$ points & masnounsned \\
\hline
\end{tabular}


Quadro. Valores de sensibilidade e especificidade de cada questão da MAN.

\begin{tabular}{|c|c|c|c|c|c|c|}
\hline \multirow[b]{2}{*}{$\begin{array}{l}\text { Questסes } \\
\text { da MAN }\end{array}$} & \multicolumn{3}{|c|}{ Sensibilidade (\%) } & \multicolumn{3}{|c|}{ Especificidade (\%) } \\
\hline & $\begin{array}{c}\text { FERREIRA } \\
\text { (2005) }\end{array}$ & $\begin{array}{l}\text { RUBENSTEIN } \\
\text { et al. (2001)* }\end{array}$ & $\begin{array}{l}\text { DONINI et } \\
\text { al. }(2000)^{* *}\end{array}$ & $\begin{array}{c}\text { FERREIRA } \\
\text { (2005) }\end{array}$ & $\begin{array}{l}\text { RUBENSTEIN } \\
\text { et al. (2001)* }\end{array}$ & $\begin{array}{l}\text { DONINI et } \\
\text { al. }(2000)^{* *}\end{array}$ \\
\hline$\overline{\mathbf{A}}$ & 22,0 & 77,5 & 58,4 & 80,0 & 98,1 & 69,8 \\
\hline$\overline{\mathbf{B}}$ & 39,0 & 87,5 & 93,9 & 72,0 & 77,4 & 22,6 \\
\hline C & 66,0 & 77,5 & 46,8 & 56,0 & 92,5 & 73,6 \\
\hline D & 30,0 & 91,0 & 63,4 & 68,0 & 90,6 & 53,8 \\
\hline$\overline{\mathbf{E}}$ & 56,0 & 65,2 & 80,6 & 56,0 & 94,3 & 31,4 \\
\hline$F$ & 59,0 & 79,5 & 63,2 & 96,0 & 77,4 & 93,3 \\
\hline $\mathbf{G}$ & 100,0 & 48,3 & 99,4 & 0,0 & 60,4 & 1,6 \\
\hline $\bar{H}$ & 36,0 & 58,4 & 50,4 & 64,0 & 75,5 & 34,0 \\
\hline 1 & 5,0 & $4 \overline{41,6}$ & 19,1 & 100,0 & 98,1 & 91,5 \\
\hline $\mathbf{J}$ & 30,0 & $\overline{12,2}$ & 49,6 & 68,0 & 96,2 & 79,2 \\
\hline $\mathbf{K}$ & 45,0 & 58,8 & 61,1 & 24,0 & 73,6 & 63,2 \\
\hline$L$ & 48,0 & 16,5 & 50,8 & 64,0 & 100,0 & 75,5 \\
\hline $\bar{M}$ & 67,0 & 56,5 & 86,6 & 40,0 & 79,2 & 26,4 \\
\hline $\mathbf{N}$ & 28,0 & 47,2 & 79,0 & 88,0 & 98,1 & 51,9 \\
\hline$\overline{0}$ & 53,0 & 65,2 & 94,7 & 60,0 & 96,2 & 23,6 \\
\hline $\bar{P}$ & 63,0 & 61,8 & 84,7 & 56,0 & 88,7 & 21,7 \\
\hline$\overline{\mathbf{Q}}$ & 13,0 & 61,4 & 54,5 & 100,0 & 96,0 & 100,0 \\
\hline$\overline{\mathbf{R}}$ & 59,0 & 12,5 & 89,6 & 76,0 & 100,0 & 50,5 \\
\hline
\end{tabular}

- Rubenstein LZ, Harker JO, Salva A, Guigoz Y e Vellas B. Screening for undernutrition in geriatric practice: developing the Short-form Mini Nutritional Assessment (MNA-SF). J Ger Med Sci 2001; 56 (6): M366-M372.

* Donini LM, de Felice MR, Tagliaccica A, Palazzotto A, Bernardini L, Cannella C. Valeur prédictive du Mini Nutritional Assessment en Long Séjour Gériatrique. Age \& Nutrition 2000; 11(1): 3-11. 
